Aus der Klinik für Kardiologie und Pneumologie

(Prof. Dr. med. G. Hasenfuß)

der Medizinischen Fakultät der Universität Göttingen

\title{
Einfluss des Chemokins CCL5 auf die arterielle Thrombose und Neointimabildung nach experimenteller Gefäßwandläsion
}

\section{INAUGURAL - DISSERTATION}

zur Erlangung des Doktorgrades

der Medizinischen Fakultät der

Georg-August-Universität zu Göttingen

\author{
vorgelegt von \\ Julia Meier \\ aus \\ Altenburg
}

Göttingen 2015 
Dekan:

I. Berichterstatterin:

II. Berichterstatter/in:

III. Berichterstatter/in:

Tag der mündlichen Prüfung:
Prof. Dr. rer. nat. H. K. Kroemer

PD Dr. med. F. S. Czepluch

Prof. Dr. med. Martin Oppermann

13. Juli 2016 
Hiermit erkläre ich, die Dissertation mit dem Titel „Einfluss des Chemokins CCL5 auf die arterielle Thrombose und Neointimabildung nach experimenteller Gefäßwandläsion" eigenständig angefertigt und keine anderen als die von mir angegebenen Quellen und Hilfsmittel verwendet zu haben.

Göttingen, den 10.12.2015 


\section{INHALTSVERZEICHNIS}

INHALTSVERZEICHNIS.

1 EINLEITUNG

1.1 Epidemiologie und Ätiologie der Atherosklerose .......................................................... 1

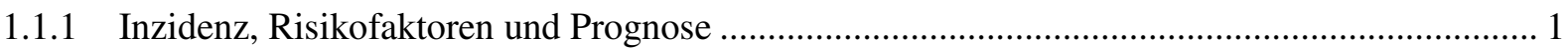

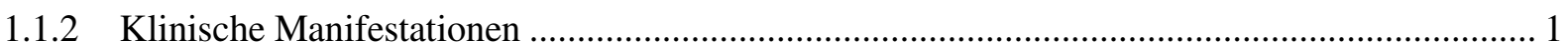

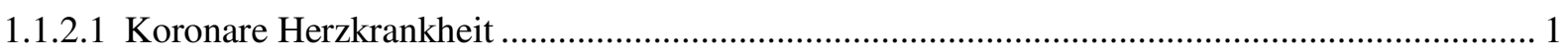

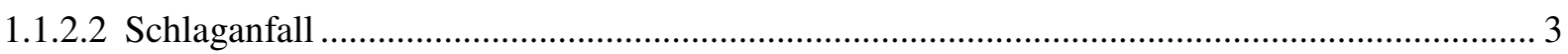

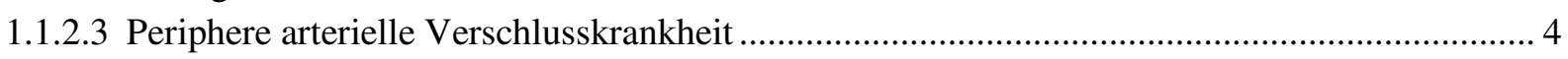

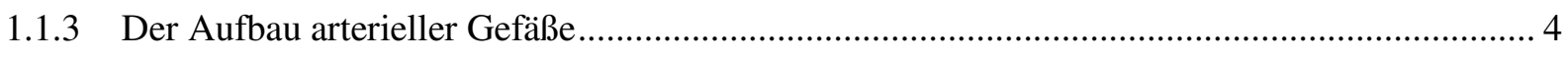

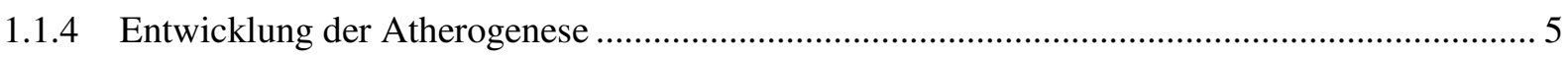

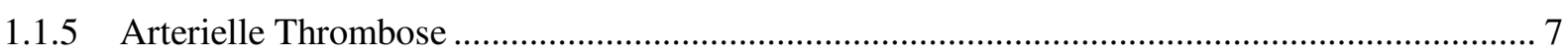

1.2 Einfluss verschiedener Faktoren auf die Pathogenese der Atherosklerose ........................8

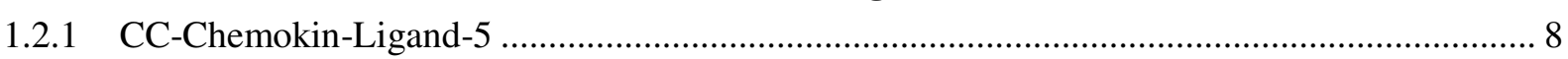

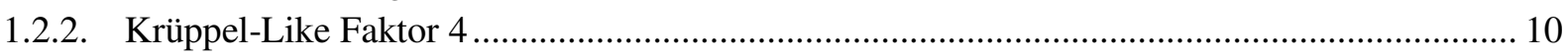

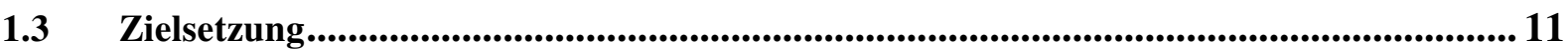

2 MATERIAL UND METHODEN .........................................12

2.1 Verwendete Materialien und Geräte ..................................................................... 12

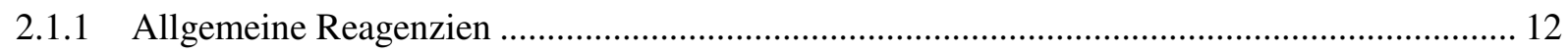

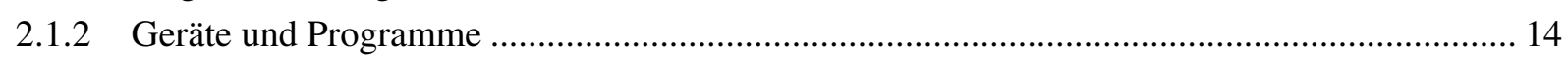

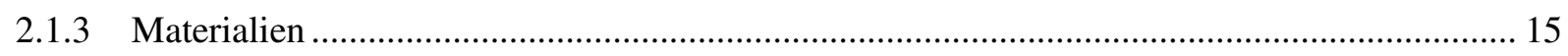

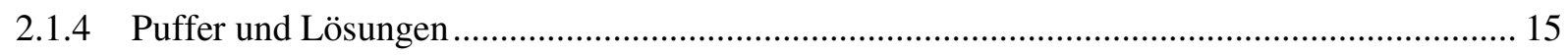

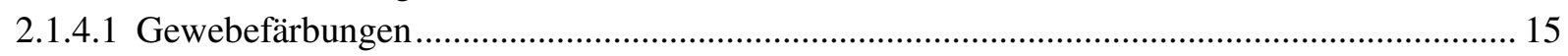

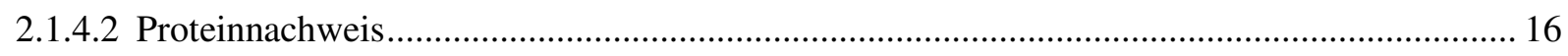

2.2 Untersuchungen im Tiermodell ....................................................................................... 16

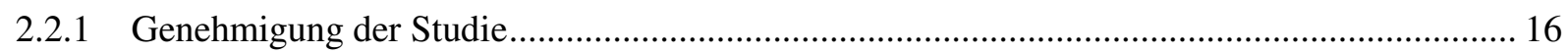

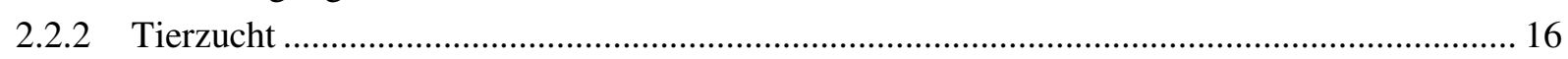

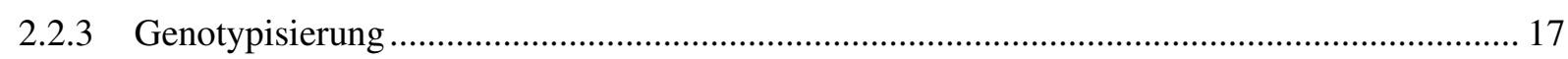

2.2.4 Experimentelle Induktion einer Gefäßwandläsion ............................................................... 18

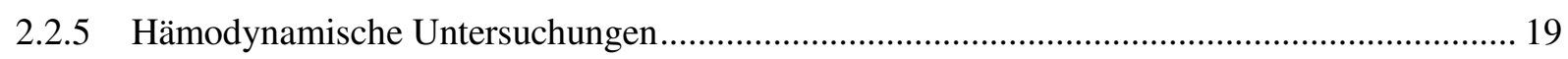

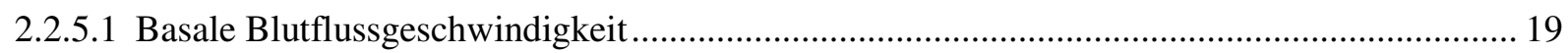

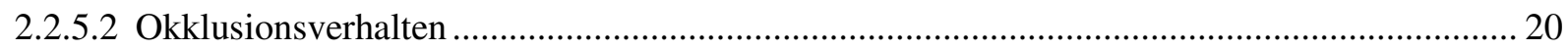

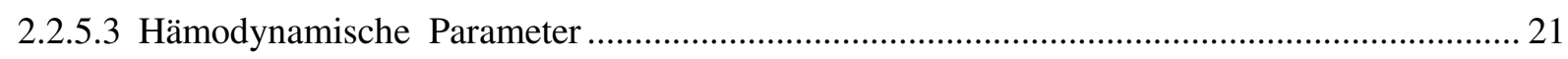

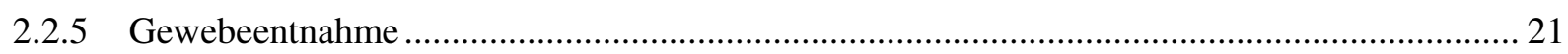




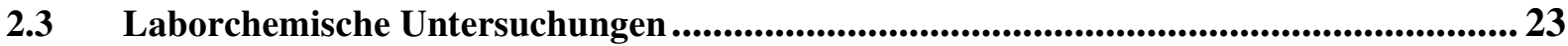

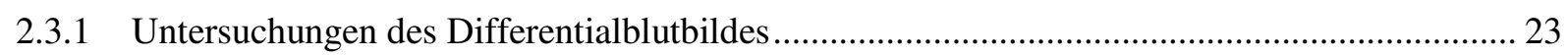

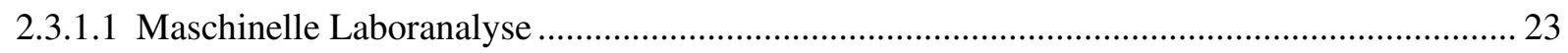

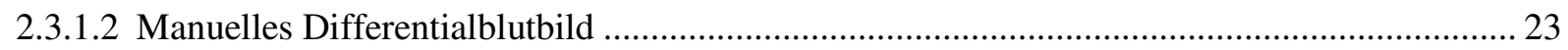

2.3.2 Bestimmung von Cholesterin und Triglyzeriden ................................................................ 24

2.4 Histologische Analyse des Thrombus und der Neointima................................................... 24

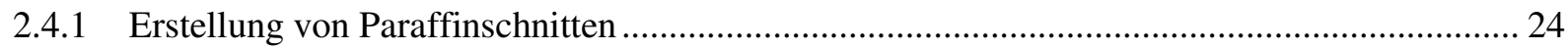

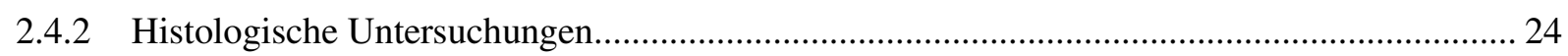

2.4.2.1 Entparaffinierung und Wässerung der Gewebeschnitte ....................................................... 24

2.4.2.2 Masson-Trichrom-Färbung zur Detektion thrombotischen Materials ....................................... 24

2.4.2.3 Verhoeff' sche Elastika-Färbung zur Detektion elastischer Fasern.......................................... 25

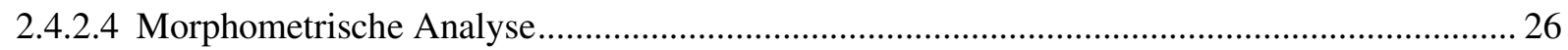

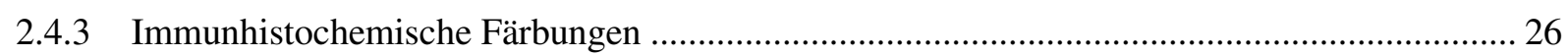

2.4.3.1 Allgemeines Färbeprotokoll für CCR1, CCR5, Mac-2, CD45 und KLF4 ............................. 26

2.4.3.2 Auswertung der immunhistochemischen Färbungen............................................................ 28

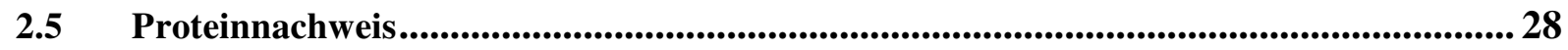

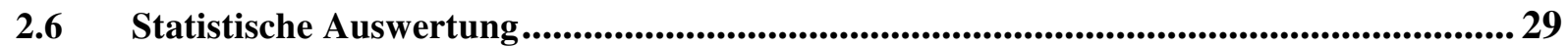

3 ERGEBNISSE .............................................................................30

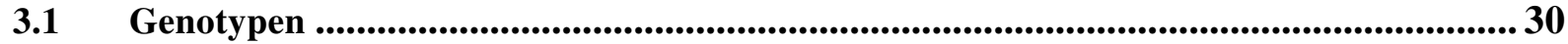

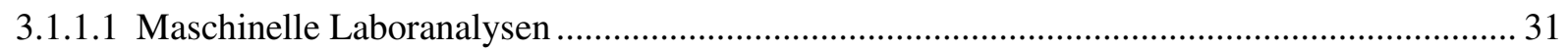

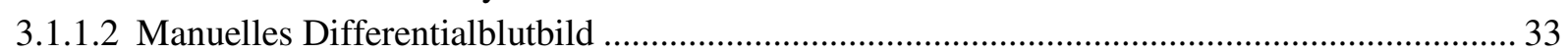

3.2 Auswirkungen der CCL5-Defizienz auf den Blutfluss ................................................... 34

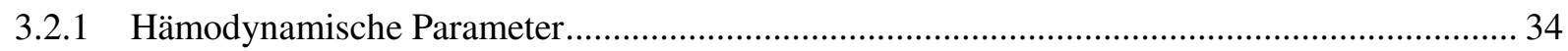

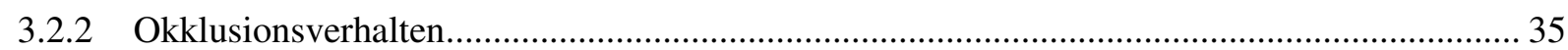

3.3 Auswirkungen der CCL5-Defizienz auf vaskuläre Umbauvorgänge ............................... 36

3.3.1 Entwicklung und Organisation der arteriellen Thrombose ..................................................... 36

3.3.2 Auswirkungen der CCL5-Defizienz auf die arterielle Thrombose ........................................... 38

3.3.3 Auswirkungen der CCL5-Defizienz auf die Neointimabildung............................................... 39

3.4 Auswirkungen der CCL5-Defizienz auf die Zellinfiltration ............................................. 41

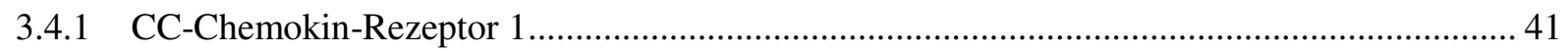

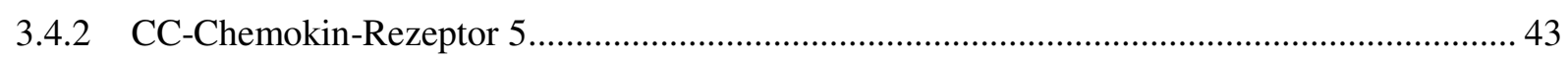

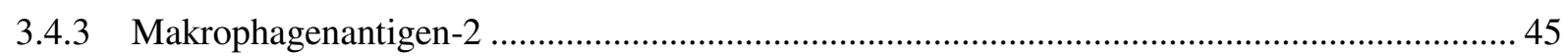

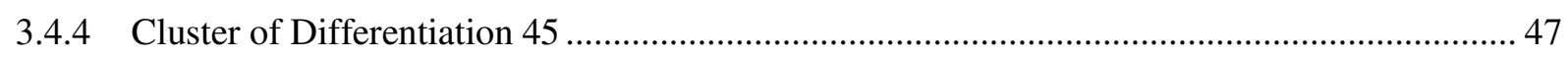

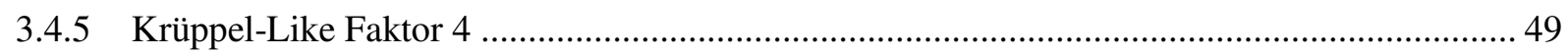

3.5 Auswirkungen der CCL5-Defizienz auf humorale Faktoren ............................................ 51

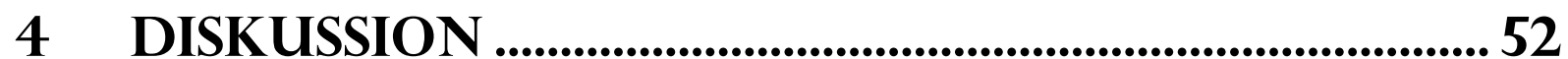

4.1 CCL5 und arterielle Thrombose .................................................................................5 52

4.2 CCL5 und Neointimabildung ....................................................................................................... 54

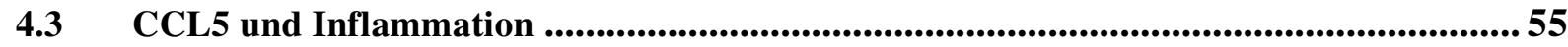




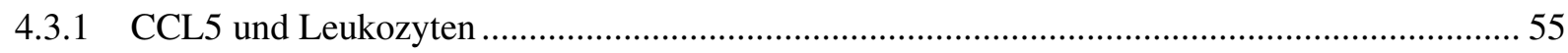

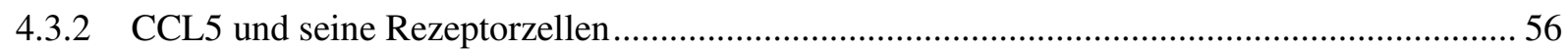

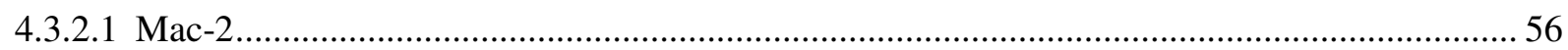

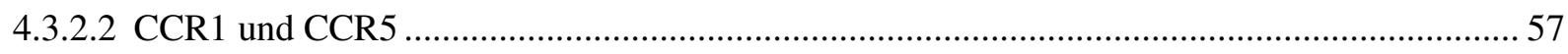

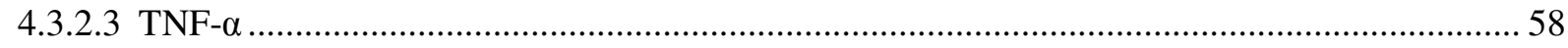

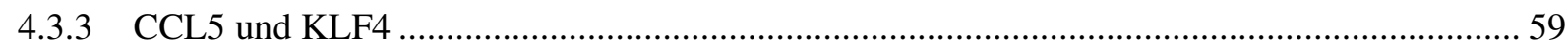

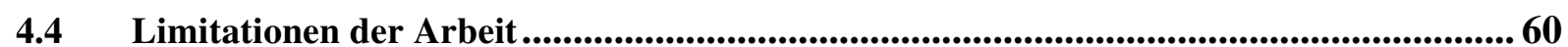

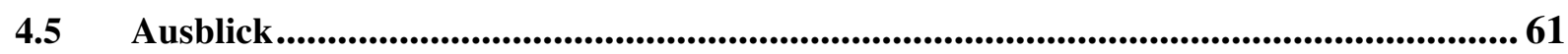

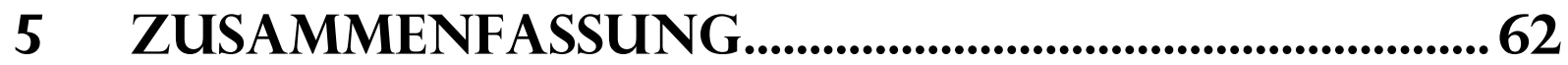

6 LITERATUR VERZEICHNIS ................................................ 63

7 ABBILDUNGSVERZEICHNIS ..........................................69

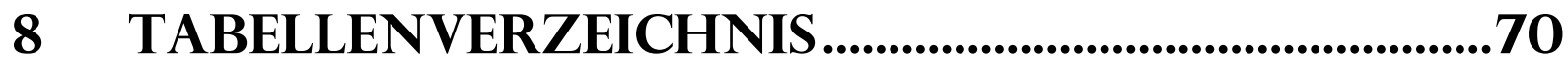




\section{ABKüRZUNGSVERZEICHNIS}

\begin{tabular}{|c|c|}
\hline $\mathrm{ABC}$ & Avidin-Biotin-Complex \\
\hline ABTS & 2,2'-Azino-di-(3-ethylbenzthiazolin-6-sulfonsäure) \\
\hline AEC & 3-Amino-9-Ethylcarbazol \\
\hline ACS & Acute Coronary Syndrome (akutes Koronarsyndrom) \\
\hline AMI & Akuter Myokardinfarkt \\
\hline AP & Angina pectoris \\
\hline ApoE & Apolipoprotein E \\
\hline aqua dest. & destilliertes Wasser \\
\hline AUC & Area Under the Curve (Fläche unter der Konzentrations-Zeit-Kurve, hier: \\
\hline BMI & Body-Mass-Index \\
\hline BSA & Bovine Serum Albumin (Rinderserumalbumin) \\
\hline $\mathrm{bp}$ & Basenpaare \\
\hline bspw. & beispielsweise \\
\hline bzw. & beziehungsweise \\
\hline $\mathrm{CD}$ & Cluster of Differentiation \\
\hline CCL & CC (zwei direkt angrenzende Cysteine)-Chemokin Ligand \\
\hline CCR & CC (zwei direkt angrenzende Cysteine)-Chemokin Rezeptor \\
\hline $\mathrm{cTn}$ & Kardiales Troponin \\
\hline dex. & dexter (rechts) \\
\hline dNTP & Desoxyribonukleosidtriphosphat \\
\hline EDTA & Ethylene Diamine Tetraacetic Acid (Ethylendiamintetraacetat) \\
\hline EKG & Elektrokardiogramm \\
\hline ELISA & $\begin{array}{l}\text { Enzyme, Linked Immunosorbent Assay (enzymgekoppelter } \\
\text { Immunadsorptionstest) }\end{array}$ \\
\hline ENI & European Neuroscience Institute Göttingen \\
\hline eNOS & endotheliale Stickstoffmonoxid-Synthase \\
\hline EZM & Extrazellulärmatrix \\
\hline gDNA & genomische DNA \\
\hline HRP & Horseradisch Peroxidase (Meerettich-Peroxidase) \\
\hline hsTn & Hochsensitives Troponin \\
\hline IQR & Interquartile Range (Interquartilsabstand) \\
\hline KHK & Koronare Herzerkrankung \\
\hline KLF & Krüppel-Like Factor \\
\hline LDL & Low-Density Lipoprotein (Lipoprotein niederer Dichte) \\
\hline MCP-1 & Monocyte Chemotactic Protein-1 \\
\hline MIP-1 $\alpha$ & Macrophage Inflammatory Protein-1 $\alpha$ \\
\hline MIP-1 $\beta$ & Macrophage Inflammatory Protein-1 $\beta$ \\
\hline $\mathrm{MgCl}_{2}$ & Magnesiumchlorid \\
\hline MI & Myokardinfarkt \\
\hline mRNA & messenger Ribonukleinsäure \\
\hline $\mathrm{NaOH}$ & Natronlauge \\
\hline
\end{tabular}




\begin{tabular}{|c|c|}
\hline NDS & Normal Donkey Serum (normales Eselserum) \\
\hline $\mathrm{NF}-\kappa \mathrm{B}$ & Nuclear Factor kappa B (Nukleärer Faktor kappa B) \\
\hline NGS & Normal Goat Serum (normales Ziegenserum) \\
\hline NI & Neointima \\
\hline NO & Stickstoffmonoxid \\
\hline NRS & Normal Rabbit Serum (normales Kaninchenserum) \\
\hline NSTEMI & $\begin{array}{l}\text { Non-ST-Segment-Elevation-Myocardial-Infarction (Nicht-ST-Strecken- } \\
\text { Hebungs-Mykordinfarkt) }\end{array}$ \\
\hline $\mathrm{OP}$ & Operation \\
\hline $\sin$. & sinister (links) \\
\hline TAE & Tris-Acetat-EDTA-Puffer \\
\hline TNF- $\alpha$ & Tumornekrosefaktor- $\alpha$ \\
\hline pAVK & Periphere arterielle Verschlusskrankheit \\
\hline PBS & Phosphate Buffered Saline (phosphatgepufferte Salzlösung) \\
\hline PCR & Polymerase Chain Reaction (Polymerase-Kettenreaktion) \\
\hline PMP & Platelet MicroParticles (Mikropartikel mit prokoagulatorischer Aktivität) \\
\hline RANTES & $\begin{array}{l}\text { Regulated on Activation, Normal } T \text { cell Expressed and Secreted } \\
\text { (alternative Bezeichnung für CCL5) }\end{array}$ \\
\hline $\mathrm{rpm}$ & rotations per minute („Umdrehungen pro Minute“) \\
\hline RT & Raumtemperatur \\
\hline SEM & Standard Error of the Mean (Standardfehler des Mittelwertes) \\
\hline STEMI & $\begin{array}{l}\text { ST-Segment-Elevation-Myocardial-Infarction (ST-Strecken-Hebungs- } \\
\text { Myokardinfarkt) }\end{array}$ \\
\hline VLDL & Very Low Density Lipoproteins (VLDL) \\
\hline UMG & Universitätsmedizin Göttingen \\
\hline ZTE & Zentrale Tierexperimentelle Einrichtung \\
\hline
\end{tabular}




\section{EINLEITUNG}

\subsection{Epidemiologie und Ätiologie der Atherosklerose}

\subsubsection{Inzidenz, Risikofaktoren und Prognose}

Die Atherosklerose ist eine progressiv fortschreitende Erkrankung der großen Gefäße, welche die häufigste Ursache für Erkrankungen des Herz-Kreislauf-Systems in der westlichen Gesellschaft charakterisieren (Lusis 2000). Krankheiten des Herz-Kreislauf-Systems stellten im Jahr 2012 mit 40,2\% die häufigste Todesursache in der Bundesrepublik Deutschland dar (Statistisches Bundesamt 2013).

Als ursächlich für die jährlich steigenden Zahlen werden sowohl verschiedene umweltbezogene als auch genetische Risikofaktoren betrachtet (Lusis 2000). Zu Letzteren zählen bspw. Hyperlipidämie, arterielle Hypertonie und Thrombophilie im Sinne erhöhter Fibrinogenwerte. Bezüglich umweltbezogener Risikofaktoren werden Überernährung, Bewegungsmangel und das Rauchen von Zigaretten genannt (Assmann et al. 1999; Dietel et al. 2012).

Je größer die Anzahl und das Ausmaß der Risikofaktoren wie bspw. Diabetes mellitus, Hypertonie, Dyslipidämie, starkes Übergewicht, eine begleitende periphere arterielle Verschlusskrankheit (pAVK) und frühere Herzinfarkte für eine Koronarsklerose sind, desto ungünstiger fällt die Prognose für eine koronare Herzkrankheit (KHK) aus (Dietel et al. 2012).

\subsubsection{Klinische Manifestationen}

\subsubsection{Koronare Herzkrankheit}

Die KHK stellt die klinische Manifestation der Atherosklerose in den Koronararterien dar, wobei die Koronarstenose in einer Koronarinsuffizienz resultiert. Es herrscht somit ein Missverhältnis zwischen dem Angebot und dem Bedarf an Sauerstoff. Die Hauptrisikofaktoren der Atherosklerose beeinträchtigen die Endothelzellen, welche die Diffusionsbarriere bilden, metabolische Funktionen ausüben und am Fettstoffwechsel beteiligt sind, dahingehend, dass die lokale Regulation des Gefäßtonus und das Aufrechterhalten einer antikoagulatorischen Oberfläche gestört sind. Darüber hinaus werden die Endothelzellen in ihrer Kontrollfunktion von Adhäsion und Einwanderung von Entzündungszellen gehindert. Prädilektionsstellen für die Entstehung atherosklerotischer Plaque stellen insbesondere Verzweigungsstellen epikardialer 
Arterien dar, da an diesen Stellen ein turbulenter Koronarfluss herrscht (Stary et al. 1992). Ausschlaggebend für das Ausmaß des von der Ischämie betroffenen Myokardareals ist die Lokalisation der Obstruktion. Allgemein gilt, dass ein stetiger Progress der Koronarsklerose die Entstehung von Kollateralgefäßen induziert, so dass das Sauerstoffangebot aufrechterhalten werden kann (Dietel et al. 2012).

Eine mögliche Manifestation der KHK stellt der akute Myokardinfarkt (MI) dar, dem definitionsgemäß eine Myokardnekrose aufgrund einer signifikanten Ischämie zu Grunde liegt (Mendis et al. 2011). Letztere ist durch einen Anstieg der Nekrosemarker kardiales Troponin (cTn) und hochsensitives Troponin (hsTn) gekennzeichnet, die nur im Herzmuskelgewebe exprimiert werden und daher als kardiospezifisch betrachtet werden.

Das Acute Coronary Syndrome (ACS) beinhaltet die instabile Angina pectoris (AP), den Nicht-ST-Streckenhebungsinfarkt (NSTEMI), den ST-Streckenhebungsinfarkt (STEMI) sowie den plötzlichen Herztod (Mendis et al. 2011). Nahezu ausschließlich resultiert das ACS aus einem luminalen Thrombus oder einer plötzlichen Einblutung in die Plaque, die von einem Gefäßspasmus begleitet sein kann (Davies 2000). Dieser kann zum einem das Gefäß nachhaltig okkludieren und somit zu einem STEMI mit charakteristischen Veränderungen im Elektrokardiogramm (EKG) führen, andererseits als unvollständig und dynamisch imponieren wie bspw. bei einer instabilen AP. Die häufigste Ursache, die zur Entstehung einer arteriellen Thrombose führt, ist in der Ruptur einer Plaque begründet (Davies 2000; Falk et al. 1995). In der Folge wird thrombogenes Material, welches aus dem Inneren der Plaque durch einen strukturellen Defekt in der fibromatösen Schicht hervortritt, den vorbeiströmenden Blutbestandteilen präsentiert (s. Abbildung 1).

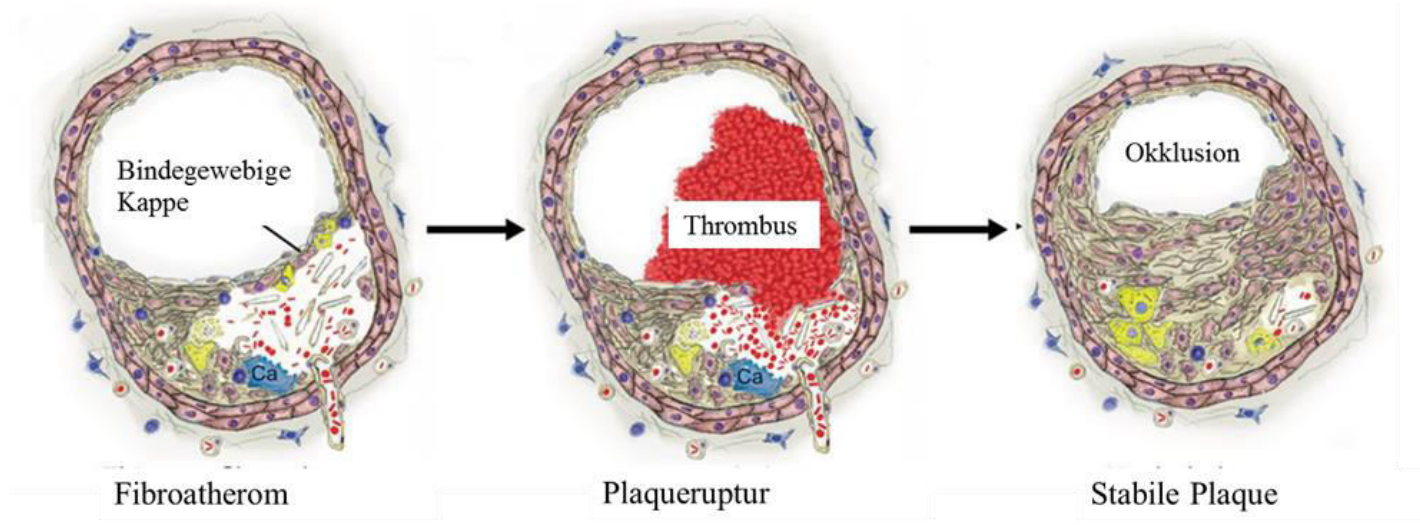

\section{Abbildung 1 Ruptur und Heilung einer Plaque}

Ruptur der fibroatheromatösen Kappe mit der Ausbildung eines Thrombus und einer anschließenden bindegewebigen Reaktion und konstriktivem Remodelling. Modifiziert nach Bentzon et al. 2014, S.1857. Abdruck mit freundlicher Genehmigung von E. Falk. 
Aufgrund der Tatsache, dass gelegentlich verdrängtes Plaquematerial im Thrombus nachgewiesen werden kann, wird ein paralleles Vorhandensein von Thrombose und Ruptur diskutiert, die sich gegenseitig beeinflussen (Bentzon et al. 2014).

\subsubsection{Schlaganfall}

Der Begriff Schlaganfall bezeichnet ein Syndrom vaskulärer Genese, das durch ein plötzlich einsetzendes, fokales neurologisches Defizit gekennzeichnet ist. Als Oberbegriff werden darunter verschiedene zerebrovaskuläre Erkrankungen mit teilweiser unterschiedlicher Ätiologie und Symptomatik zusammengefasst. Abzugrenzen sind hier die Subarachnoidalblutung, die 80-85\% durch einen Riss eines Aneurysmas einer Hirnbasisarterie bedingt ist (Suarez et al. 2006) sowie die Sinusvenenthrombose, ein Verschluss der ableitenden Hirnvene (Bousser und Ferro 2007). Weiterhin ist klinisch die Hirnblutung abzugrenzen, deren Ursprung in einem Riss einer parenchymatösen Arterie liegt und etwa 15\% aller Schlaganfälle ausmacht.

Mit einer Verteilungshäufigkeit von $80 \%$ stellt der ischämische Hirninfarkt die wichtigste Ursache des Schlaganfalles dar, wobei ein lokaler Verschluss ursächlich ist. Dieser resultiert in einer mangelnden Sauerstoff- und Glukoseversorgung und führt damit zu einem Zusammenbruch des Funktions- und Erhaltungsstoffwechsel in dem von der betroffenen Arterie versorgten Hirnareal (van der Worp et al. 2007). Der ischämische Schlaganfall ist in den westlichen Industriestaaten die dritthäufigste Todesursache (Rothwell et al. 2004) mit einer Inzidenz von 182/100 000 (Berger et al. 2000), was 146000 Neuerkrankungen pro Jahr in Deutschland entspricht. Das durchschnittliche Erkrankungsalter liegt bei ca. 65 Jahren, wobei Männer in Relationen häufiger erkranken als Frauen und das Risiko, einen Schlagfall zu erleiden, nimmt mit steigenden Lebensalter zu (Sudlow und Warlow 1996; Kolominsky-Rabas et al. 1998). Atherosklerotische Plaques in den extrakraniellen Abschnitten der A. carotis, im Besonderen im Bereich der Bifurkation der A. carotis communis, stellen einerseits eine wichtige Quelle dar, die zu Plaque-assoziierten thrombembolischen Ereignissen führen können. Auf der anderen Seite führt die Einengung des Lumens aufgrund atherosklerotischer Plaques zu einem Verschluss des betreffenden Gefäßes (Iannuzzi et al. 1995). Mittels ultrasonographischer Untersuchungen können die Dicke der Plaque, Charakter und Lokalisation in der $A$. carotis bestimmt werden und Ianuzzi et al. konnten zeigen, dass diese ultrasonographischen Bestimmungen mit ischämischen zerebrovaskulären Ereignissen korrelieren. Die Ultraschalluntersuchung hat einen hohen Stellenwert in der Diagnostik erlangt und dient dazu, das Auftreten zerebrovaskulärer ischämischer Ereignisse in Gegenwart atherosklerotischer Plaque in der A. carotis vorherzusagen (Iannuzzi et al. 1995). 


\subsubsection{Periphere arterielle Verschlusskrankheit}

Die pAVK ist als stenosierende und okkludierende Veränderung der Aorta oder der Extremitätenarterien definiert (Dietel et al. 2012). Diese Läsionen können segmental auftreten und folglich zu einer Stenose oder einem Verschluss führen, wobei üblicherweise die Aorta oder die Arterien der unteren Extremitäten betroffen sind. Als ursächlich werden neben atherosklerotischen Veränderungen, Thrombosen, Embolien, Vaskulitiden, fibromuskuläre Dysplasien, Engpasssyndrome, zystische Adventitiadegenerationen und Traumata genannt.

Im Vergleich zu Personen ohne pAVK haben an pAVK erkrankte Personen ein erhöhtes Risiko für kardiovaskuläre Ereignisse, das selbst nach einer Reduktion der klassischen Risikofaktoren für atherosklerotische Gefäßerkrankungen 1,6fach bis 2fach erhöht bleibt (Roger et al. 2012; Fowkes et al. 2008; Heald et al. 2006). Die Stadieneinteilung der pAVK reicht von keinen Beschwerden über Ulkus und Nekrosen, bei denen die Kriterien der kritischen Ischämie nicht erfüllt werden, bis hin zum Gangrän (Dietel et al. 2012).

\subsubsection{Der Aufbau arterieller Gefäße}

Der histologische Aufbau der arteriellen Gefäßwand umfasst drei Schichten (s. Abbildung 2): Intima (Tunica intima), Media (Tunica media) und Adventitia (Tunica adventitia). Die Intima, die lumenwärts gerichtet die innerste Schicht bildet, besteht aus Endothelzellen sowie einer subendothelialen Schicht und wird formal von der Membrana elastica interna zur Media hin abgegrenzt.

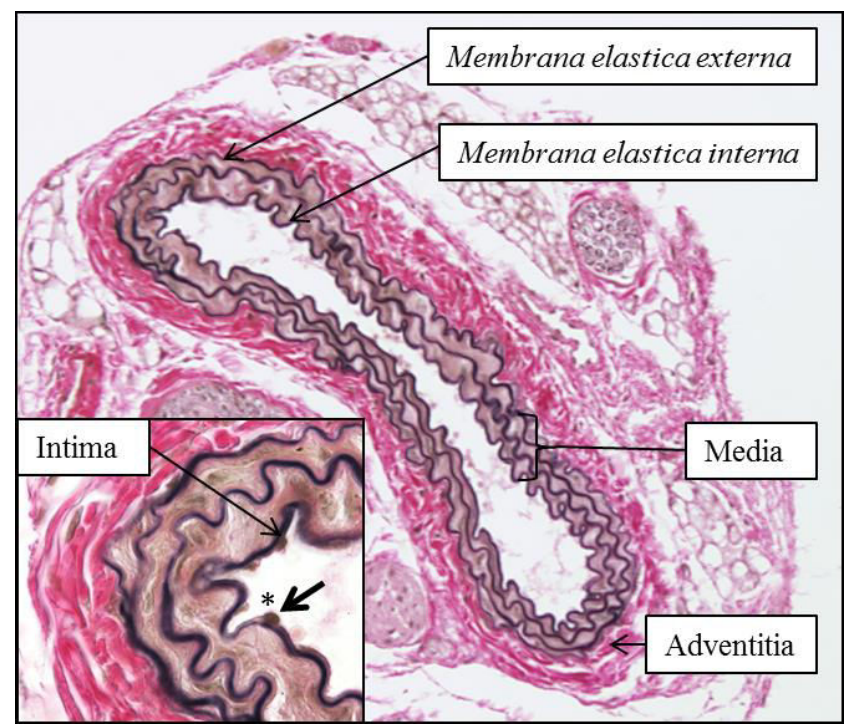

\section{Abbildung 2 Aufbau arterieller Gefäße}

Querschnitt der murinen A. carotis communis dex. in Verhoeff'scher-Elastika-Färbung, 100fache Vergrößerung. $\rightarrow$ Endothelzelle, 1000fache Detailvergrößerung. 
Zu den Funktionen der Endothelzellschicht zählen die Diffusionsbarriere, metabolische Funktionen im Sinne einer Aktivierung und Inaktivierung von Hormonen und Mediatoren sowie die Teilnahme am Fettstoffwechsel. Darüber hinaus übt die Endothelzellschicht synthetische Funktionen wie die Produktion von Basallaminae, Kollagen IV, Laminin und Fibronektin aus. Außerdem befinden sich im Zytoplasma Granulae, die den Von-Willebrand-Faktor zur primären Hämostase sowie das Adhäsionsmolekül P-Selektin enthalten. Weiterführend stehen die Endothelzellen über parakrin sezernierte Substanzen mit den innersten MediaMuskelzellen in Verbindung, sodass eine Einflussnahme auf die Gefäßdilatation ausgeübt werden kann. Die subendotheliale Schicht stellt ein lockeres Bindegewebe dar, das Fibroblasten und glatte Muskelzellen aufweist. Daran schließt sich, nach Außen gerichtet, die Media, bestehend aus glatten Muskelzellen an, die zirkulär oder in flachen Spiralen angeordnet sind sowie die Extrazelluläre Matrix (EZM). In größeren Gefäßen legt sich weiterhin eine Membrana elastica externa an. Abschließend wird das Gefäß von der Adventitia umschlossen, die hauptsächlich aus Bindegewebe besteht und zur Versorgung der Arterienwand Gefäßnerven und kleinste Blutgefäße führt, die bis in die Media eindringen (Junqueira und Carneiro 2004).

\subsubsection{Entwicklung der Atherogenese}

Aufgrund der progressiv fortschreitenden Eigenschaften ist ein phasenweiser Verlauf dieser Erkrankung der großen Gefäße charakteristisch, wobei die Entwicklung atherosklerotischer Plaques bzw. die Pathogenese der Atherosklerose einen komplexen und noch nicht vollständig aufgeklärten Vorgang darstellt. In dem Bestreben der potenziellen Aufklärung der Pathogenese werden in der Zusammenschau sowohl die „Response-to-injury“-Hypothese nach Ross (Ross et al. 1977) als auch die „Lipoprotein-induced atherosclerosis“-Hypothese nach Goldstein (Goldstein und Brown 1977) diskutiert. Als initiierender Prozess wird die Akkumulation von Low-Density Lipoprotein Cholesterols (LDL-Cholesterin) betrachtet, deren Oxidation und Glykosylierung als Stimulus zur Freisetzung von Monozyten anziehenden Chemokinen dient sowie zu einer Hochregulation endothelialer Adhäsionsmoleküle führt (Osterud und Bjorklid 2003). Weiterhin wird die Freilegung des Endothels bzw. die endotheliale Dysfunktion als Ausgangspunkt eines chronisch entzündlichen Prozesses betrachtet, der zu einer fortgeschrittenen, komplizierten Läsion führen kann, sofern dieser unvermindert und exessiv fortbesteht (Ross 1999). Diese Mechanismen resultieren in der Einleitung und Progression der Atherosklerose: 
- Typ I-Läsionen (initiale Läsionen): zeichnen sich durch einen erhöhten Anteil von Lipoproteinen aus sowie einer erhöhten Anzahl von solitären Makrophagen, die sich zu den so genannten Makrophagen-Schaumzellen differenzieren. Prädisponierend für diese und folgende Läsionen sind Areale in Arterien, deren Intima bereits aufgrund physiologischer Adaptionsvorgänge verdickt ist (Stary 1987, 1989).

- Typ II-Läsionen (Fettstreifen): bestehen hauptsächlich aus MakrophagenSchaumzellen und fakultativen lipidbeladenen glatten Muskelzellen. Mikroskopisch betrachtet, imponieren Typ II-Läsionen mit schichtartig formierten MakrophagenSchaumzellen (Stary et al. 1994).

- Typ III-Läsionen (Übergangsform): werden als Zwischenstufe mit uneinheitlicher Charakteristik verstanden (Stary et al. 1994).

- Typ IV-Läsionen (Atherom): sind durch eine dichte Akkumulation extrazellulärer Lipide gekennzeichnet (Lipidkern), welche eine intimale Desorganisation initiiert. Darüber hinaus können kalzifizierte Zellorganellen in den glatten Muskelzellen detektiert werden. Erste Kapillaren sprießen im Randbereich des Lipidkerns ein, die sich lumenwärts ausrichten (Stary et al. 1995).

- Typ V-Läsionen (Fibroatherom): sind durch markante Bindegewebsschichten definiert und werden weiterhin unterteilt in:

○ Typ Va-Läsionen (vielschichtiges Fibroatherom): die Bindegewebsschichten sind mit einem Atherom vergesellschaftet.

○ Typ Vb-Läsionen (kalzifizierte Läsionen): zusätzlich lassen sich kalzifizierte Areale im Bereich des Atheroms detektieren.

○ Typ Vc- Läsionen (fibrotische Läsionen): die ursprüngliche Intima ist verdickt und von Bindegewebe durchsetzt, dagegen können Lipidkern oder kalzifizierte Areale bei einer gering ausgeprägten Lipidschicht fehlen.

Die Kapillaren im Randbereich des Lipidkerns nehmen in ihrer Anzahl und Größe zu sowie in ihrer Ausbreitung im Bindegewebe. Als Komplikationen dieser Läsionen werden Fissuren und Hämatome beschrieben, die sich bereits klinisch manifestieren können (Stary et al. 1995).

- Typ VI-Läsionen (komplizierte Läsionen): werden anhand ihrer oberflächlichen Beschaffenheit weiterhin unterteilt in:

○ Typ VIa-Läsionen (Oberflächendefekt): sind durch Fissuren und Ulzerationen gekennzeichnet. 
○ Typ VIb-Läsionen (Blutung oder Hämatom): können sowohl aus den oberflächlichen Defekten als auch aus den eingesprossten Gefäßen resultieren.

○ Typ VIc-Läsionen (Thrombose): Risse und Hämatome liegen zugrunde, die wiederholt auftreten können sowie kleinere Thrombi, die sich selbst wiederholt reformieren. Funktionsbeeinträchtigungen oder Verlust der Endothelzellschicht können zudem die Thrombusbildung bahnen (Stary et al. 1995).

\subsubsection{Arterielle Thrombose}

Thrombotische Ablagerungen können einerseits aus oberflächlichen Defekten resultieren und anderseits durch Veränderungen des Blutflusses bzw. eines Gefäßverschlusses hervorgerufen werden. Neben okkludierenden Eigenschaften mit teilweise letalen Konsequenzen, stößt die arterielle Thrombose Mechanismen an, die die zunehmende Intimaverdickung aufrecht erhalten (Stary et al. 1995). Ferner wird durch die Ruptur eines Fibroatheroms thrombotisches Material freigelegt, das im Verlauf die Plättchenaggregation sowie die Gerinnung initiiert. Diese Veränderungen resultieren aus einer Aktivierung der Gerinnungskaskade aufgrund des freiliegenden Gewebefaktors und der Interaktion der Plättchen mit der aktivierten thrombotischen Matrix (Ross 1999). Folglich kommt es zu einer prompten zellulären Antwort, indem sowohl die Expression der leukozytären Adhäsionsmoleküle auf den Endothelzellen der Arterien als auch die Expression von Chemokinen seitens der Gefäßzellen gesteigert wird (Mestas und Ley 2008; Weber und Noels 2011). Diese molekularen Stimuli rekrutieren zirkulierende Monozyten, die in die Intima einwandern, wo sie durch Mediatoren wie bspw. den Monozytenstimulierenden Faktor (M-CSF) zu Makrophagen differenzieren (Clinton et al. 1992). Schließlich resultiert die Ansammlung mononukleärer Phagozyten in den atherosklerotischen Plaques nicht nur aus deren Einstrom, der durch Adhäsionsmoleküle und Chemo-Attraktanzien initiiert wird, sondern auch deren Retention innerhalb der Plaque. Diese Interaktionen zwischen ungeschützten Komponenten der atherosklerotischen Plaque sowie Plättchenrezeptoren und Gerinnungsfaktoren kann zu einer Aktivierung der Plättchen führen und folglich zur Bildung eines aufgelagerten Thrombus. In der Folge kann dieser Prozess in einer Lumenokklusion resultieren und somit die Symptome eines akuten ischämischen Syndroms verursachen (Badimon und Vilahur 2014).

In post-mortem-Analysen konnte gezeigt werden, dass eine Thrombusbildung im Lumen der Koronargefäße hauptsächlich aus einer Plaqueruptur resultiert (55-65\%), gefolgt von Plaqueerosionen (30-35\%) und am wenigsten wahrscheinlich von kalzifizierten Läsionen (27\%) (Sakakura et al. 2013). 


\subsection{Einfluss verschiedener Faktoren auf die Pathogenese der Atherosklerose}

\subsubsection{CC-Chemokin-Ligand-5}

Hinsichtlich des Chemokins CCL5 konnte eine Beteiligung in der Progression der Atherosklerose gezeigt werden (Liu et al. 2012). Chemokine werden von diversen Gewebszellen sezerniert und können darüber hinaus durch aktivierte Plättchen freigesetzt werden. Insbesondere fördert eine kontinuierliche Freisetzung von Chemokinen in einem entzündlichen Gebiet die Aufrechterhaltung der Migration von Effektorzellen im Sinne einer chronischen Entzündung. Dabei sind Chemokine sowohl in akuten Entzündungsreaktionen als auch in chronischen Entzündungen wie bspw. Arthritis, Erkrankungen der Atemwege und Atherosklerose beteiligt (Strieter et al. 1994). Hinsichtlich der chemotaktisch wirkenden Zytokine werden zwei große Familien unterschieden, die die Rekrutierung von Leukozyten und Lymphozyten fördern (Baggiolini et al. 1994). Dies sind zum einem die CXC-Chemokine, bei denen die beiden Aminosäuren Cystein-X-Cystein durch ein Residuum miteinander verbunden sind sowie andererseits die CC-Chemokine mit direkt angrenzenden Cysteinen (Clark-Lewis et al. 1995). Letztere beeinhalten unter anderem folgende Chemokine: MCP-1 (Monocyte Chemotactic Protein-1), MIP-1 $\alpha$ (Macrophage Inflammatory Protein-1 $\alpha$ ), MIP-1 $\beta$ (Macrophage Inflammatory Protein-1 $\beta$ ) und CCL5, ein CC-Chemokin mit dem Liganden 5, wobei zwei Cysteine direkt aufeinander folgen und das auch als RANTES (Regulated upon Activation, Normal T cell Expressed and Secreted) bekannt ist.

Zu den CCL5 produzierenden Zellen zählen Plättchen, Makrophagen, Eosinophile, Fibroblasten sowie Endothel-, Epithel- und Endometriumzellen. CCL5 nimmt eine essenzielle Rolle im Entzündungsprozess ein, indem es T-Zellen, Makrophagen, Dendritische Zellen, Eosinophile, Natural Killer-(NK)-Zellen, Mastzellen sowie Basophile auf die Seite der Entzündung und Infektion lockt (Appay und Rowland-Jones 2001; Levy 2009).

Es konnte gezeigt werden, dass aktivierte Plättchen unter anderem CCL5 an die Endothelauskleidung früher atherosklerotischer und neointimaler Läsionen sowie an Monozyten über das Adhäsionsmolekül P-Selektin abgeben (Schober 2002; Huo et al. 2003). Die Ablagerung und Immobilisation von CCL5, das aus den Plättchen stammt, bewirkt eine Verstärkung der Rekrutierung von Monozyten. Diesbezüglich konnte gezeigt werden, dass dieser Effekt durch aktivierte Endothelzellen der Aorta, nicht jedoch durch an der Oberfläche der Plättchen haftendes CCL5 initiiert wird (von Hundelshausen et al. 2001; Schober 2002). 
Darüber hinaus ist die Bereitschaft von CCL5, an Glykosaminoglykanen zu binden und somit zur Bildung von Oligomeren höherer Ordnung zu führen, für dessen Aktivität in vivo essenziell. Baltus et al. konnten diesbezüglich demonstrieren, dass diese Bildung von Oligomeren höherer Ordnung für die Anheftung von Monozyten und T-Zellen durch den CCChemokinrezeptor 1 (CCR1) vermittelt wird, wohingegen die Verbreitung und Migration von CCL5 durch CCR5 vermittelt wird (Baltus et al. 2003). Bezüglich seiner pleiotropen Effekte wurden für CCL5 neben der Bindung an CCR1 und CCR5 ebenfalls die Bindung an CCR3 beschrieben (Ferrandi et al. 2007; Houard et al. 2009).

Des Weiteren ist CCR1 ein Chemokinrezeptor für CCL3 und wird von Makrophagen und TZellen exprimiert (Charo und Taubman 2004). Weiterhin wird für den Chemokinrezeptor CCR3 neben CCL5 der Ligand CCL11, das Chemokin Eotaxin-1, beschrieben, das von glatten Gefäßmuskelzellen exprimiert wird und bei Gefäßerkrankungen wie bspw. der Atherosklerose hochreguliert wird (Kodali et al. 2006).

Darüber hinaus bindet CCR5 unter anderem die CC-Chemokine Macrophage Inflammatory

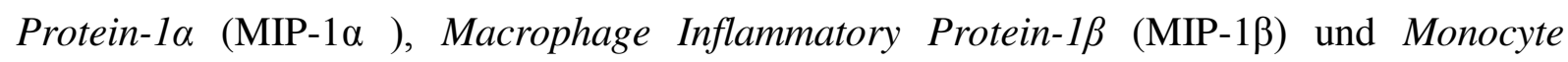
Chemotactic Protein-1 (MCP-1) (Blanpain et al. 1999).

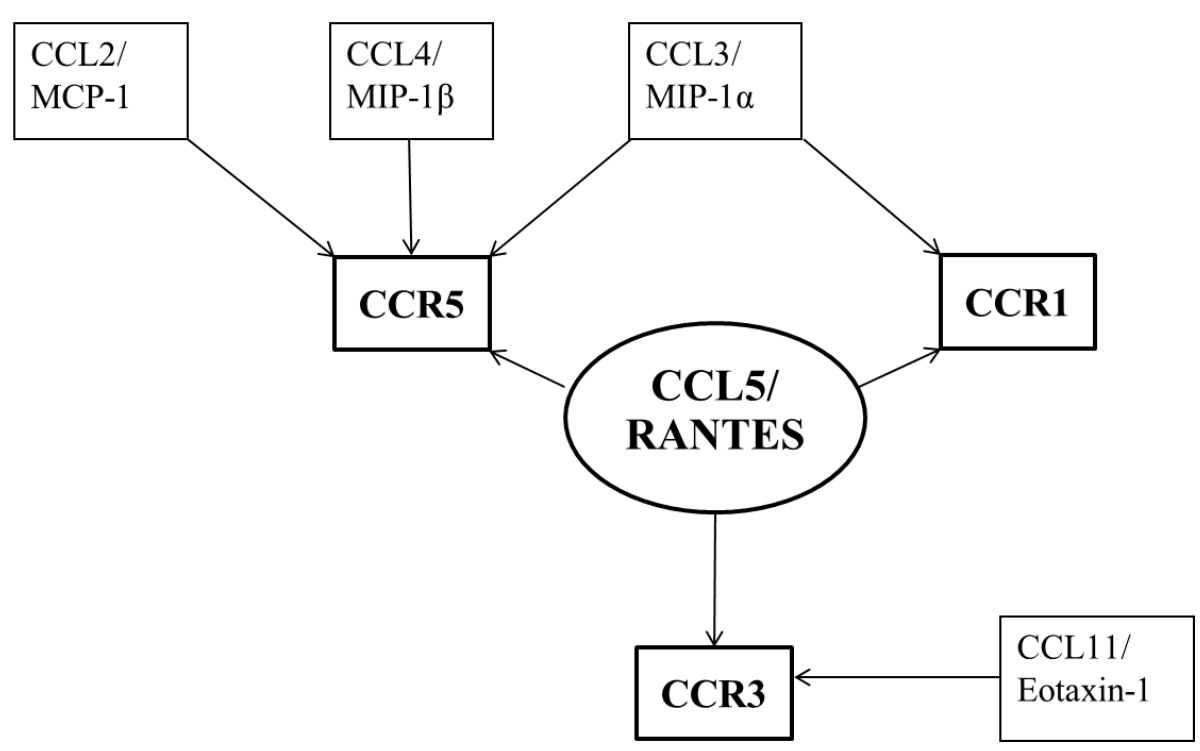

Abbildung 3 Synopsis der Liganden-Rezeptoren-Interaktionen 


\subsubsection{Krüppel-Like Faktor 4}

Krüppel-like-Faktoren (KLFs) sind Transkriptionsfaktoren, die als Mitglieder einer Zinkfinger-Familie eine Schlüsselrolle in der Regulation der zellulären Differenzierung und Entwicklung von Geweben einnehmen (Atkins und Jain 2007). Bisher konnte für drei Mitglieder der KLF Familie eine Expression in Endothelzellen nachgewiesen werden: KLF2, KLF4 und KLF6 (Kuo et al. 1997; Yet et al. 1998; Kojima et al. 2000; Botella et al. 2002). Im Besonderen konnte für KLF4 gezeigt werden, dass ein konditioneller, endothelspezifischer GenKnockout in einer reduzierten atherosklerotischen Plaque und einer signifikant reduzierten inflammatorischen Zellinfiltration resultiert (Zhou et al. 2012). Darüber hinaus führt der konditionelle, endothelzellspezifische Gen-Knockout zu einer signifikant verkürzten Gerinnungszeit, ausgehend von der Grundlinie und nach Zytokinstimulation mittels TNF- $\alpha$. Die konditionelle, endothelzellspezifische KLF4-Defizienz führt $\mathrm{zu}$ einer erhöhten Anfälligkeit für Atherothrombose in Mäusen, wohingegen das Vorhandensein von KLF4 einen protektiven Einfluss ausübt (Zhou et al. 2012). Des Weiteren resultiert der konditionelle, endothelzellspezifische Gen-Knockout für KLF4 in Endothelzellen und hämatopoetischen Zellen im Mausmodell einerseits in der Zunahme der Bildung einer Neointima als Folge auf eine Gefäßläsion. Auf der anderen Seite führt der endothelzellspezifische Gen-Knockout zu einer vermehrten Rekrutierung von Entzündungszellen wie Makrophagen und T-Zellen, aufgrund einer gesteigerten Induktion von Adhäsionsmolekülen (Yoshida et al. 2014). Bezüglich der gegenseitigen Beeinflussung der Faktoren wird für KLF2 und KLF4 ein synergistischer Effekt beschrieben, indem ein homozygoter Verlust von KLF2 zu einer gesteigerten Expression von KLF4 im Lungengewebe führt (Atkins et al. 2008). Obgleich beide Faktoren funktionelle Ähnlichkeiten aufweisen, indem sie die endotheliale Stickstoffmonoxid-Synthase (eNOS) induzieren und die proinflammatorische Zytokinmediation inhibieren, kann ein proinflammatorisches Milieu zu einer veränderten genetischen Regulation führen, die auf unterschiedliche Regulationen innerhalb der KLF Familie zurückzuführen ist. Während die Expression von KLF2 durch proinflammatorische Stimuli unterdrückt wird, ist die Expression von KLF4 erhöht (Zhou et al. 2012). Weitere Hinweise, dass andere Transkriptionsfaktoren den Verlust von KLF4 kompensieren, zeigen die Experimente von Yoshida et al., die dessen Rolle in den glatten Gefäßmuskelzellen nach Induktion einer Läsion untersucht haben (Yoshida et al. 2008). In WildtypMäusen induzierte die Läsion eine rasche und transiente Expression der KLF4 mRNA, die zu einer direkten Reduktion der mRNA des Differenzierungsmarkers für glatte Gefäßmuskelzellen führt. Die KLF4-Defizienz hingegen resultierte in einer verspäteten, jedoch nicht gänzlich aufgehobenen Reduktion des Differenzierungsmarkers (Yoshida et al. 2008). Diese Ergebnis- 
se deuten ebenfalls auf eine kompensatorische Regulation von KLF4 durch andere Transskriptionssfaktoren hin. Darüber hinaus konnte gezeigt werden, dass eine KLF4Defizienz in einer herabgesetzten Expression von CCR2 in Vorstufen von Monozyten resultiert, in deren Folge es zu einem Verlust von inflammatorischen Monoyzten sowie deren Differenzierung kommt (Alder et al. 2008).

\subsection{Zielsetzung}

In verschiedenen Studien konnte bisher gezeigt werden, dass eine medikamentös induzierte Blockade der Rezeptoren für CCL5 die Bildung einer Neointima sowie die Infiltration von Makrophagen in die Neointima im Mausmodell abschwächt (Schober 2002; Veillard et al. 2004).

Ziel dieser Studie ist es nun, den Effekt einer direkten CCL5-Defizienz auf die arterielle Thrombose und Neointimabildung zu untersuchen. Hierfür werden die vaskulären Umbauvorgänge im Sinne einer arteriellen Thrombose und Bildung einer Neointima im Rahmen der Progression atherosklerotischer Plaque untersucht. Unter Anwendung des Gen-KnockoutMausmodells für CCL5 wird die Versuchsgruppe $\mathrm{ApoE}^{-/-}$x CCL5 ${ }^{-/}$generiert sowie die Kontrollgruppe mithilfe des Wildtyp-Mausmodells, $\mathrm{ApoE}^{-/-}$x CCL5 ${ }^{+/+}$. Die zusätzliche Kreuzung mit Gen-Knockout-Mäusen für ApoE dient der Erzeugung einer Hypercholesterinämie. Zur Induktion einer endothelialen Dysfunktion wird das $\mathrm{FeCl}_{3}$-Modell der Gefäßverletzung angewendet, in dessen Folge sich eine arterielle Thrombose mit konsekutiven vaskulären Umbauvorgängen einstellt. Um die Genotypen zu charakterisieren, werden die Blutbestandteile wie Blutfette (Triglyceride und Cholesterin) und zelluläre Bestandteile (Differentialblutbild) analysiert sowie Biomarker des Entzündungsprozesses identifiziert, um mögliche einflussnehmende Faktoren ausschließen zu können. Darüber hinaus wird der Einfluss der CCL5Defizienz auf den antithrombotisch bzw. antiatherogen wirkenden ZinkfingerTranskriptionsfaktors KLF4 im Gewebe untersucht. 


\section{MATERial UND Methoden}

\subsection{Verwendete Materialien und Geräte}

\subsubsection{Allgemeine Reagenzien}

\begin{tabular}{|c|c|c|}
\hline Artikel & Art.-Nummer & Firma \\
\hline Aceton & 8222511000 & Merck KGaA, Darmstadt, DE \\
\hline ABC-Link $^{\circledR}$ & PK 6100 & Vector Laboratories, Burlingame, CA, USA \\
\hline AEC Substrate Kit ${ }^{\circledR}$ & 002007 & Invitrogen $^{\mathrm{TM}}$, Carlsbad, CA, USA \\
\hline Antibody-Diluent & S3022 & Dako Deutschland GmbH, Hamburg, DE \\
\hline Biebrich-Scharlachrot & B6008 & Sigma-Aldrich, Steinheim, DE \\
\hline Biozym ${ }^{\circledR}$ LE Agarose & 840004 & $\begin{array}{l}\text { Biozym Scientific GmbH, Hessisch Olden- } \\
\text { dorf, DE }\end{array}$ \\
\hline BSA (Bovine Serum Albumin) & A7906 & Sigma-Aldrich, Steinheim, DE \\
\hline Chloroform & 1024452500 & Merck KGaA, Darmstadt, DE \\
\hline Dinatriumhydrogenphosphat & 1063461000 & Merck KGaA, Darmstadt, DE \\
\hline Direct PCR Tail & $31102 \mathrm{~T}$ & $\begin{array}{l}\text { PEQLAB Biotechnologie GmbH, Erlangen, } \\
\text { DE }\end{array}$ \\
\hline $\begin{array}{l}\text { EDTA (Ethylendiamintetraacetat, } \\
0,5 \mathrm{M})\end{array}$ & AM9260G & AMBION GmbH, Kaufungen, DE \\
\hline Eisenchlorid (29\%, in aqua dest.) & 236489 & Sigma-Aldrich, Steinheim, DE \\
\hline Eisessig & 1000631000 & Merck KGaA, Darmstadt, DE \\
\hline Entellan $^{\circledR}$ & 1076910100 & Merck KGaA, Darmstadt, DE \\
\hline Ethidiumbromidlösung & 22184 & Carl Roth ${ }^{\circledR} \mathrm{GmbH}$, Karlsruhe, DE \\
\hline Ethanol & 1009831000 & Merck KGaA, Darmstadt, DE \\
\hline Formalin & 252549 & Sigma-Aldrich, Steinheim, DE \\
\hline Giemsas Azur-Eosin-Methylenblau & 1092030025 & Merck KGaA, Darmstadt, DE \\
\hline Gill’s Hämatoxylin ${ }^{\circledR}$ & 6765007 & $\begin{array}{l}\text { Thermo Fisher Scientific Germany, Braun- } \\
\text { schweig, DE }\end{array}$ \\
\hline Go Taq ${ }^{\circledR}$ Flexi DNA Polymerase & M8305 & Promega Corporation, Madison, WI, USA \\
\hline Magnesiumchlorid, $25 \mu \mathrm{M}$ & A351H & Promega Corporation, Madison, WI, USA \\
\hline 5x Green Go Taq ${ }^{\circledR}$ Flexi Buffer & M891A & Promega Corporation, Madison, WI, USA \\
\hline Go Taq ${ }^{\circledR}$ DNA Polymerase & M380B & Promega Corporation, Madison, WI, USA \\
\hline
\end{tabular}




\begin{tabular}{|c|c|c|}
\hline Hämatoxylin & 1043020100 & Merck KGaA, Darmstadt, DE \\
\hline Immu-Mount $^{\circledR}$ & 9990402 & $\begin{array}{l}\text { Thermo Fisher Scientific Germany, } \\
\text { Braunschweig, DE }\end{array}$ \\
\hline Iod & 207772 & Sigma-Aldrich, Steinheim, DE \\
\hline Isofluran & B506 & Abbott, GmbH+Co KG, Wiesbaden, DE \\
\hline Isopropanol (2-Propanol) & 278475 & Sigma-Aldrich, Steinheim, DE \\
\hline Kaliumchlorid & 1.049 .365 .000 & Merck KGaA, Darmstadt, DE \\
\hline Kaliumdihydrogenphosphat & 420A877573 & Merck KGaA, Darmstadt, DE \\
\hline Kaliumiodid & P4286 & Sigma-Aldrich, Steinheim, DE \\
\hline Ketamin, $10 \%$ & 84029 & medistar, Holzwickede, DE \\
\hline Marker, 100 bp DNA Ladder & N3231L & New England Biolabs ${ }^{\circledR}$, Ipswich, MA, USA \\
\hline May-Grünwald ${ }^{\circledR}$ & HX811416 & Merck KGaA, Darmstadt, DE \\
\hline Methanol & 106009 & Merck KGaA, Darmstadt, DE \\
\hline Mini PAP Pen & $00-8877$ & Invitrogen $^{\mathrm{TM}}$, Carlsbad, CA, USA \\
\hline Natriumhydroxid, $2 \mathrm{M}$ & 1.091 .361 .000 & Merck KGaA, Darmstadt, DE \\
\hline Natriumchlorid & 3957.2 & Carl Roth $^{\circledR} \mathrm{GmbH}$, Karlsruhe, DE \\
\hline Natriumthiosulfat-Pentahydrat & 1.065 .161 .000 & Merck KGaA, Darmstadt, DE \\
\hline Normales Ziegenserum (NGS) & X0907 & Dako Deutschland GmbH, Hamburg, DE \\
\hline Normales Rattenserum (NRS) & X0902 & Dako Deutschland GmbH, Hamburg, DE \\
\hline PBS, $10 \%$ Gibco $^{\circledR}$ & 70011-036 & $\begin{array}{l}\text { Thermo Fischer Scientific, Waltham, MA, } \\
\text { USA }\end{array}$ \\
\hline PCR Nukleotide Mix ${ }^{\circledR}$ & $\mathrm{C} 1145$ & Promega Corporation, Madison, WI, USA \\
\hline Phosphomolybdänsäure & 221856 & Sigma-Aldrich, Steinheim, DE \\
\hline Phosphotungstensäure & P4006 & Sigma-Aldrich, Steinheim, DE \\
\hline Pikrinsäure, gesättigt & P6744 & Sigma-Aldrich, Steinheim, DE \\
\hline $\begin{array}{l}\text { Proteinase K, rekombinant, PCR } \\
\text { Grade }^{\circledR}\end{array}$ & 03115828001 & Roche Diagnostics, Mannheim, DE \\
\hline $\begin{array}{l}\text { Puffertabletten (Pufferlösung für } \\
\text { Blutausstrichfärbungen) }\end{array}$ & 109468 & Merck KGaA, Darmstadt, DE \\
\hline Salzsäure, konzentriert & 1099110001 & Merck KGaA, Darmstadt, DE \\
\hline Säurefuchsin $(1 \%$, in aqua dest.) & F8129 & Sigma-Aldrich, Steinheim, DE \\
\hline Solvent Blue 43 & 531251 & Sigma-Aldrich, Steinheim, DE \\
\hline Triton ${ }^{\circledR}-\mathrm{X}-100$ & 93426 & $\begin{array}{l}\text { Fluka }^{\circledR} \text { Analytical; Sigma- Aldrich } \\
\text { Steinheim, DE }\end{array}$ \\
\hline
\end{tabular}




\begin{tabular}{|c|c|c|}
\hline Trizma-Base $^{\circledR}$ & T6066 & Sigma-Aldrich, Steinheim, DE \\
\hline Tween $20^{\circledR}$ & P1379 & Sigma-Aldrich, Steinheim, DE \\
\hline VectaShield Mounting Medium ${ }^{\circledR}$ & $\mathrm{H}-1000$ & $\begin{array}{l}\text { Vector Laboratories, Inc., Burlingame, } \\
\text { CA, USA }\end{array}$ \\
\hline Wasserstoffperoxid, $30 \%$ & 55760 & $\begin{array}{l}\text { Otto Fischar GmbH \& Co. KG, } \\
\text { Saarbrücken, DE }\end{array}$ \\
\hline Xylazin $^{\circledR}, 2 \%$ & 12095 & Serumwerk Bernburg AG, Bernburg, DE \\
\hline Xylolersatzmittel & 9990505 & $\begin{array}{l}\text { Thermo Fisher Scientific Germany, } \\
\text { Braunschweig, DE }\end{array}$ \\
\hline Zinkformalin & 6764255 & $\begin{array}{l}\text { Thermo Fisher Scientific Germany, } \\
\text { Braunschweig, DE }\end{array}$ \\
\hline Zitronensäure & C1909 & Sigma-Aldrich, Steinheim, DE \\
\hline
\end{tabular}

\subsubsection{Geräte und Programme}

\begin{tabular}{|c|c|}
\hline Artikel & Firma \\
\hline AlphaEaseFC $^{\circledR}$ & Alpha Innotech Corporation, Randburg, ZA \\
\hline ARCHITECT $^{\circledR}$ c16000 & Abbott Laboratories, Abott Park, Illinois, USA \\
\hline Axio Vision ${ }^{\circledR} 3.0$ (Graphikprogramm) & Carl Zeiss AG, Oberkochen, DE \\
\hline Beckmann Coulter $\mathrm{A}^{\mathrm{C}} \mathrm{T} 5$ diff Hematology Analyzer ${ }^{\circledR}$ & $\begin{array}{l}\text { Beckmann Coulter GmbH Deutschland, Krefeld, } \\
\text { nF. }\end{array}$ \\
\hline Fluoreszenzmikroskop (Zeiss Axiovert 200) & Carl Zeiss AG, Oberkochen, DE \\
\hline$\mu Q u a n t^{\mathrm{TM}}$ Microplate Spectrophotometer & BioTek $^{\circledR}$ Instruments, Highland Park, VT, USA \\
\hline Gelelektrophorese-Apparatur (Sub-Cell ${ }^{\circledR}$ GT Cell) & Bio-Rad Laboratories GmbH, München, DE \\
\hline GraphPad Prism $^{\circledR}$ (Statistikprogramm) & GraphPad Software Inc., La Jolla, CA, USA \\
\hline High lighter ${ }^{\circledR} 3100$ & $\begin{array}{l}\text { Olympus Imaging America Inc., Center Valley, } \\
\text { PA, USA }\end{array}$ \\
\hline Image Pro Plus $^{\circledR}$ (Graphikprogramm) & Media Cybernetics, Bethesda, MD, USA \\
\hline Isoflurananlage Penlon & Penlon Limited, Abingdon, UK \\
\hline Mastercycler gradient ${ }^{\circledR}$ & Eppendorf AG, Hamburg, DE \\
\hline Mikroskop (Olympus ${ }^{\circledR}$ BX51) & Olympus Deutschland GmbH, Hamburg, DE \\
\hline MultiImage Light Cabinet ${ }^{\circledR}$ & Alpha Innotech Corporation, Randburg, ZA \\
\hline Power PAC 200 Supply ${ }^{\circledR}$ & Bio-Rad Laboratories GmbH, München, DE \\
\hline Thermomixer comfort $^{\circledR}$ & Eppendorf AG, Hamburg, DE \\
\hline T106 small animal blood flow meter & Transonic Systems, Ithaca, NY, USA \\
\hline WINDAQ ${ }^{\circledR}$ Data Acquisition sofware Version 2.61 & DATAQ Instruments, Akron, OH, USA \\
\hline $\begin{array}{l}\text { WINDAQ }{ }^{\circledR} \text { Waveform Browser playback } \\
\text { and analysis software Version } 2.61\end{array}$ & DATAQ Instruments, Akron, OH, USA \\
\hline
\end{tabular}




\subsubsection{Materialien}

\begin{tabular}{|c|c|c|}
\hline Artikel & Art.-Nummer & Firma \\
\hline Filterpapier & D3701 & GE Healthcare, München, DE \\
\hline Insulinspritzen, $1 \mathrm{ml}$ & $9161309 \mathrm{~V}$ & B. Braun Melsungen AG, Melsungen, DE \\
\hline Mikrolance $^{\mathrm{TM}}, 20 \mathrm{G}$ & 301300 & $\begin{array}{l}\text { Becton Dickinson, } \text { BD }^{\circledR} \text {, Franklin Lakes, NJ, } \\
\text { USA }\end{array}$ \\
\hline Naht 6-0 & Ethilon BV-4 & $\begin{array}{l}\text { Ethicon, Johnson \& Johnson medical GmbH, } \\
\text { Norderstedt, DE }\end{array}$ \\
\hline $\begin{array}{l}\text { Perfusionsbesteck mit Flügeln, BD } \\
\text { Valu Set }\end{array}$ & 387435 & $\begin{array}{l}\text { Becton Dickinson, BD }{ }^{\circledR} \text {, Franklin Lakes, NJ, } \\
\text { USA }\end{array}$ \\
\hline Pinzetten, fein, Dumont \#5/45 & 1125135 & Fine Science Tools ${ }^{\circledR}$ GmbH, Heidelberg, DE \\
\hline $\begin{array}{l}\text { Pinzette, gebogen, Extra Graefe } \\
\text { Forceps }\end{array}$ & 115110 & Fine Science Tools ${ }^{\circledR} \mathrm{GmbH}$, Heidelberg, DE \\
\hline Pinzette, gerade, Extra Graefe Forceps & 115010 & Fine Science Tools ${ }^{\circledR} \mathrm{GmbH}$, Heidelberg, DE \\
\hline Schere, klein, Extra Fine Bonn & 1408408 & Fine Science Tools ${ }^{\circledR} \mathrm{GmbH}$, Heidelberg, DE \\
\hline Spritze $5 \mathrm{ml}$, Discordit II & 309050 & $\begin{array}{l}\text { Becton Dickinson, } \text { BD }^{\circledR} \text {, Franklin Lakes, NJ, } \\
\text { USA }\end{array}$ \\
\hline
\end{tabular}

\subsubsection{Puffer und Lösungen}

\subsubsection{Gewebefärbungen}

\begin{tabular}{|c|c|c|}
\hline Anilinblau-Lösung & $\begin{array}{l}2,5 \mathrm{ml} \\
2 \mathrm{ml} \\
\text { auf } 100 \mathrm{ml}\end{array}$ & $\begin{array}{l}\text { Solvent Blue } 43 \\
\text { Eisessig } \\
\text { aqua dest. }\end{array}$ \\
\hline Biebrich-Scharlachrot-Säurefuchsin-Lösung & $\begin{array}{l}90 \mathrm{ml} \\
10 \mathrm{ml} \\
1 \mathrm{ml}\end{array}$ & $\begin{array}{l}\text { Biebrich-Scharlachrot (1\%, in aqua } \\
\text { dest.) } \\
\text { Säurefuchsin }(1 \% \text {, in aqua dest.) } \\
\text { Eisessig }\end{array}$ \\
\hline Bouin-Lösung & $\begin{array}{l}750 \mathrm{ml} \\
250 \mathrm{ml} \\
50 \mathrm{ml}\end{array}$ & $\begin{array}{l}\text { gesättigte Pikrinsäure } \\
\text { Formalin } \\
\text { Eisessig }\end{array}$ \\
\hline Zitratpuffer & $\begin{array}{l}2,1 \mathrm{~g} \\
\text { auf } \mathrm{pH}=6 \\
\text { auf } 1000 \mathrm{ml}\end{array}$ & $\begin{array}{l}\text { Zitronensäure } \\
\text { Natriumhydroxid } \\
\text { aqua dest. }\end{array}$ \\
\hline $\begin{array}{l}\text { PBS } \\
\text { (Phosphate Buffered Saline) }\end{array}$ & $\begin{array}{l}160 \mathrm{~g} \\
4 \mathrm{~g} \\
28,8 \mathrm{~g} \\
4,8 \mathrm{~g} \\
\text { auf } 2000 \mathrm{ml}\end{array}$ & $\begin{array}{l}\text { Natriumchlorid } \\
\text { Kaliumchlorid } \\
\text { Dinatriumhydrogenphosphat } \\
\text { Kaliumdihydrogenphosphat } \\
\text { aqua dest. }\end{array}$ \\
\hline $\begin{array}{l}\text { Phosphomolybdänsäure-Phosphotungstensäure- } \\
\text { Lösung }\end{array}$ & $\begin{array}{l}5 \mathrm{~g} \\
5 \mathrm{~g} \\
\text { auf } 200 \mathrm{ml}\end{array}$ & $\begin{array}{l}\text { Phosphomolybdänsäure } \\
\text { Phosphotungstensäure } \\
\text { aqua dest. }\end{array}$ \\
\hline Puffer & $\begin{array}{l}2 \text { Stück } \\
\text { auf } 2000 \mathrm{ml}\end{array}$ & $\begin{array}{l}\text { Puffertabletten } \\
\text { Aqua dest. }\end{array}$ \\
\hline van Giesson-Lösung & $\begin{array}{l}95 \mathrm{ml} \\
5 \mathrm{ml}\end{array}$ & $\begin{array}{l}\text { Pikrinsäure, gesättigt } \\
\text { Säurefuchsin, } 1 \%\end{array}$ \\
\hline
\end{tabular}




\begin{tabular}{|c|c|c|}
\hline Verhoeff'sche Iodinlösung & $\begin{array}{l}2 \mathrm{~g} \\
4 \mathrm{~g} \\
\text { auf } 100 \mathrm{ml}\end{array}$ & $\begin{array}{l}\text { Iod } \\
\text { Kaliumiodid } \\
\text { Aqua dest. }\end{array}$ \\
\hline \multirow{3}{*}{ Weigerts-Eisenhämatoxylin-Lösung } & $\begin{array}{l}\text { Lösung A } \\
1 \mathrm{~g} \\
\text { auf } 100 \mathrm{ml}\end{array}$ & $\begin{array}{l}\text { Hämatoxylin } \\
\text { Ethanol (95\%, in aqua dest.) }\end{array}$ \\
\hline & $\begin{array}{l}\text { Lösung B } \\
4 \mathrm{ml} \\
1 \mathrm{ml} \\
\text { auf } 100 \mathrm{ml}\end{array}$ & $\begin{array}{l}\text { Eisenchloridlösung ( } 29 \% \text {, in aqua dest.) } \\
\text { konzentrierte Salzsäure } \\
\text { aqua dest. }\end{array}$ \\
\hline & $\mathrm{A}: \mathrm{B}$ & $1: 1$ \\
\hline
\end{tabular}

\subsubsection{Proteinnachweis}

\begin{tabular}{|c|c|c|}
\hline Blockpuffer, 1\% BSA in PBS & $\begin{array}{l}1 \mathrm{~g} \\
\text { auf } 100 \mathrm{ml}\end{array}$ & $\begin{array}{l}\text { BSA } \\
\operatorname{PBS}\left(\text { Gibco }^{\circledR}\right)\end{array}$ \\
\hline PBS, $1 \%$ & $\begin{array}{l}100 \mathrm{ml} \\
900 \mathrm{ml}\end{array}$ & $\begin{array}{l}\text { PBS }\left(\text { Gibco }^{\circledR}\right) \\
\text { aqua dest. }\end{array}$ \\
\hline $\begin{array}{l}\text { Waschpuffer, } \\
0,1 \% \text { BSA und } 0,05 \% \text { Tween } 20 \text { in PBS }\end{array}$ & $\begin{array}{l}1 \mathrm{~g} \\
500 \mu \mathrm{l} \\
\text { auf } 1000 \mathrm{ml}\end{array}$ & $\begin{array}{l}\text { BSA } \\
\text { Tween } 20^{\circledR} \\
\text { PBS }\left(\text { Gibco }^{\circledR}\right)\end{array}$ \\
\hline
\end{tabular}

\subsection{Untersuchungen im Tiermodell}

\subsubsection{Genehmigung der Studie}

Die tierexperimentelle Studie wurde nach $\S 8$ des Tierschutzgesetzes vom Niedersächsischen Landesamt für Verbraucherschutz und Lebensmittelsicherheit genehmigt (AZ 33.9-42502-0411/0398). Haltung und Versuche erfolgten gemäß nationalen Bestimmungen.

\subsubsection{Tierzucht}

Für die Experimente wurden jeweils männliche und weibliche Mäuse des genetischen Hintergrundes C57BL/6J und des einzelnen Gen-Knockouts für das Apolipoprotein E (ApoE) der Firma Charles Rivers WIGA GmbH (Wilmington, MA, USA) sowie des einzelnen GenKnockouts für CCL5 von der Firma Jackson Laboraties (Bar Harbor, ME, USA) bezogen. Die Tiere wurden im European Neuroscience Institute (ENI) in Göttingen gehalten und initial wurden Tiere mit dem jeweiligen Gen-Knockout für ApoE ${ }^{-/-}$und $\mathrm{CCL5}^{-/-}$miteinander verpaart. Letztlich standen Mäuse mit einem Doppel-Gen-Knockout für ApoE und CCL5 (Apo$\left.\mathrm{E}^{-/-} \times \mathrm{CCL5}^{-/}\right)$als Versuchsgruppe zur Verfügung. Als Kontrollgruppe wurden Mäuse mit 
einem Einzel-Gen-Knockout für ApoE $\left(\mathrm{ApoE}^{-/-} \mathrm{x} \mathrm{CCL}^{+/+}\right)$verwendet. Zur Genotypisierung der Nachkommen wurde bei den Tieren im Alter von 3 Wochen eine Schwanzbiopsie entnommen. Diese wurden bis zur Durchführung der Genotypisierungen bei $-80^{\circ} \mathrm{C}$ gelagert.

\subsubsection{Genotypisierung}

Zur Durchführung der Genoytpisierungen wurden Schwanzbiopsien lysiert, mit Direct PCR Lysis Buffer und Proteinkinase $\mathrm{K}$ versehen und über Nacht bei $54^{\circ} \mathrm{C}$ und $700 \mathrm{rpm}$ im Thermomixer inkubiert, um die genomische DNA (gDNA) zu erhalten. Im Anschluss erfolgte die Inaktivierung der Proteinkinase $\mathrm{K}$, indem die Proben für $45 \mathrm{~min}$ bei $85^{\circ} \mathrm{C}$ und $700 \mathrm{rpm}$ inkubiert wurden.

Die im Protokoll genannten Bestandteile des PCR-Puffers wurden entsprechend für die jeweiligen Proteine ApoE und CCL5 pipettiert und abschließend in einem Polymerase Chain Reaction Tube mit der gewonnenen gDNA versehen:

\begin{tabular}{lll}
\hline Go Taq $^{\circledR}$ Flexi DNA Polymerase & M8305 & Promega Corporation, Madison, WI, USA \\
\hline Magnesiumchlorid, $25 \mu \mathrm{M}$ & A351H & Promega Corporation, Madison, WI, USA \\
\hline $5 \mathrm{x}$ Green Go Taq ${ }^{\circledR}$ Flexi Buffer & M891A & Promega Corporation, Madison, WI, USA \\
\hline Go Taq $^{\circledR}$ DNA Polymerase & M380B & Promega Corporation, Madison, WI, USA \\
\hline
\end{tabular}

Die Proben wurden zunächst präinkubiert und in 35 Zyklen jeweils denaturiert, hybridisiert und synthetisiert, sowie im Anschluss bei $72^{\circ} \mathrm{C}$ verlängert. Die Auswertung erfolgte mittels einer Agarose-Gelelektrophorese $\left(S u b-C e l l^{\circledR} G T\right.$ Cell), wofür zunächst $130 \mathrm{ml}$ Tris(hydroxymethyl)-aminomethan-Acetat-EDTA (TAE)-Puffer mit 2\%iger Agarose über einen Kochvorgang zu einem homogenen Gemisch angesetzt wurde. Diesem wurde nach dem Kochen $12 \mu 1$ Ethidiumbromid zugesetzt und in den Gießstand der Gelelektrophorese-Apparatur ausgegossen. Das entstandene Gel wurde mit TAE-Laufpuffer überschichtet und die Kämme möglichst langsam und parallel herausgezogen. Zur Markierung wurden $5 \mu 1100$ bp Markerprobe sowie $10 \mu \mathrm{l}$ der jeweiligen Probe in die Kammern der Apparatur aufgetragen. Diese wurde mit einer Spannung von $120 \mathrm{~V}$ für 45 min über ein Netzteil angeschlossen (PowerPac 200 Power Supply), um die gDNA gemäß ihres Verhaltens im elektrischen Feld aufzutrennen. Im Anschluss wurde das Gel vorsichtig aus der Laufkammer herausgenommen und in eine UV-Box gelegt, so dass unter UV-Beleuchtung mit der Software AlphaEaseFC eine Fotographie aufgenommen werden konnte (s. Abbildung 4). 
Die Genotypisierungen erfolgten durch Gerrit Gründer und Celina Fraatz, BiologischTechnische Assistenten der Klinik für Kardiologie und Pneumologie.
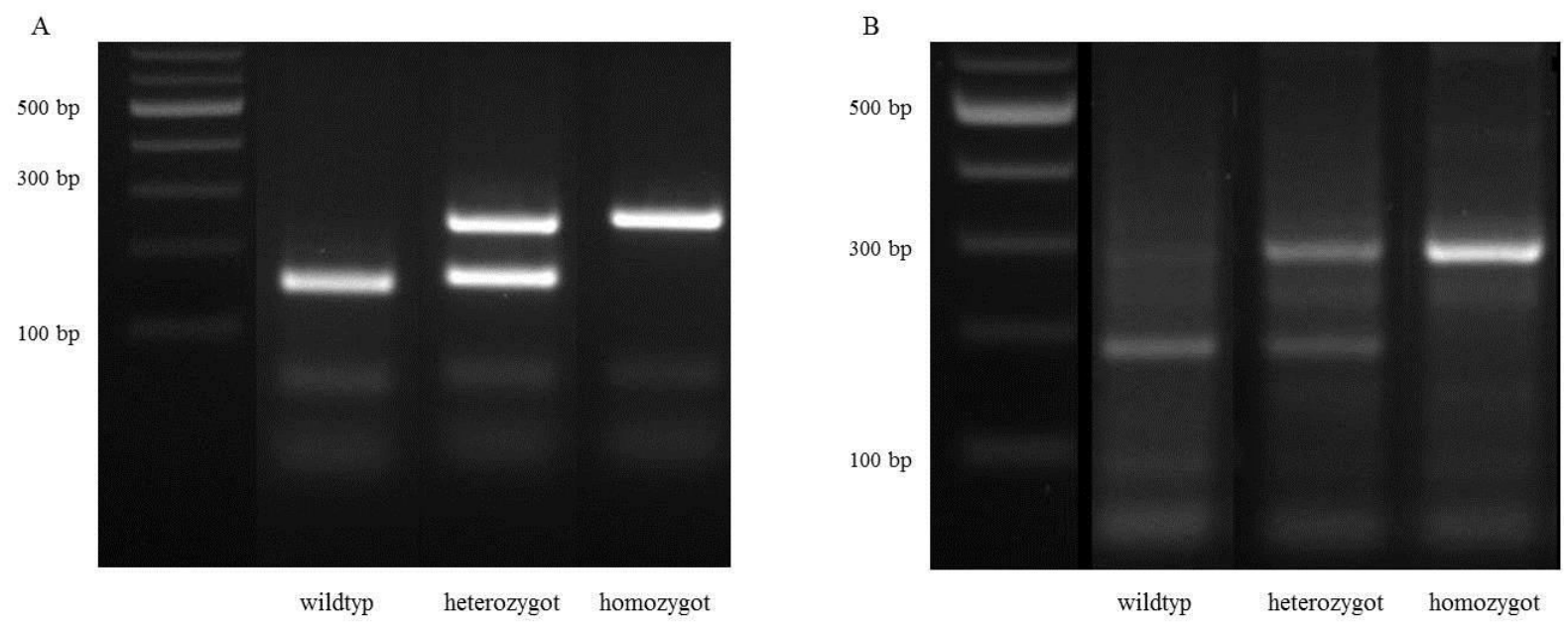

\section{Abbildung 4 Genotypisierung}

Dargestellt sind die jeweiligen Banden Für ApoE (A): wildtyp (+/+) bei 155 bp, heterozygote Variante (+/-) bei 155 bp und 245 bp sowie die homozygote Variante (-/-) bei 245 bp. Entsprechend in (B) die Banden für CCL5: wildtyp (+/+) bei 192 bp, heterozygote Variante (+/-) 192 bp und 300 bp sowie die homozygote Variante (-/-) bei $300 \mathrm{bp}$.

\subsubsection{Experimentelle Induktion einer Gefäßwandläsion}

Um eine experimentelle Gefäßwandläsion zu induzieren, wurde das Verfahren der Eisen(III)chlorid-Applikation in Anlehnung an Konstantinides et al. verwendet (Konstantinides et al. 2001). Die Mäuse wurden mit einem Gemisch aus $\mathrm{O}_{2}$ und 2\%igen Isofluran über eine MundNasen-Maske narkotisiert. Die OP wurde unter dem Mikroskop Olympus ${ }^{\circledR}$ BX51 der gleichnamigen Firma durchgeführt. Nach einer alkoholischen Desinfektion wurde die Haut über der Fossa jugularis kopfwärts über eine Länge von ca. $2 \mathrm{~cm}$ inzidiert und mithilfe von Haken offen gehalten. Anschließend wurde die A. carotis communis sin. im Trigonum caroticum aufgesucht und bis auf die Tunica media frei präpariert, so dass mittels zwei Markierungsfäden die Arterie unterminiert und so vom umliegenden Gewebe abgehoben werden konnte. 
A)

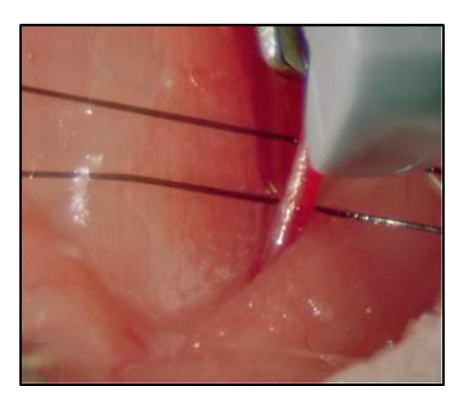

B)

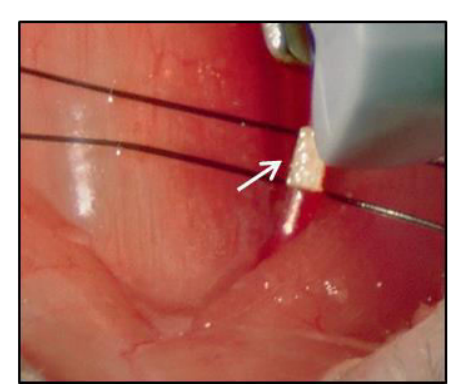

C)

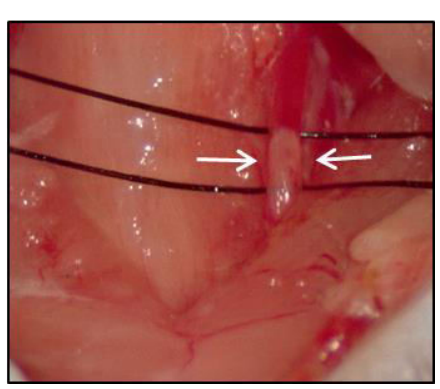

Abbildung 5 Eisen(III)-chlorid-Maus-Modell der Gefäßwandläsion

Die Induktion der experimentellen Gefäßwandläsion mit Bildung der arteriellen Thrombose in der A.carotis communis sin. unter Anwendung des Eisen(III)-chlorid-Maus-Modells. Präoperative Messung des basalen Blutflusses (A). Applikation des Eisen(III)-chlorid, $\rightarrow$ Filterpapier (B) Gefäßwandläsion, $\rightarrow$ Thrombotische Läsion (C).

Um das Gefäß herum wurde daraufhin eine Dopplersonde positioniert (s. Abbildung 5A). Mithilfe dieser Sonde und dem Blutflussmessgerät (small animal blood flow meter Typ 106) konnten die Veränderungen des Blutflusses gemessen werden. Im Anschluss wurde ein, in Eisen(III)-chlorid getränktes, Filterpapier für 3 min unterhalb des Sondenkopfes platziert (s. Abbildung 5B), wodurch eine Gefäßwandläsion induziert wurde, die letztlich in einer arteriellen Thrombose resultierte (s. Abbildung 5C). Anschließend wurde der Blutfluss gemessen, wobei gemäß der technischen Messfehlerangabe des Herstellers eine Abnahme der Blutflussgeschwindigkeit auf $\leq 0,2 \mathrm{ml} / \mathrm{min}$ als vollständiger thrombotischer Verschluss betrachtet wurde. Die daraufhin eingetretenen Veränderungen des Blutflusses wurden über einen Zeitraum von 20 min aufgezeichnet. Nach Beendigung dieser Aufzeichnungen wurde der Sondenkopf entfernt und die Wunde mit einer Hautnaht verschlossen. Postinterventionell erhielten die Tiere Metamizol zur Analgesie.

\subsubsection{Hämodynamische Untersuchungen}

\subsubsection{Basale Blutflussgeschwindigkeit}

Mithilfe des Blutflussmessgerätes und des Programms WINDAQ $Q^{\circledR}$ Data Acquisition (Version 2.61) wurde die basale Blutflussgeschwindigkeit $[\mathrm{ml} / \mathrm{min}]$ der A. carotis communis sin. $\left(=\mathrm{t}_{0}\right)$ aufgezeichnet. Nachfolgend wurde die aufgezeichnete Blutflusskurve mittels der Software WINDAQ $Q^{\circledR}$ Waveform Browser analysiert. 


\subsubsection{Okklusionsverhalten}

Durch die experimentelle Induktion der Gefäßwandläsion wurde eine Einengung des Gefäßlumens induziert, die in einer Abnahme des Blutflusses resultierte. Sobald sich der Blutfluss der Arterie auf $\leq 0,2 \mathrm{ml} / \mathrm{min}$ verlangsamt hatte, wurde von einem kompletten Verschluss des Gefäßes ausgegangen. Sofern die Geschwindigkeit des Blutflusses von 0,2 ml/min im Verlauf der Messperiode nicht überschritten hatte, wurde dieses Verhalten als eine „stabile Stenose“ des Gefäßes definiert. Durch eine Ablösung des thrombotischen Materials im Sinne einer Embolisation konnte eine erneute Zunahme der Blutflussgeschwindigkeit in der Arterie bei einem vorangehenden Verschluss beobachtet werden, die als „,instabile Stenose“ definiert wurde. Das Ausbleiben der Abnahme der Blutflussgeschwindigkeit nach experimenteller Induktion einer Gefäßwandläsion mit einem kontinuierlichen Blutfluss $>0,2 \mathrm{ml} / \mathrm{min}$ wurde als „keine Stenose“ beschrieben (s. Abbildung 6).

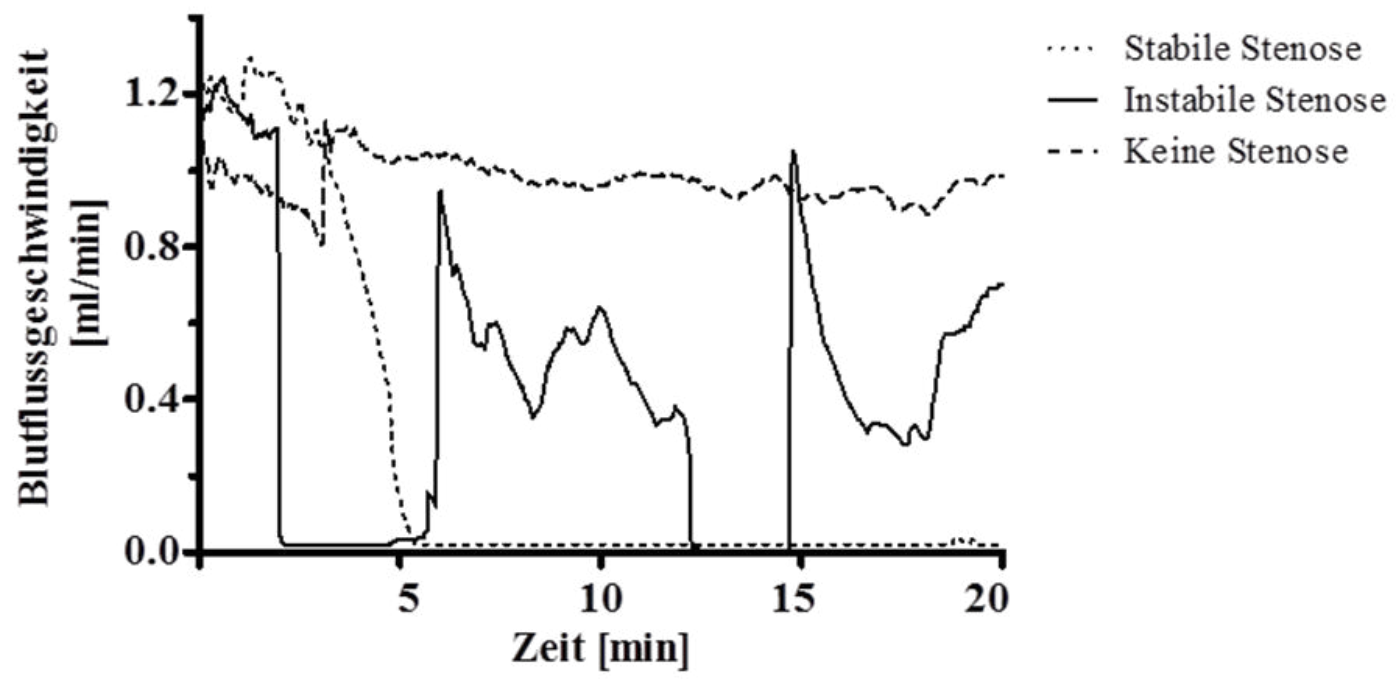

\section{Abbildung 6 Repräsentative Flusskurven der Blutflussgeschwindigkeit}

Dargestellt sind repräsentative Flusskurven wie sie für die Kategorien der stabilen, instabilen sowie ausbleibenden Stenose nach Induktion einer experimentellen Gefäßwandläsion beobachtet wurden. 


\subsubsection{Hämodynamische Parameter}

Weiterführende Analysen des Verhaltens des Blutflusses wurden nach Induktion der Gefäßwandläsion mittels des Programms WINDA $Q^{\circledR}$ Data Acquisition (Version 2.61) durchgeführt und wie folgt definiert (s. Tabelle 1).

\begin{tabular}{|l|c|l|}
\hline Bezeichnung & Einheit & Beschreibung \\
\hline $\mathrm{t}_{1}$ & $\min$ & Zeit bis zum Eintreten der 1.Okkluion \\
\hline $\mathrm{t}_{2}$ & $\mathrm{~min}$ & Endzeitpunkt der Messung nach $20 \mathrm{~min}$ \\
\hline AUC $_{1}$ & $\mathrm{ml}$ & $\begin{array}{l}\text { Blutvolumen, das bis zum Zeitpunkt } \mathrm{t}_{1} \text { durch die } \text { A. carotis communis sin. } \\
\text { geflossen ist }\end{array}$ \\
\hline${\text { AUC } \mathrm{t}_{2}}$ & $\begin{array}{l}\text { Blutvolumen, das bis zum Zeitpunkt } \mathrm{t}_{2} \text { durch die } \text { A. carotis communis sin. } \\
\text { geflossen ist }\end{array}$ \\
\hline Blutfluss, $\mathrm{t}_{2}$ & $\mathrm{ml} / \mathrm{min}$ & $\begin{array}{l}\text { Geschwindigkeit des Blutflusses zum Zeitpunkt } \mathrm{t}_{2} \text { durch A. carotis communis } \\
\text { sin. }\end{array}$ \\
\hline
\end{tabular}

Tabelle 1 Definition der hämodynamischen Parameter.

\subsubsection{Gewebeentnahme}

Für die Durchführung histologischer Analysen wurden den Mäusen nach ihrem Tod sowohl die verletzte $A$. carotis communis sin. als auch die unverletzte $A$. carotis communis dex. zur Kontrolle entnommen. In der Abbildung 7 ist der zeitliche Ablauf des Versuchs dargestellt.

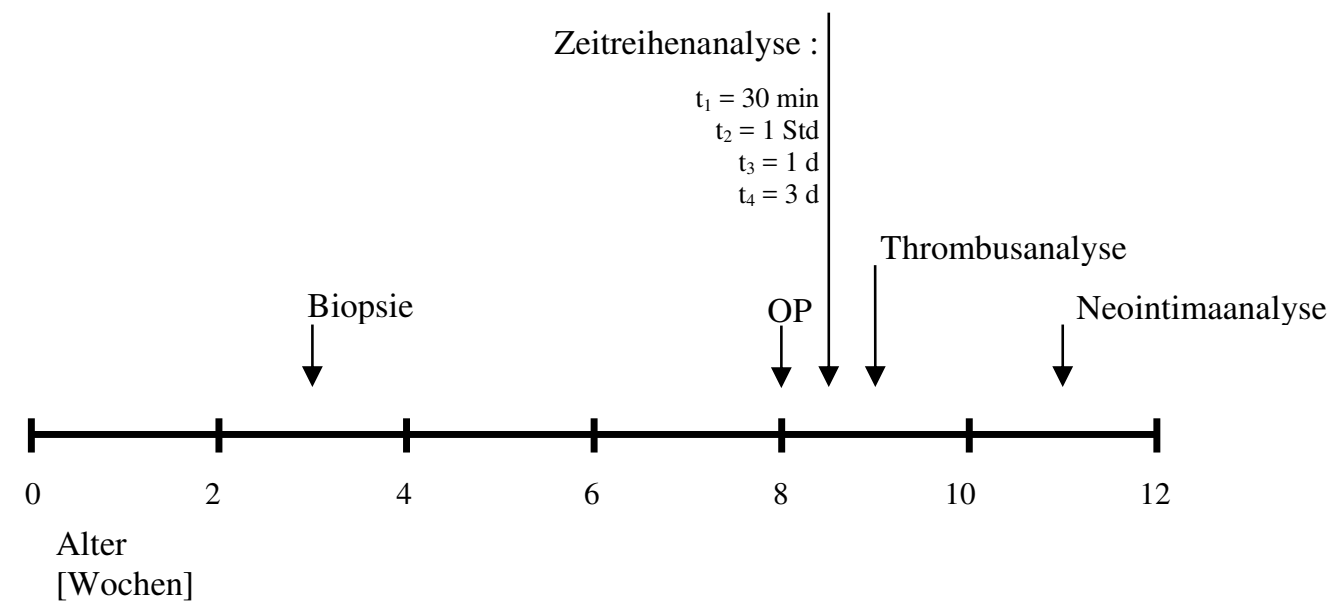

Abbildung 7 Versuchsablauf

Dargestellt ist der Versuchsablauf anhand eines Zeitstrahls von der Geburt und bioptischen Gewebeentnahme der Tiere über den Zeitpunkt der OP sowie die verschiedenen Zeitpunkte der Gewebeentnahme. 
Als Hypnotika wurden Natriumchlorid, Xylazin sowie Ketamin im Verhältnis 2:1:1 verwendet, welches peritoneal injiziert wurde. Die Dosierung erfolgte gewichtsadaptiert mit 2,4 $\mu \mathrm{l} / \mathrm{g}$ Körpergewicht. Zur Durchführung der Gewebeentnahme wurde das narkotisierte Tier rücklings und mit abgespreizten Extremitäten auf der Wärmeplatte positioniert. Das Operationsgebiet wurde anschließend oberflächlich desinfiziert und die Haut wiederum über der Fossa jugularis kopfwärts über eine Länge von ca. $2 \mathrm{~cm}$ inzidiert und mittels Haltehaken offengehalten. Nachfolgend wurden sowohl die verletzte A. carotis communis sin. als auch die unverletzte A. carotis communis dex. in den jeweiligen Trigonae caroticae aufgesucht und soweit frei präpariert, dass das Gefäß mit einem Markierungsfaden unterminiert werden konnte. Daraufhin erfolgte die kardiale Blutentnahme, in dem die Nadel unterhalb des Xiphoideus angesetzt und in die Richtung des Herzens unter Sogwirkung in den Thorax eingeführt wurde. Das entnommene Blut wurde in einem Eppendorfgefäß für 10 min bei $3000 \mathrm{rpm}$ zentrifugiert. Der Überstand (Serum) wurde vorsichtig abgenommen, in saubere Gefäße überführt und bis zur Analyse bei $-20{ }^{\circ} \mathrm{C}$ gelagert.

Im Folgenden wurde zunächst der Bauchraum entlang des Rippenbogens eröffnet, um anschließend durch Aufschneiden des Thorax am Ansatz der Rippen links lateral des Sternums, diesen bis zur oberen Thoraxapertur zu eröffnen. Nachdem das Herz aus dem Perikard herausgelöst wurde, wurden die Aorta thoracis sowie die Vena cava inferior durchtrennt. Letzteres ermöglichte eine anschließende sichere Perfusion der oberen Körperhälfte mit $5 \mathrm{ml}$ 20\%igem Zinkformalin (in aqua dest.), das über ein Perfusionsbesteck in den linken Ventrikel eingebracht wurde. Im Anschluss wurde zunächst die A. carotis communis sin. und danach die A. carotis communis dex. entnommen, indem diese durch eine feine Pinzette unterhalb der Bifurkation gefasst wurde und mit einer Schere oberhalb dieser durchtrennt wurde. Durch leichten Zug auf das Gefäß wurde sichergestellt, dass die Läsion in ihrer gesamten Länge im unteren Winkel des Trigonum caroticum dargestellt und unterhalb dieser, durch einen Schnitt, das Gefäß herausgenommen werden konnte. Analog wurde mit der rechten Seite verfahren, wobei das unverletzte Gefäß in seiner gesamten Länge herausgelöst wurde. Die Gefäße wurden anschließend in Glasgefäße überführt, die ebenfalls mit 20\%igem Zinkformalin gefüllt waren, und für vier Stunden in der Flüssigkeit fixiert. 


\subsection{Laborchemische Untersuchungen}

\subsubsection{Untersuchungen des Differentialblutbildes}

Um laborchemische Analysen des Blutbildes durchführen zu können, wurde bei nichtoperierten $\mathrm{ApoE}^{-/-}$x $\mathrm{CCL5}^{+/+}$- bzw. ApoE ${ }^{-/-}$x $\mathrm{CCL5}^{-/-}$-Mäusen im Alter von 8 bis 10 Wochen eine kardiale Blutentnahme unter Isoflurannarkose durchgeführt und das gewonnene Vollblut anschließend mittels Ethylendiamintetraessigsäure (EDTA) antikoaguliert. Die Mäuse wurden nach der Blutentnahme durch einen Genickbruch eliminiert und das gewonnene Serum wurde bei $-20^{\circ} \mathrm{C}$ asserviert.

\subsubsection{Maschinelle Laboranalyse}

Die maschinellen Analysen wurden im Institut für Klinische Chemie der UMG mit dem Coulter $\mathrm{A}^{\mathrm{C}} \mathrm{T} 5$ diff der Firma Beckmann Coulter durchgeführt.

\subsubsection{Manuelles Differentialblutbild}

Die manuellen Analysen wurden in der Klinik für Hämatologie und Onkologie der UMG durchgeführt. Diesbezüglich wurden Blutausstriche mit der hämatologischen Standardfärbung nach Pappenheim, die als Differentialfärbung der Zellbestandteile dient, angefertigt und analysiert (s. Abbildung 8).

Hierfür standen die Objektträger nach erfolgter Trocknung für 3 min in unverdünnter MayGrünwald-Lösung und wurden anschließend für $10 \mathrm{sec}$ mit einer Pufferlösung abgespült. Nachfolgend wurden die gespülten Objektträger für 15 min in eine 4\%igen Giemsa-Lösung getaucht und anschließend nochmals mit einer Pufferlösung abgespült, um Niederschläge zu vermeiden. Abschließend folgte eine mikroskopische Begutachtung.

A)

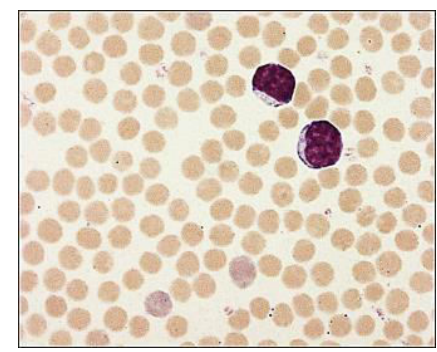

B)

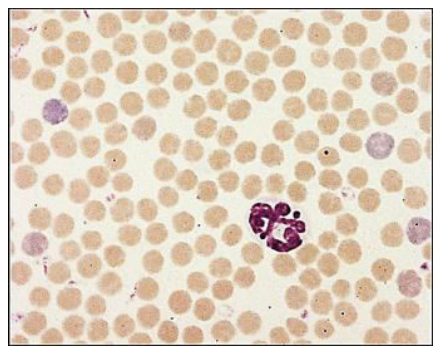

C)

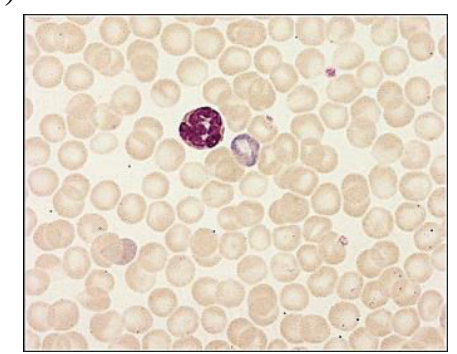

Abbildung 8 Beispielhafte Fotografien eines Blutausstriches (Papenheim-Färbung)

Zu erkennen sind zwei große Lymphozyten (A), ein segmentierter Granulozyt (B), sowie ein stabkerniger Granulozyt (C). 1000fache Vergrößerung. 


\subsubsection{Bestimmung von Cholesterin und Triglyzeriden}

Die quantitativen Bestimmungen von Gesamt-Cholesterin und Triglyzeriden wurden im Institut für Klinische Chemie der UMG mittels des Analyzers ARCHITECT c16000 der Firma Abbot durchgeführt.

\subsection{Histologische Analyse des Thrombus und der Neointima}

\subsubsection{Erstellung von Paraffinschnitten}

Für die Herstellung von Paraffinschnitten wurden sowohl die verletzte A. carotis communis sin. als auch die unverletzte $A$. carotis communis dex. zunächst für $4 \mathrm{~h}$ in Zinkformalin fixiert, um anschließend in einer aufsteigenden Alkoholreihe entwässert zu werden, da Paraffin nicht wasserlöslich ist. Diesbezüglich wurden die Arterien in Chloroform als Intermedium überführt, um den Alkohol durch ein Lösungsmittel zu ersetzen. Letzteres wurde wiederum durch Paraffin ersetzt und bei $4^{\circ} \mathrm{C}$ ausgehärtet. Das Schneiden der Paraffinblöcke erfolgte mit einem Rotationsmikrotom auf eine Dicke von $5 \mu \mathrm{m}$ und einem Abstand von $50 \mu \mathrm{m}$ zum nachfolgenden Schnittpräparat.

\subsubsection{Histologische Untersuchungen}

\subsubsection{Entparaffinierung und Wässerung der Gewebeschnitte}

Für die histologische Aufbereitung und Färbung der Gewebeschnitte wurden diese dreimalig für jeweils 5 min in Xylol gelöst und anschließend in einer absteigenden Alkoholreihe gewässert.

\subsubsection{Masson-Trichrom-Färbung zur Detektion thrombotischen Materials}

Zur Quantifizierung thrombotischen Materials im Rahmen der Zeitreihenanalyse und Untersuchung des Thrombus nach $7 \mathrm{~d}$ wurde die Färbung nach Masson-Trichrom verwendet. Hierzu wurden die Gewebeschnitte nach erfolgter Entparaffinierung und Wässerung für weitere 5 min in aqua dest. gestellt und nachfolgend über Nacht in Bouin-Lösung nachfixiert. Am nächsten Tag wurden die Gewebeschnitte gespült, gefolgt von einer 10-minütigen Behandlung in Weigerts-Eisenhämatoxylin-Lösung, um eine Kernfärbung vorzunehmen und anschließender 10-minütiger Waschung. Nachfolgend wurden die Gewebeschnitte für 5 min in aqua dest. überführt und für weitere $15 \mathrm{~min}$ in Biebrich-Scharlachrot-Säurefuchsin inkubiert. 
Im Anschluss an eine 15-minütige Behandlung mit einer PhosphomolybdänsäurePhosphotungstensäure-Lösung erfolgte die Kollagenanfärbung, indem die Gewebeschnitte für 8 min in einer Anilinblau-Lösung gelagert wurden, gefolgt von einer anschließenden Spülung in aqua dest. Zur Differenzierung lagen die Schnitte für 3 min in 1\%iger Essigsäure. Anschließend folgte eine aufsteigende Alkoholreihe sowie zweimalige Inkubation über 5 min in Xylol und das Eindecken der Gewebeschnitte mittels Entellan ${ }^{\circledR}$.

\subsubsection{Verhoeff'sche Elastika-Färbung zur Detektion elastischer Fasern}

Die Detektion der elastischen Fasern diente zum einem der morphometrischen Analyse der Neointimabildung sowie zum anderen der Erstellung einer Übersicht über die angefertigten Schnitte für nachfolgende immunhistochemische Färbungen. Hierzu wurden die Gewebeschnitte nach erfolgter Entparaffinierung und Wässerung zunächst für 15 min in einer Verhoeff'schen Jodinlösung inkubiert, gefolgt von einer 20-minütigen Waschung. Nachdem die Gewebeschnitte für weitere $5 \mathrm{~min}$ in aqua dest. überführt worden waren, erfolgte eine Differenzierung der Färbung in 2\%igen Eisen(III)-chlorid für ca. 2,5 min, sowie 5\%igen Natriumthiosulfat für $1 \mathrm{~min}$. Anschließend wurde das Ergebnis mikroskopisch betrachtet und bei ausreichender Differenzierung wurde mit einer weiteren Waschung, zunächst 5 min in Leitungswasser und danach $5 \mathrm{~min}$ in aqua dest., fortgefahren. Nachfolgend wurden die Gewebeschnitte zur Kernfärbung für ca. 1 min in einer van Giesson-Lösung inkubiert, anschließend in einer aufsteigenden Ethanolreihe entwässert, in Xylol fixiert und mittels Entellan ${ }^{\circledR}$ eingedeckt. 


\subsubsection{Morphometrische Analyse}

Für die Auswertung der Schnitte wurden diese unter dem Mikroskop betrachtet. Mithilfe des Programms Image Pro Plus ${ }^{\circledR}$ wurde von jedem Schnitt ein Foto in 100facher Vergrößerung erstellt.

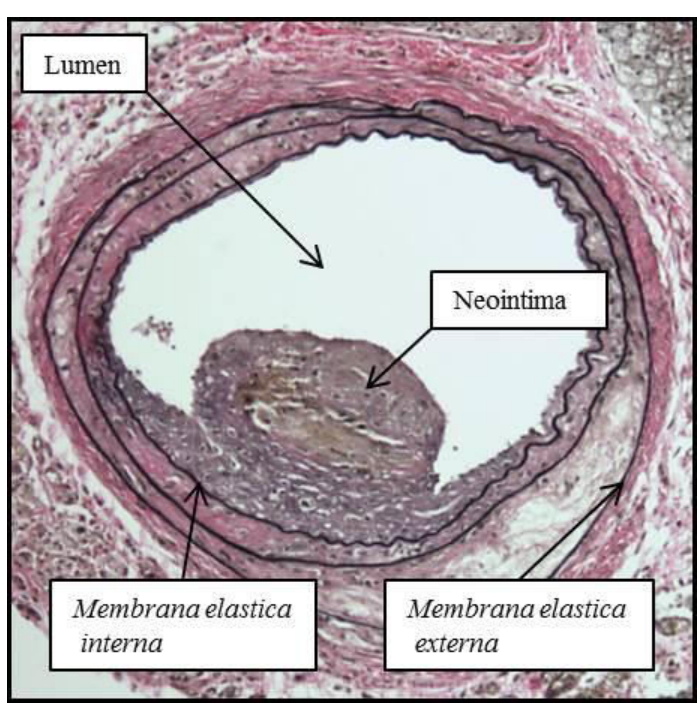

\section{Abbildung 9 Morphometrische Analyse}

Es wurden jeweils 3 bis 5 Schnitte mit entsprechend thrombotischem Material bzw. Thrombus oder Neointima morphometrisch wie folgt analysiert:

\begin{tabular}{|l|c|l|}
\hline Bezeichnung & Einheit & Beschreibung \\
\hline Neointima & $\mu \mathrm{m}^{2}$ & Fläche luminal der Membrana elastica interna - Fläche des Lumens \\
\hline Lumenstenose & $\%$ & $100-($ Fläche der Neointima / Fläche der Membrana elastica interna) x 100 \\
\hline Media & $\mu \mathrm{m}^{2}$ & $\begin{array}{l}\text { Fläche luminal der Membrana elastica externa }- \text { Fläche luminal der Memb- } \\
\text { rana elastica interna }\end{array}$ \\
\hline I/M-Ratio & - & Neointima / Media \\
\hline
\end{tabular}

Tabelle 2 Definitionen der morphologischen Parameter

\subsubsection{Immunhistochemische Färbungen}

\subsubsection{Allgemeines Färbeprotokoll für CCR1, CCR5, Mac-2, CD45 und KLF4}

Nach dem Entparaffinieren und Wässern der Gewebeschnitte wurden diese für $10 \mathrm{~min}$ in 3\%igem Wasserstoffperoxid in Methanol gelöst, inkubiert, um die endogene PeroxidaseAktivität zu blockieren und anschließend für $5 \mathrm{~min}$ in aqua dest. gewaschen. Um das mas- 
kierte Epitop für den Antikörper frei zugänglich zu machen, wurden die Gewebeschnitte für 6 min bei 800 Watt in Citrat-Puffer gekocht und anschließend bei RT für 20 min abgekühlt. Nach kurzer Trocknung der Objektträger wurden die Gewebeschnitte jeweils mit dem PAP PEN Mini umrundet, damit die später erfolgende Benetzung mit Antikörpern während der Inkubationszeit nicht verfließen konnte. Nachfolgend wurden unspezifische Bindungen mittels Normalseren, entsprechend der Spezies des Sekundärantikörpers, für 20 min blockiert. Anschließend erfolgte die Inkubation der Gewebeschnitte mit den Primärantikörpern in Antibody-Diluent gelöst bei $4^{\circ} \mathrm{C}$ über Nacht. An dieser Stelle wurde ebenfalls eine Negativprobe mitgeführt, wobei der Gewebeschnitt lediglich mit Antibody-Diluent inkubiert wurde. Am nächsten Morgen erfolgte eine dreimalige Spülung der Gewebeschnitte mittels PBS und die sich anschließende Inkubation mit den in PBS gelösten Sekundärantikörpern für 60 min. Nach einer erneuten Spülung mittels PBS wurde zunächst eine Markierung des Sekundärantikörpers durch in PBS gelösten $A B C$-Link für 20 min durchgeführt sowie eine sich anschließende enzymatische Umsetzung mittels AEC Substrate Kit je nach Farbumschlag für 5-15 min. Im weiteren Verlauf erfolgte eine Waschung mit aqua dest. sowie eine Gegenfärbung mit Gill's Hämatoxylin und eine erneute Waschung. Abschließend wurden die Gewebeschnitte nach einer kurzen Trocknung mittels ImmuMount ${ }^{\circledR}$ eingedeckt und unter dem Mikroskop bei einer 100fachen bzw. 400fachen Vergrößerung betrachtet. Folgende primäre und sekundäre Antikörper wurden verwendet:

\begin{tabular}{lll}
\hline Artikel & Art.-Nummer & Firma \\
\hline CCR1-Antikörper & ab1681 & Abcam, Cambridge, MA, USA \\
\hline CCR5-Antikörper & B0061 & $\begin{array}{l}\text { Assay Biotechnology Company, Sunnyvale, } \\
\text { CA, USA }\end{array}$ \\
\hline KLF4-Antikörper & ab72543 & Abcam, Cambridge, MA, USA \\
\hline Mac-2-Antikörper & CL8942AP & Caderlane $^{\circledR}$, Burlington, CA, USA \\
\hline CD45-Antikörper & sc-53665 & Santa-Cruz Biotechnology, Heidelberg, DE \\
\hline Goat anti-rabbit-Antikörper & B2770 & invitrogen ${ }^{\mathrm{TM}}$, Carlsbad, CA, USA \\
\hline Goat anti-rat-Antikörper & CLC40015 & Caderlane $^{\circledR}$, Burlington, CA, USA \\
\hline
\end{tabular}




\subsubsection{Auswertung der immunhistochemischen Färbungen}

Nach Beendigung der Färbung wurden die Gewebeschnitte unter einem Lichtmikroskop analysiert und mit Hilfe des Programms Image Pro Plus ${ }^{\circledR}$ in den Vergrößerungen 100, 400 und 1000fach fotografiert. Um vergleichbare Ergebnisse erzielen zu können, wurden die Arterien zunächst morphometrisch in 100facher Vergrößerung, wiederum mittels des Graphikprogramms Image Pro Plus ${ }^{\circledR}$, analysiert. Im Anschluss daran wurde die jeweilige positive Fläche im Bereich des Thrombus bzw. der Neointima ermittelt und im prozentualen Verhältnis zur gesamten berechneten Fläche des Thrombus bzw. der Neointima gesetzt. Analog wurde mit der gesamten Fläche der Arterie verfahren. Aus der Differenz der gesamten Fläche der Arterie abzüglich der Fläche des Thrombus bzw. der Neointima wurde die Media errechnet. Als Resultat wurden somit die positive Fläche jeweils des Thrombus bzw. der Neointima, der Media und der gesamten Fläche in Prozent berechnet.

\subsection{Proteinnachweis}

Mittels ELISA (Ezyme-linked Immunosorbent Assay) wurden die Konzentrationen selektierter Proteine im Blut der Mäuse detektiert. Zur Durchführung einer quantitativen Analyse der eingesetzten Antikörper wurden Mini ELISA Entwicklungszusätze verwendet. Die Präparation der Inkubationsplatte erfolgte durch Auftragen von jeweils $100 \mu 1$ des Primärantikörpers in die entsprechenden Vertiefungen der ELISA Platte, die anschließend versiegelt und über Nacht bei RT inkubiert worden war. Am nächsten Morgen wurde die Inkubationsplatte abgesaugt und gewaschen. Im Anschluss erfolgte eine Blockierung um unspezifische Bindungen $\mathrm{zu}$ vermeiden, indem in jede Vertiefung $300 \mu \mathrm{l}$ Blockpuffer pipettiert wurden, gefolgt von einer 30-minütigen Inkubation bei RT. Das Absaugen des Puffers wurde von einer abschlieBenden viermaligen Waschung gefolgt. Zur Auftragung des Standards bzw. der Serumproben wurden diese in einer absteigenden Reihenfolge verdünnt und von diesen jeweils $100 \mu$ in die entsprechenden Vertiefungen hinzugegeben und für $2 \mathrm{~h}$ bei RT inkubiert. Abschließend wurden jeweils $100 \mu \mathrm{l}$ des Sekundärantikörpers aufgetragen und erneut für $2 \mathrm{~h}$ bei RT inkubiert.

Nach erneutem Absaugen und Waschen der Platte erfolgte die Komplexbildung mit dem Enzym-gebundenen Antikörper, indem in jede Vertiefung 5,5 $\mu 1$ Avidin-HRP Conjugate (1 : 2000 verdünnt) aufgetragen wurde, gefolgt von einer 30-minütigen Inkubation bei RT. Durch Hinzugabe von $100 \mu \mathrm{l}$ ABTS-Liquid Substrate konnte das Reaktionsprodukt nachgewiesen werden. Abschließend konnten die Extinktionen bei den Wellenlängen $405 \mathrm{~nm}$ und $650 \mathrm{~nm}$ 
mittels des $\mu$ Quant ${ }^{\mathrm{TM}}$ Mikroplatten-Photometers bestimmt werden. Folgende ELISA wurden verwendet:

\begin{tabular}{lll}
\hline Artikel & Art.-Nummer & Firma \\
\hline CCL5 & $1110124-\mathrm{M}$ & PeproTech Germany, Hamburg, DE \\
\hline TNF- $\alpha$ & $0712054-\mathrm{M}$ & PeproTech Germany, Hamburg, DE \\
\hline
\end{tabular}

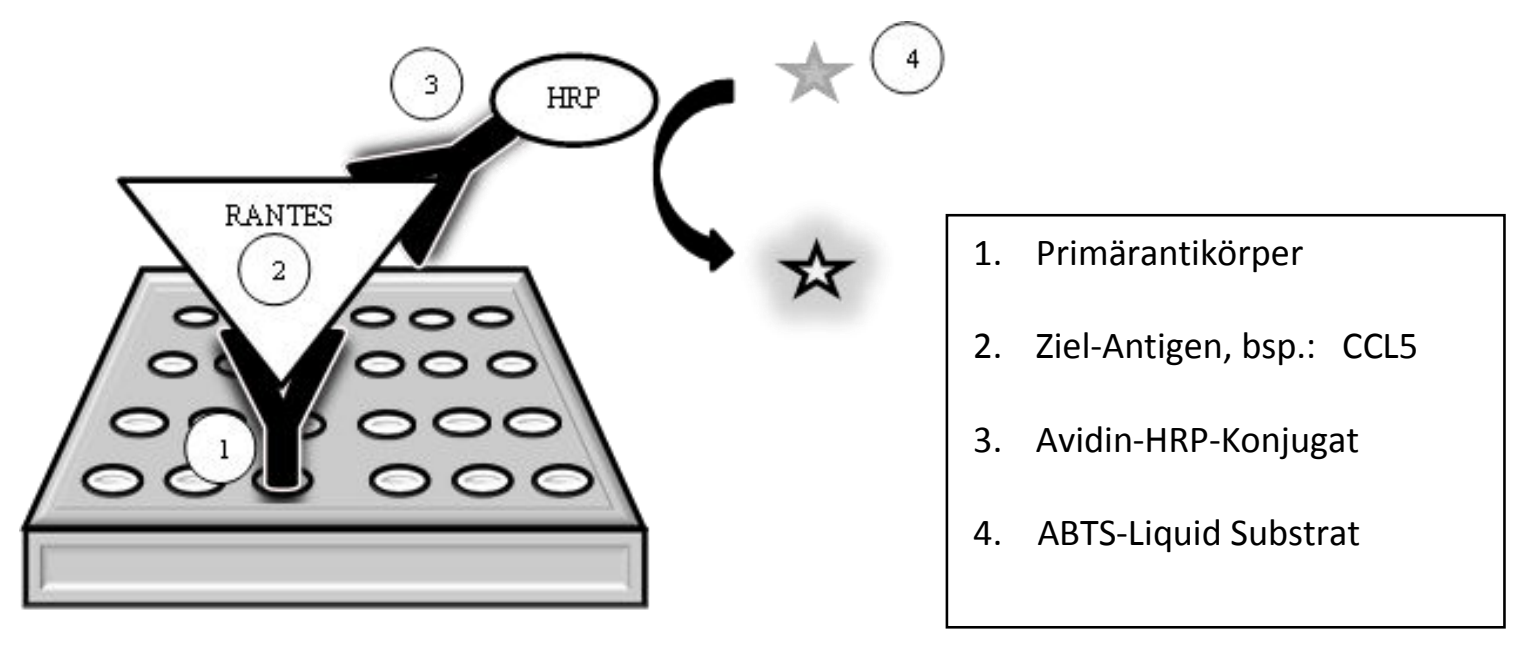

Abbildung 10 Schematische Darstellung des ELISA

Anhand der gemessenen Extinktionen konnten die Konzentrationen der eingesetzten Substrate in den Serumproben mit Hilfe von Standardkurven berechnet werden.

\subsection{Statistische Auswertung}

Alle Tests waren zweiseitig und verwendeten ein Signifikanzniveau von $p<0,05$. Um kontinuierliche Variablen auf das Vorliegen einer Normalverteilung zu testen, wurde der modifizierte Kolmogorov-Smirnov Test (Lilliefors Test) verwendet. Dabei wurden parametrische Daten mit dem unabhängigen t-Test geprüft und als Mittelwert \pm Standard Error of the Mean (SEM) angegeben. Kontinuierliche Variablen wurden als Median mit dem zugehörigen Interquartilsabstand [25. Perzentile; 75. Perzentile] dargestellt und mit dem Mann-Whitney-U-Test verglichen. Für die statistische Auswertung und graphische Darstellung wurde das Programm GraphPad Prism ${ }^{\circledR}$ Version 5 verwendet. 


\section{ERGEBNISSE}

\subsection{Genotypen}

Basierend auf den Ergebnissen der Genotypisierungen wurden die Tiere mit dem einzelnen Gen-Knockout für ApoE untereinander gepaart, um die $\mathrm{ApoE}^{-/-}$x $\mathrm{CCL}^{+/+}$-Gruppe als Kontrollgruppe zu generieren. Um Tiere für die Versuchsgruppe zu erzeugen, wurden jeweils Tiere mit einem einzelnen Gen-Knockout für ApoE und CCL5 miteinander verpaart, so dass letztlich die $\mathrm{ApoE}^{-/-}$x CCL5 ${ }^{-/}$-Doppel-Knockout-Gruppe resultierte. Es wurden männliche Tiere für die Versuche verwendet, um hormonelle Schwankungen zu vermeiden. Zum Zeitpunkt der OP hatten die $\mathrm{ApoE}^{-/-} \mathrm{x} \mathrm{CCL5}^{-/-}$-Mäuse ein medianes Alter von 59 Tagen [58; 62], die $\mathrm{ApoE}^{-/-} \times \mathrm{CCL5}^{+/+}$-Mäuse von 60 Tagen $[59 ; 63](\mathrm{p}=0,677)$. Weiterhin wurde ein medianes Gewicht von 26,1 g [24,1; 26,9] in der ApoE $^{-/-}$x CCL5 $^{-/-}$-Gruppe ermittelt sowie von 26,2 g $[24,2 ; 27,5]$ in der $\mathrm{ApoE}^{-/-}$x $\mathrm{CCL5}^{+/+}$-Gruppe (p=0,572). Für die weiterführende Charakterisierung der beiden Gruppen wurden laborchemische Analysen des Blutes durchgeführt sowie Blutausstriche angefertigt. 


\subsubsection{Maschinelle Laboranalysen}

Hinsichtlich der Erythrozytenanzahl, der Erythrozytenindizes und der Thrombozytenanzahl konnte präoperativ kein Unterschied zwischen der $\mathrm{ApoE}^{-/-}$x $\mathrm{CCL5}^{-/-}$-Gruppe und der $\mathrm{ApoE}^{-/-}$x CCL5 ${ }^{+/+}$-Gruppe eruiert werden. Es zeigte sich im Differentialblutbild eine signifikant reduzierte Anzahl an Neutrophilen Granulozyten (prozentual, $\mathrm{p}<0,01$ ) und Monozyten (absolut, $\mathrm{p}<0,5)$ in der $\mathrm{ApoE}^{-/-}$x $\mathrm{CCL5}^{-/-}$-Gruppe und eine signifikant erhöhte Anzahl an Lymphozyten (absolut, $\mathrm{p}<0,05$ und prozentual, $\mathrm{p}<0,01$ ) im Vergleich zur ApoE ${ }^{-/-}$x CCL5 ${ }^{+/+}$Gruppe (s. Tabelle 3).

\begin{tabular}{|c|c|c|c|}
\hline & $\begin{array}{c}\operatorname{ApoE}^{-/-} \times \mathrm{CCL5}^{+/+} \\
(\mathrm{n}=10)\end{array}$ & $\begin{array}{c}\operatorname{ApoE}^{-/-} \times \mathrm{CCL5}^{-/-} \\
(\mathrm{n}=10)\end{array}$ & p-Wert \\
\hline Erythrozyten $\left[10^{6} / \mu 1\right]$ & $7,88 \pm 0,68$ & $7,63 \pm 0,27$ & n.s. \\
\hline Thrombozyten $\left[10^{3} / \mu 1\right]$ & $459,6 \pm 48,36$ & $391,5 \pm 41,73$ & n.s. \\
\hline Hämoglobin [g/dl] & $11,59 \pm 0,78$ & $11,74 \pm 0,41$ & n.s. \\
\hline Hämatokrit [\%] & $37,06 \pm 2,69$ & $37,88 \pm 1,47$ & n.s. \\
\hline $\operatorname{MCV}[\mathrm{fl}]$ & $49,40 \pm 0,52$ & $49,50 \pm 0,56$ & n.s. \\
\hline $\mathrm{MCH}[\mathrm{pg}]$ & $15,54 \pm 0,06$ & $15,39 \pm 0,09$ & n.s. \\
\hline $\mathrm{MCHC}[\mathrm{g} / \mathrm{dl}]$ & $31,49 \pm 0,39$ & $31,06 \pm 0,17$ & n.s. \\
\hline Leukozyten $\left[10^{3} / \mu 1\right]$ & $6,70 \pm 0,64$ & $6,38 \pm 0,37$ & n.s. \\
\hline Neutrophile $\left[10^{3} / \mu 1\right]$ & $1,05 \pm 0,12$ & $0,77 \pm 0,07$ & n.s. \\
\hline Neutrophile [\%] & $15,42 \pm 0,82$ & $11,92 \pm 0,84$ & $* *$ \\
\hline Lymphozyten $\left[10^{3} / \mu 1\right]$ & $5,04 \pm 0,48$ & $8,27 \pm 1,34$ & $*$ \\
\hline Lymphozyten [\%] & $75,65 \pm 1,93$ & $83,59 \pm 1,19$ & $* *$ \\
\hline Monozyten $\left[10^{3} / \mu 1\right]$ & $0,54 \pm 0,10$ & $0,25 \pm 0,04$ & $*$ \\
\hline Monozyten [\%] & $6,98 \pm 1,248$ & $4,64 \pm 0,81$ & n.s. \\
\hline Eosinophile $\left[10^{3} / \mu \mathrm{l}\right]$ & $0,05 \pm 0,01$ & $0,02 \pm 0,01$ & n.s. \\
\hline Eosinophile [\%] & $0,53 \pm 0,13$ & $0,51 \pm 0,25$ & n.s. \\
\hline Basophile $\left[10^{3} / \mu 1\right]$ & $0,03 \pm 0,01$ & $0,02 \pm 0,00$ & n.s. \\
\hline Basophile [\%] & $0,34 \pm 0,04$ & $0,33 \pm 0,05$ & n.s. \\
\hline
\end{tabular}

\section{Tabelle 3 Differentialblutbild, maschinell, präoperativ}

Zum Zeitpunkt der Induktion der Gefäßwandverletzung durchgeführte Analysen der $\mathrm{ApoE}^{-/-} \mathrm{x} \mathrm{CCL5}^{+/+}$- und $\mathrm{ApoE}^{-/} \times \mathrm{CCL5}^{-/-}$-Gruppe. Mittelwert $\pm(\mathrm{SEM})$, n.s. $=$ nicht signifikant; $*<0,05 ; * *<0,01$. 
Darüber hinaus wurden die laborchemischen Untersuchungen des Differentialblutbildes postoperativ durchgeführt, jedoch konnten keine signifikanten Unterschiede in der $\mathrm{ApoE}^{-/-} \mathrm{x}$ $\mathrm{CCL5}^{-/-}$-Gruppe im Vergleich zur $\mathrm{ApoE}^{-/-} \mathrm{x} \mathrm{CCL5}^{+/+}$-Gruppe nachgewiesen werden (s. Tabelle 4).

\begin{tabular}{|c|c|c|c|}
\hline & $\begin{array}{c}\operatorname{ApoE}^{-/-} \times \mathrm{CCL5}^{+/+} \\
(\mathrm{n}=7)\end{array}$ & $\begin{array}{c}\operatorname{ApoE}^{-/-} \times \mathrm{CCL5}^{-/-} \\
(n=5)\end{array}$ & p-Wert \\
\hline Erythrozyten $\left[10^{6} / \mu 1\right]$ & $7,67 \pm 0,19$ & $7,75 \pm 0,47$ & n.s. \\
\hline Thrombozyten $\left[10^{3} / \mu 1\right]$ & $511,3 \pm 25,95$ & $579,4 \pm 104,6$ & n.s. \\
\hline Hämoglobin [g/dl] & $11,52 \pm 0,22$ & $11,94 \pm 0,78$ & n.s. \\
\hline Hämatokrit [\%] & $37,74 \pm 0,83$ & $37,96 \pm 1,98$ & n.s. \\
\hline $\operatorname{MCV}[\mathrm{fl}]$ & $49,66 \pm 0,44$ & $49,26 \pm 0,82$ & n.s. \\
\hline $\mathrm{MCH}[\mathrm{pg}]$ & $15,17 \pm 0,16$ & $15,38 \pm 0,18$ & n.s. \\
\hline $\mathrm{MCHC}[\mathrm{g} / \mathrm{dl}]$ & $30,54 \pm 0,26$ & $31,34 \pm 0,40$ & n.s. \\
\hline Leukozyten $\left[10^{3} / \mu 1\right]$ & $4,32 \pm 0,71$ & $4,40 \pm 0,54$ & n.s. \\
\hline Neutrophile $\left[10^{3} / \mu 1\right]$ & $1,09 \pm 0,30$ & $1,08 \pm 0,08$ & n.s. \\
\hline Neutrophile [\%] & $23,66 \pm 3,89$ & $26,34 \pm 1,52$ & n.s. \\
\hline Lymphozyten $\left[10^{3} / \mu 1\right]$ & $2,97 \pm 0,46$ & $3,02 \pm 0,41$ & n.s. \\
\hline Lymphozyten [\%] & $70,16 \pm 4,88$ & $68,44 \pm 1,82$ & n.s. \\
\hline Monozyten $\left[10^{3} / \mu 1\right]$ & $0,22 \pm 0,06$ & $0,21 \pm 0,09$ & n.s. \\
\hline Monozyten [\%] & $5,27 \pm 1,14$ & $3,61 \pm 1,75$ & n.s. \\
\hline Eosinophile $\left[10^{3} / \mu \mathrm{l}\right]$ & $0,03 \pm 0,01$ & $0,02 \pm 0,01$ & n.s. \\
\hline Eosinophile [\%] & $0,57 \pm 0,22$ & $0,43 \pm 0,23$ & n.s. \\
\hline Basophile $\left[10^{3} / \mu 1\right]$ & $0,01 \pm 0,00$ & $0,05 \pm 0,03$ & n.s. \\
\hline Basophile [\%] & $0,34 \pm 0,12$ & $1,11 \pm 0,54$ & n.s. \\
\hline
\end{tabular}

Tabelle 4 Differentialblutbild, maschinell, 21 d nach Induktion einer Gefäßwandverletzung Dargestellt als Mittelwert \pm SEM, n.s.= nicht signifikant.

Innerhalb der $\mathrm{ApoE}^{-/-}$x $\mathrm{CCL5}^{+/+}$-Gruppe konnten zum Zeitpunkt der Untersuchung der Neointima keine Unterschiede im Vergleich zu den präoperativen Analysen gezeigt werden. Innerhalb der ApoE ${ }^{-/-}$x CCL5 ${ }^{-/-}$-Gruppe konnte zum gleichen Zeitpunkt eine hoch signifikante Verringerung der absoluten Leukozytenzahl nachgewiesen werden, ebenso ließen sich die Lymphozyten signifikant verringert darstellen. 


\subsubsection{Manuelles Differentialblutbild}

Weiterhin wurden manuelle Differentialblutbildanalysen durchgeführt, um eine genaue Beurteilung der Morphologie der ausgestrichenen Zellen zu erhalten. In der Gegenüberstellung der $\mathrm{ApoE}^{-/}$x CCL5 $5^{+/+}$-Gruppe zur ApoE ${ }^{-/-} \mathrm{x} \mathrm{CCL5}^{-/-}$-Gruppe konnten weder in den Analysen vor der experimentellen Induktion der Gefäßwandverletzung, noch zum Zeitpunkt der Gewebeentnahme an Tag 21 ein signifikanter Unterschied festgestellt werden (s. Tabelle 5 und Tabelle 6).

\begin{tabular}{|lccc|}
\hline & $\begin{array}{c}\text { ApoE }{ }^{-/-} \mathbf{X C L 5}^{+/+} \\
(\mathbf{n = 1 0})\end{array}$ & $\begin{array}{c}\mathbf{A p o E}^{-/-} \mathbf{x ~ C C L 5}^{-/-} \\
(\mathbf{n = 1 0})\end{array}$ & $\mathbf{p - W e r t}$ \\
\hline Stabkernige Leukozyten [\%] & $0,30 \pm 0,15$ & $0,20 \pm 0,13$ & n.s. \\
\hline Segmentkernige Leukozyten [\%] & $19,00 \pm 2,59$ & $21,20 \pm 2,11$ & n.s. \\
\hline Lymphozyten [\%] & $77,70 \pm 4,10$ & $76,80 \pm 2,52$ & n.s. \\
\hline Monozyten [\%] & $0,30 \pm 0,21$ & $00,00 \pm 0,00$ & n.s. \\
\hline Eosinophile [\%] & $0,50 \pm 0,22$ & $10,80 \pm 0,63$ & n.s. \\
\hline
\end{tabular}

Tabelle 5 Manuelles Differentialblutbild, manuell, präoperativ

Mittelwert \pm SEM, n.s.= nicht signifikant.

\begin{tabular}{|c|c|c|c|}
\hline & $\begin{array}{c}\operatorname{ApoE}^{-/-} \times \operatorname{CCL5}^{+/+} \\
(n=7)\end{array}$ & $\begin{array}{c}\operatorname{ApoE}^{-/-} \times \mathrm{CCL5}^{-/-} \\
(\mathrm{n}=5)\end{array}$ & p-Wert \\
\hline Stabkernige Leukozyten [\%] & $0,57 \pm 0,43$ & $0,80 \pm 0,37$ & n.s. \\
\hline Segmentkernige Leukozyten [\%] & $29,43 \pm 6,07$ & $38,00 \pm 4,32$ & n.s. \\
\hline Lymphozyten [\%] & $68,57 \pm 5,71$ & $60,00 \pm 4,79$ & n.s. \\
\hline Monozyten [\%] & $0,71 \pm 0,36$ & $0,80 \pm 0,37$ & n.s. \\
\hline Eosinophile [\%] & $0,714 \pm 0,42$ & $0,40 \pm 0,40$ & n.s. \\
\hline
\end{tabular}

Tabelle 6 Differentialblutbild, manuell, 21d nach Induktion einer Gefäßwandverletzung

Mittelwert \pm SEM, n.s.= nicht signifikant. 


\subsubsection{Lipidstatus}

Hinsichtlich der Bestimmung des Gesamtcholesterins und der Triglyzeride zeigte sich kein

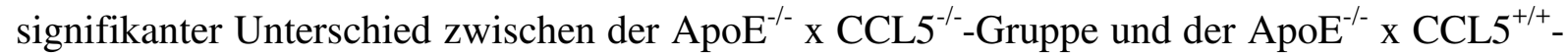
Gruppe (s. Tabelle 7).

\begin{tabular}{|llll|}
\hline & $\begin{array}{c}\mathbf{A p o E}^{-/} \mathbf{x} \mathbf{C C L 5}^{+/+} \\
(\mathbf{n}=\mathbf{1 0})\end{array}$ & $\begin{array}{c}\mathbf{A p o E}^{-/-} \mathbf{x} \mathbf{C C L 5}^{-/-} \\
(\mathbf{n}=\mathbf{1 0})\end{array}$ & p-Wert \\
\hline Gesamtcholesterin [mg/dl] & $331,1 \pm 15,74$ & $317,8 \pm 27,04$ & n.s. \\
\hline Triglyzeride [mg/dl] & $119,5[92,25 ; 235,8]$ & $147,0[110,3 ; 159,0]$ & n.s. \\
\hline
\end{tabular}

Tabelle 7 Gesamtcholesterin-und Triglyzeridbestimmungen, präoperativ

Gesamtcholesterin, Mittelwert \pm SEM und Triglyzeride, Median + IQR, n.s.= nicht signifikant.

\subsection{Auswirkungen der CCL5-Defizienz auf den Blutfluss}

Die Geschwindigkeit des Blutflusses wurde jeweils vor der experimentellen Induktion der Gefäßwandläsion (=Basaler Blutfluss zum Zeitpuntk 0, Abbildung 5a) sowie über eine Dauer von 20 min $\left(=t_{2}\right)$ mittels eines Blutflussmessgeräts und entsprechender Sonde aufgezeichnet.

\subsubsection{Hämodynamische Parameter}

Es konnte hinsichtlich der Geschwindigkeit des Blutflusses sowohl vor der Induktion der Gefäßwandläsion $\left(t_{0}\right)$ als auch 20 min nach Induktion der Läsion $\left(t_{20}\right)$ kein Unterschied manifest gemacht werden. Gleichermaßen verhielt es sich mit der Bestimmung des Blutvolumens, das innerhalb der gemessenen Zeit (AUC $\mathrm{t}_{2}$ ) durch die A. carotis communis sin. floss. Bei der Betrachtung des Eintretens der 1. Okklusion konnte kein signifikanter Unterschied beobachtet werden $(\mathrm{p}=0,071)$ sowie kein signifikanter Unterschied im Blutvolumen in der $\mathrm{ApoE}^{-/-} \mathrm{X}$ CCL5 $^{(-/)}$-Gruppe, das bis zu diesem Zeitpunkt durch die A. carotis communis sin. durchgeflossen ist $(\mathrm{p}=0,057)$ verglichen mit der $\mathrm{ApoE}^{-/-} \mathrm{x} \mathrm{CLL}^{+/+}$-Gruppe (s. Tabelle 8). 


\begin{tabular}{|llll|}
\hline & $\mathbf{A p o E}^{-/-} \mathbf{~ C C L S}^{+/+}$ & $\mathbf{A p o E}^{-/-} \times \mathbf{C C L 5}^{-/-}$ & p-Wert \\
\hline Basaler Blutfluss, [ml/min] & $1,34 \pm 0,05$ & $1,4 \pm 0,08$ & n.s \\
\hline $\mathrm{t}_{1}[\mathrm{~min}]$ & $8,20[7,28 ; 8,67]$ & $7,57[7,57 ; 8,23]$ & n.s. \\
\hline AUC $_{1}\left[\mathrm{ml} / \mathrm{t}_{1}\right]$ & $6,045 \pm 0,43$ & $4,99 \pm 0,32$ & n.s. \\
\hline AUC $_{2}[\mathrm{ml} / 20 \mathrm{~min}]$ & $7,93[5,69 ; 15,11]$ & $7,15[4,43 ; 8,98]$ & n.s. \\
\hline Blutfluss, $\mathrm{t}_{2}[\mathrm{ml} / \mathrm{min}]$ & $0,01[0,0 ; 0,85]$ & $0,27[0,02 ; 0,91]$ & n.s. \\
\hline
\end{tabular}

\section{Tabelle 8 Hämodynamische Parameter}

Dargestellt als Mittelwert \pm SEM bzw. Median $+\mathrm{IQR}$, n.s. $=$ nicht signifikant. $\mathrm{ApoE}^{-/-} \mathrm{xCCL}^{+/+}$- und $\mathrm{ApoE}^{-/-} \mathrm{x}$ $\mathrm{CCL}^{-/}{ }^{-}$-Gruppe jeweils $\mathrm{n} \geq 21$.

\subsubsection{Okklusionsverhalten}

Hinsichtlich der Untersuchungen des Verhaltens des Blutflusses bzw. des Okklusionsverhaltens nach Induktion einer experimentellen Gefäßwandläsion konnten keine signifikanten Unterschiede zwischen der ApoE $\mathrm{ACCL}^{-/ /}$- und $\mathrm{ApoE}^{-/-}$x $\mathrm{CCL5}^{-/-}$-Gruppe ermittelt werden. Unterschieden wurde dabei das Verhalten einer stabilen Stenose sowie einer instabilen Stenose mit rezidivierenden Ablösungen des thrombotischen Materials und das fehlende Eintreten einer Stenose nach Induktion der Gefäßwandverletzung (s. Abbildung 11).

A)

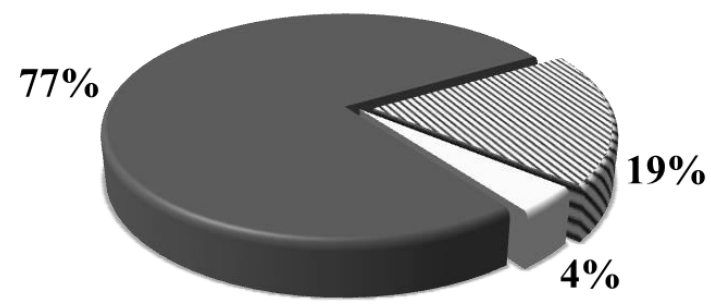

B)

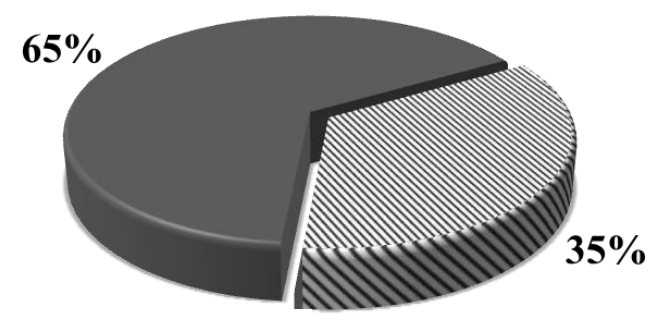

\section{Abbildung 11 Okklusionsverhalten nach Induktion der Gefäßwandläsion}

Dargestellt sind jeweils die $\mathrm{ApoE}^{-/}$× $\mathrm{CCL}^{+/+}$-Gruppe, $\mathrm{n}=26$ (A) und $\mathrm{ApoE}^{-/-}$-Gruppe $\times \mathrm{CCL}^{-/}, \mathrm{n}=23$ (B), sowie das Stenoseverhalten einer stabilen Stenose (dunkelgrau), instabilen Stenose (schraffiert) und keiner eingetretenen Stenose (weiß). 


\subsection{Auswirkungen der CCL5-Defizienz auf vaskuläre Umbauvorgänge}

\subsubsection{Entwicklung und Organisation der arteriellen Thrombose}

Zur Quantifizierung der Organisation des thrombotischen Materials erfolgte die Gewebeentnahme nach Induktion der Gefäßwandläsion zu den Zeitpunkten: 30 min, 1 h, $1 \mathrm{~d}$ und $3 \mathrm{~d}$. Zur Übersicht wurden in der Abbildung 12 die Zeitpunkte nach 7 bzw. 21 d ebenfalls aufgeführt.

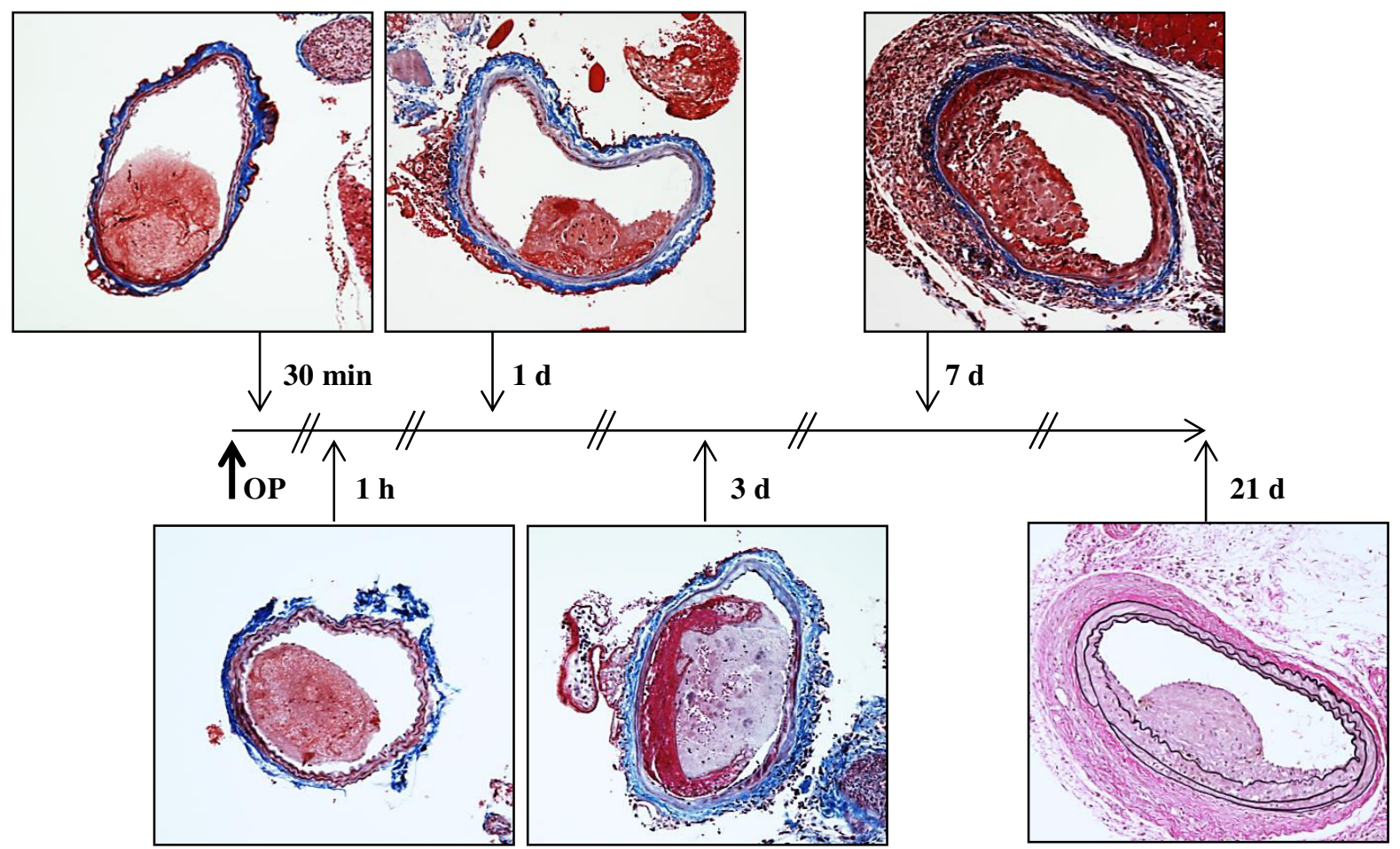

Abbildung 12 Organisation der arteriellen Thrombose anhand histologischer Schnittbilder

Dargestellt ist die histologische Untersuchung der arteriellen Thrombose am Beispiel der ApoE ${ }^{-/-} \mathrm{x} \mathrm{CCL5}^{+/+}$Gruppe in Masson-Trichrom-Färbung. 100fache Vergrößerung.

Zur quantitativen Evaluation der Organisation des thrombotischen Materials hin zur Entwicklung der Neointima erfolgte die morphometrische Analyse der gewonnenen histologischen Gewebeschnitte. Letztere erbrachte keine signifikanten Unterschiede zwischen der Versuchsgruppe und der Kontrollgruppe. In der Abbildung 13 ist die zunehmende Organisation des thrombotischen Materials mit einer Abnahme der Lumenstenose sowie einer Abnahme der Thrombus- bzw. Neointima-Fläche und einer Zunahme der Media-Fläche erkennbar. 
$\mathrm{ApoE}^{-/-} \times \mathrm{CCL5}^{+/+}$

a)

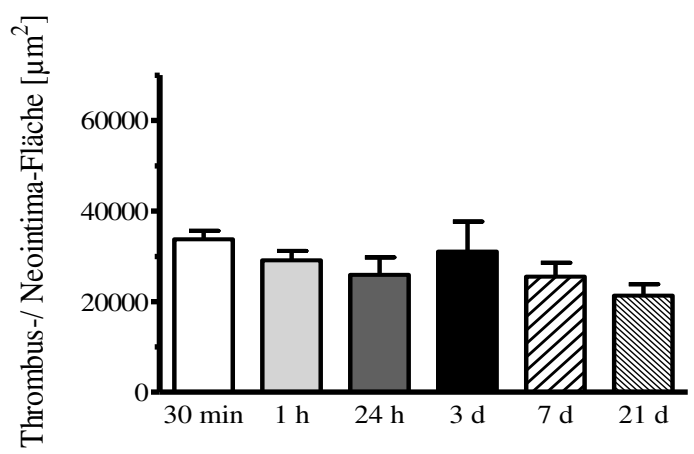

c)

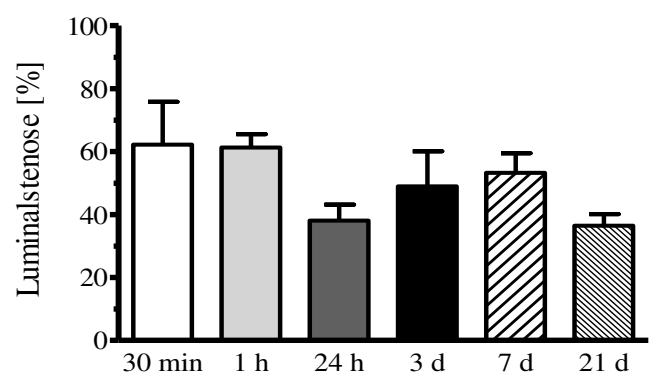

e)

$$
\mathrm{ApoE}^{-/-} \times \mathrm{CCL}^{+/+}
$$

d)

b)
$\mathrm{ApoE}^{-/-}$x $\mathrm{CCL5}^{-/-}$

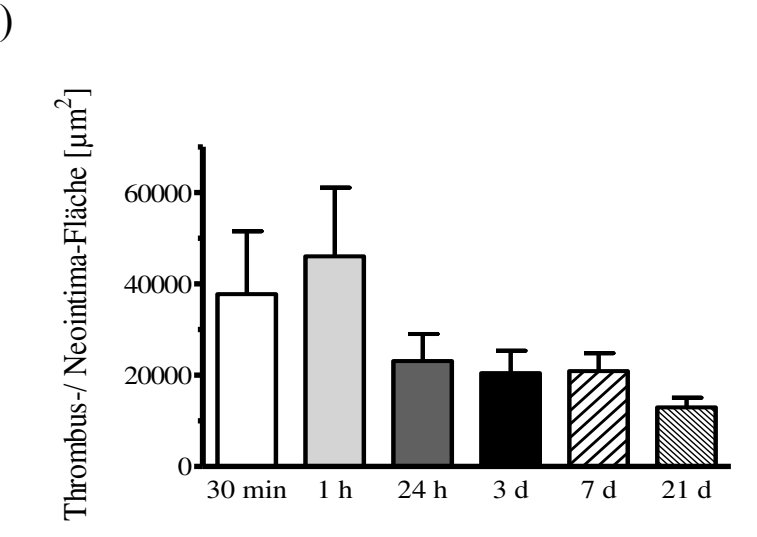

$\mathrm{ApoE}^{-/-} \times \mathrm{CCL5}^{-/-}$

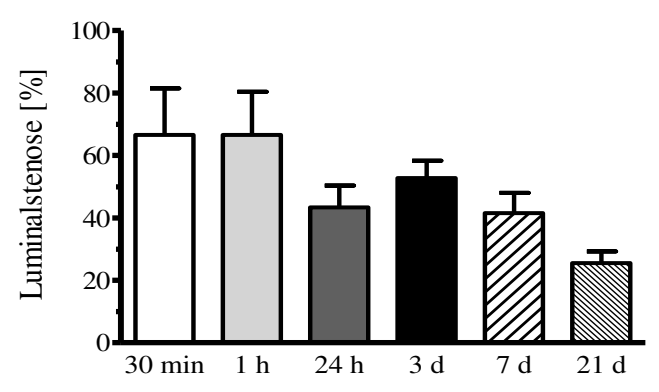

f)

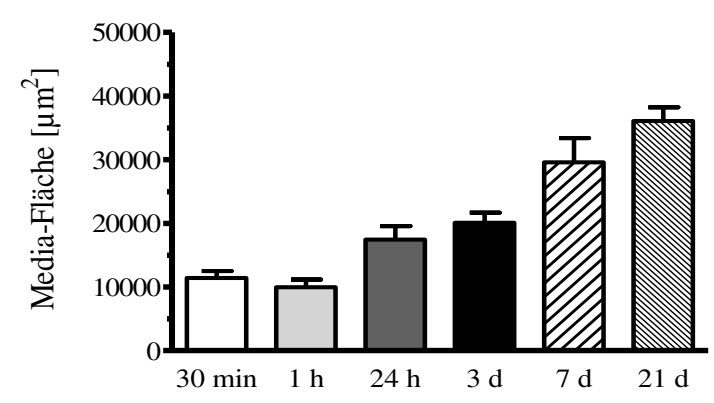

\section{Abbildung 13 Quantifizierung der Organisation der arteriellen Thrombose}

Dargestellt ist die zeitliche Organisation des thrombotischen Materials hin zur Neointima der $\mathrm{ApoE}^{-/-} \mathrm{x}$ $\mathrm{CCL5}^{+/+}$-Gruppe (a, c, e) und der ApoE ${ }^{-/-} \mathrm{CCL}^{-/-}$-Gruppe (b, d, f), $\mathrm{n} \geq 3$. Deskriptive Veranschaulichung des Trends der Zunahme der Media-Fläche sowohl in der $\mathrm{ApoE}^{-/-} \mathrm{xCCL}^{+/+}$-Gruppe (e), als auch in der $\mathrm{ApoE}^{-/} \mathrm{x}$ $\mathrm{CCL}^{-/-}$-Gruppe (f) über den Untersuchungszeitraum. 


\subsubsection{Auswirkungen der CCL5-Defizienz auf die arterielle Thrombose}

Zum Zeitpunkt der Organisation des thrombotischen Materials 7 d nach Induktion einer Gefäßwandläsion zeigten sich keine signifikanten Unterschiede in der histomorphologischen Analyse hinsichtlich der Thrombus-Fläche, der Lumenstenose sowie der Media-Fläche zwischen der $\mathrm{ApoE}^{-/-} \mathrm{x} \mathrm{CCL5}^{+/+}$- und $\mathrm{ApoE}^{-/-} \mathrm{x} \mathrm{CCL5}^{-/-}$-Gruppe (s. Abbildung 15 und Abbildung $15)$.

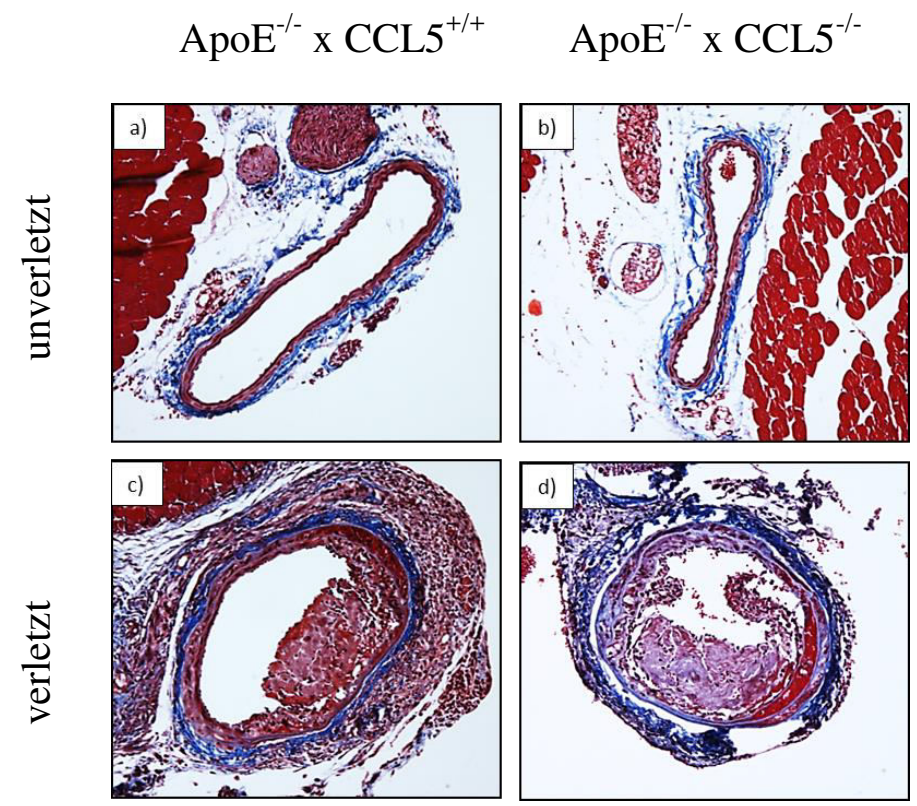

\section{Abbildung 14 Repräsentative histologische Gewebeschnitte des arteriellen Thrombus}

Dargestellt sind sowohl die verletzte A. carotis communis sin. der $\mathrm{ApoE}^{-/-} \mathrm{xCCL}^{+/+}-$(c) und der $\mathrm{ApoE}^{-/-} \mathrm{x}$ $\mathrm{CCL5}^{-/-}$-Gruppe (d) sowie vergleichend die unverletzte A. carotis communis dex. der $\mathrm{ApoE}^{-/-} \mathrm{x} \mathrm{CCL5}^{+/+}$- (a) bzw. der ApoE ${ }^{-1-}$ x $\mathrm{CCL5}^{-/}$-Gruppe (b). Masson-Trichrom-Färbung, 100fache Vergrößerung.

a)

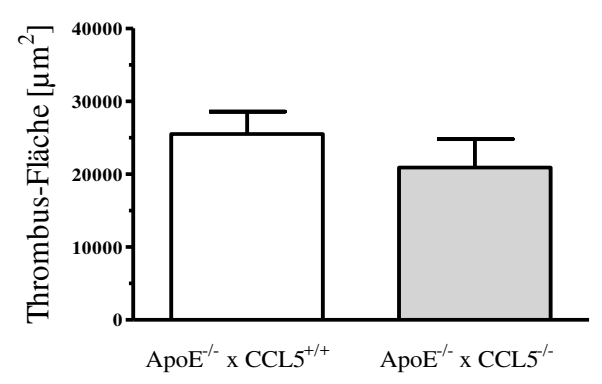

c)

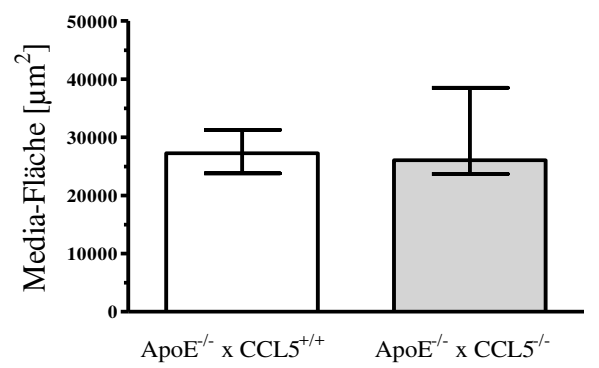

b)

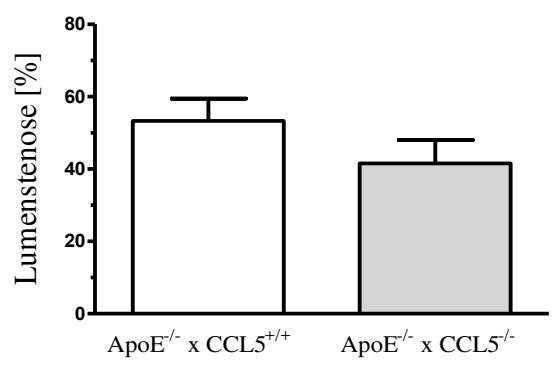

Abbildung 15 Morphometrische Analyse der Thrombus-Fläche

Thrombus-Fläche (a) und Lumenstenose (b) Mittelwert + SEM, Media-Fläche (c) Median \pm IQR. 


\subsubsection{Auswirkungen der CCL5-Defizienz auf die Neointimabildung}

In der histomorphologischen Analyse der Neointima 21 d nach Induktion einer Gefäßwandläsion konnte eine signifikante Abnahme der Neointimabildung in der $\mathrm{ApoE}^{-/-} \mathrm{x} \mathrm{CCL5}^{-/-}$im Vergleich zur ApoE ${ }^{-/-}$x CCL5 ${ }^{+/+}$-Gruppe ermittelt werden. In der Abbildung 16 sind repräsentative histologische Gewebeschnitte dargestellt, in der die reduzierte Neointima-Fläche der Versuchsgruppe (s. Abbildung 16d und 17a) vergleichend mit der Kontrollgruppe (Abbildung 16c) abgebildet ist. Demgegenüber sind im oberen Bildbereich die jeweils unverletzten Aa.carotides communes dex. dargestellt.
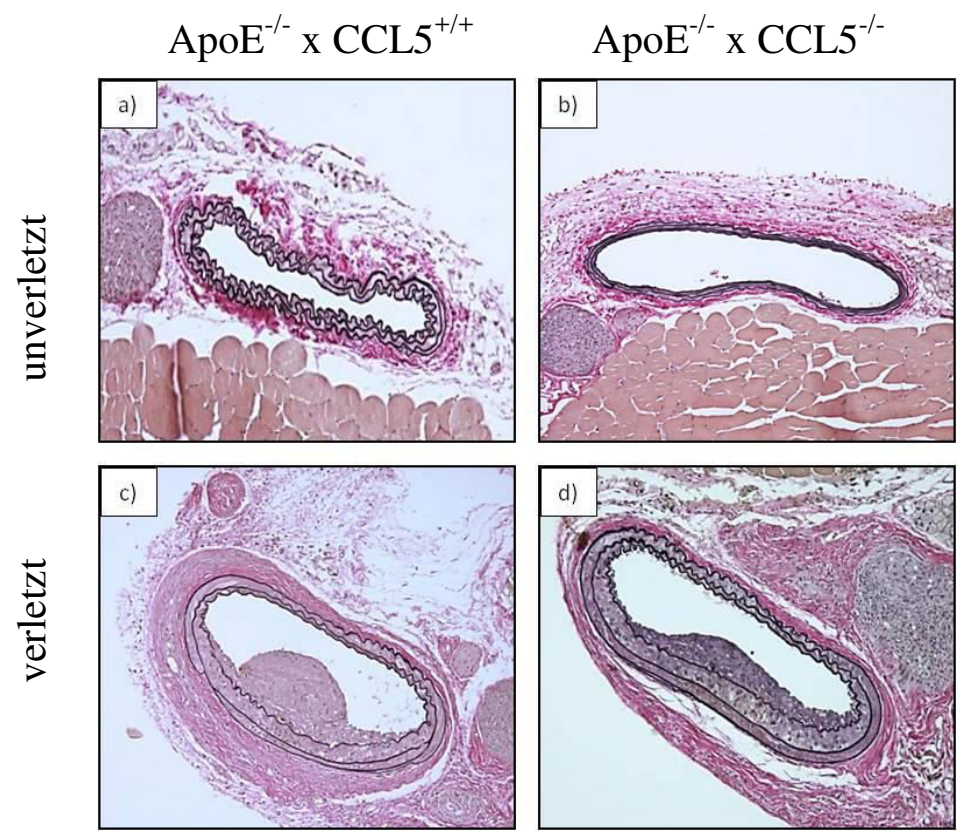

Abbildung 16 Repräsentative histologische Gewebeschnitte der Neointima-Fläche

Dargestellt sind die verletzte A. carotis communis sin. der $\mathrm{ApoE}^{-/} \times \mathrm{CCL}^{+/+}$- (c) und der $\mathrm{ApoE}^{-/-} \times \mathrm{CCL5}^{-/-}$Gruppe (d) sowie vergleichend die unverletzte A. carotis communis dex. der $\mathrm{ApoE}^{-/} \mathrm{x} \mathrm{CCL5}^{+/+}$- (a) bzw. der $\mathrm{ApoE}^{-/-} \mathrm{CCCL}^{-/-}$-Gruppe (b). Verhoeff'sche-Elastika-Färbung, 100fache Vergrößerung. 
Darüber hinaus konnte eine signifikant verringerte Lumenstenose (s. Abbildung 17b) demonstriert werden sowie ein signifikant verringertes Verhältnis der Neointima-Fläche zur MediaFläche (I/M Ratio, s. Abbildung 17d). Die Analyse der Media-Fläche (s. Abbildung 14c) erbrachte keinen signifikanten Unterschied zwischen der $\mathrm{ApoE}^{-/-} \mathrm{x} \mathrm{CCL5}^{-/-}$und der $\mathrm{ApoE}^{-/-} \mathrm{x}$ CCL5 $^{+/+}$-Gruppe.

a)

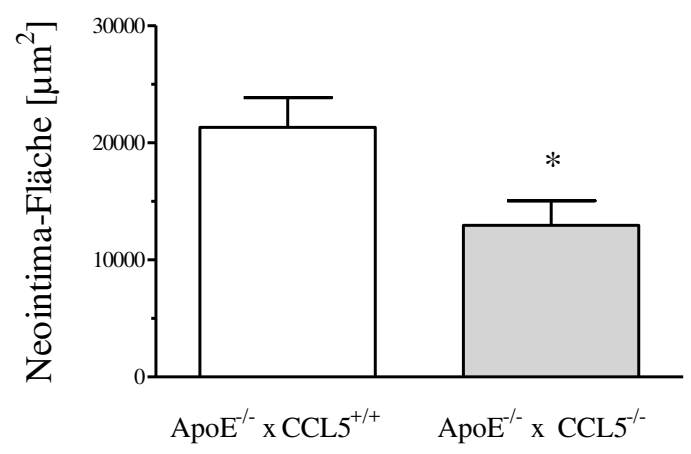

c)

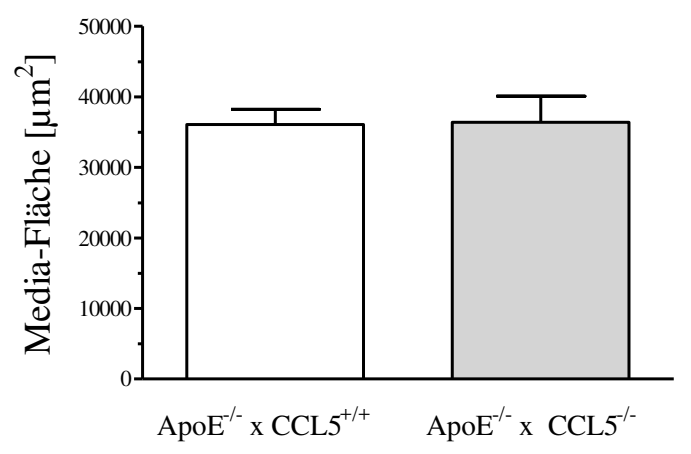

b)

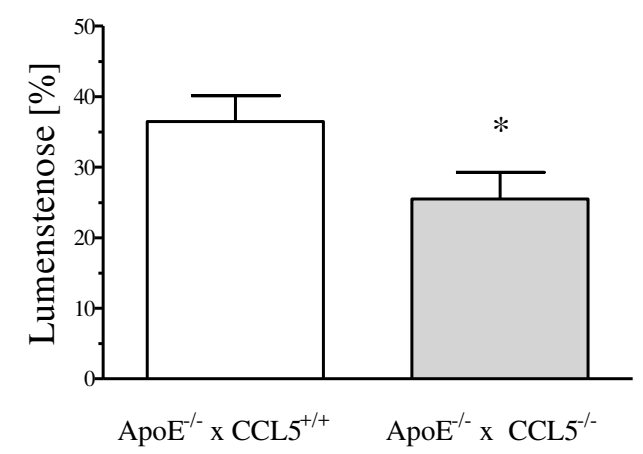

d)

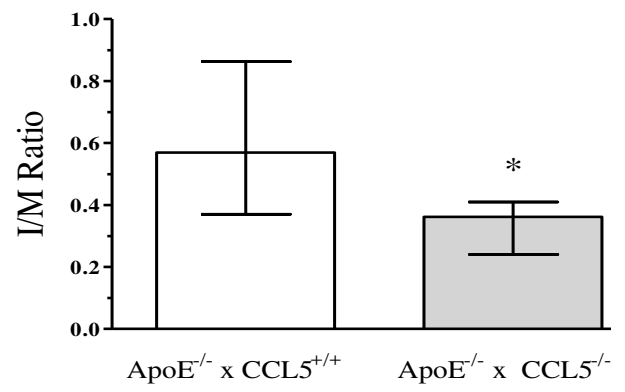

\section{Abbildung 17 Morphometrische Analyse der Neointima-Fläche}

Neointima-Fläche (a), Lumenstenose (b), Media-Fläche (c) und I/M Ratio (d), jeweils der ApoE ${ }^{-/-} \times \mathrm{CCL5}^{+/+}$Gruppe und der $\mathrm{ApoE}^{-/} \times \mathrm{CCL}^{-/}{ }^{-}$-Gruppe. Mittelwert \pm SEM bzw. Median $\pm \mathrm{IQR} . *<0,05=$ signifikant, $\mathrm{n} \geq 11$. 


\subsection{Auswirkungen der CCL5-Defizienz auf die Zellinfiltration}

\subsubsection{CC-Chemokin-Rezeptor 1}

Nach 7 d erbrachte die immunhistochemische anti-CCR1-Färbung sowohl in der CCR1 ${ }^{+}-$ Thrombus-Fläche ( $\mathrm{p}=0,349 \mathrm{~s}$. Abbildung 18a) als auch in der $\mathrm{CCR} 1^{+}$-Media-Fläche $(\mathrm{p}=0,403$ s. Abbildung 18b) keine signifikanten Unterschiede zwischen der $\mathrm{ApoE}^{-/-}$x $\mathrm{CCL5}^{-/-}$-Gruppe im Vergleich zu ApoE ${ }^{-/}$x $\mathrm{CCL}^{+/+}$-Gruppe. Des Weiteren konnte in der CCR $1^{+}$Gesamtfläche kein signifikanter Unterschied ( $\mathrm{p}=0,306 \mathrm{~s}$. Abbildung 18c) in der $\mathrm{ApoE}^{-/-} \mathrm{x}$ $\mathrm{CCL5}^{-{ }^{-}}$-Gruppe im Vergleich zu ApoE ${ }^{-/-}$x $\mathrm{CCL}^{+/+}$-Gruppe ermittelt werden.

a)

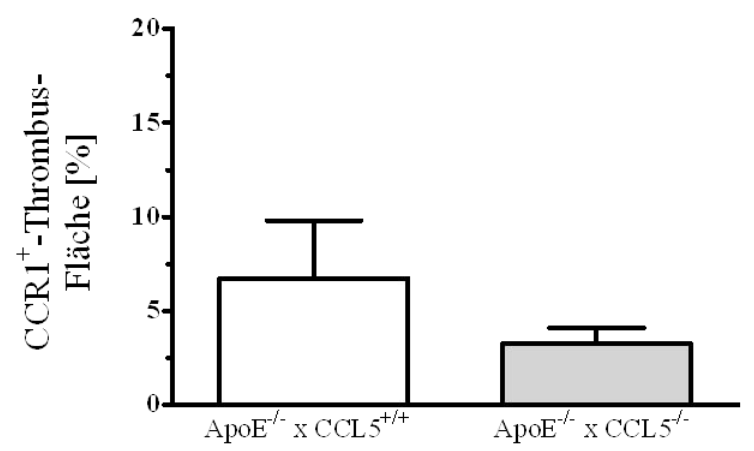

c)

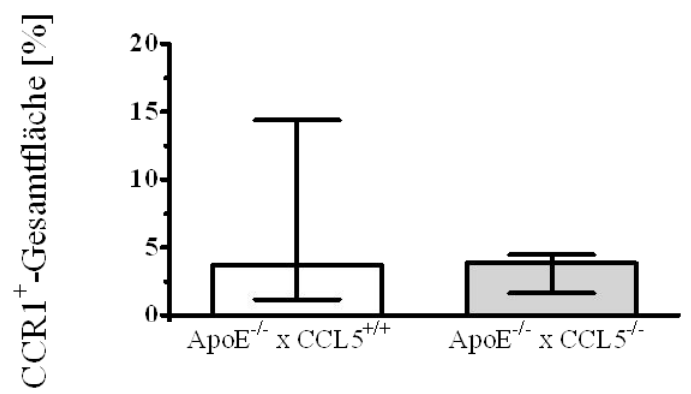

b)

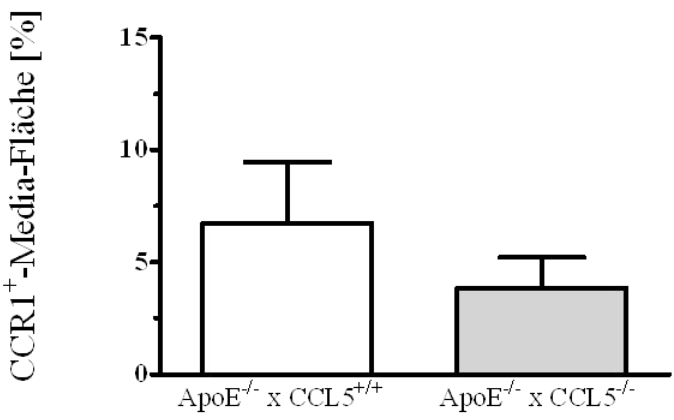

Abbildung 18 Morphometrische Analyse der CCR1 ${ }^{+}$-Fläche nach 7 d

$\mathrm{CCR}^{+}{ }^{-}$-Thrombus-Fläche (a) und $\mathrm{CCR} 1^{+}$-Media-Fläche (b) Mittelwert \pm SEM, CCR1 ${ }^{+}$-Gesamtfläche (c) Median $\pm \mathrm{IQR}, \mathrm{n} \geq 5$. 
Nach $21 \mathrm{~d}$ konnte ein signifikanter Anstieg der CCR1 ${ }^{+}$-Neointima-Fläche (p=0,037 s. Abbildung 19a und b) der $\mathrm{ApoE}^{-/-}$x $\mathrm{CCL5}^{-/-}$-Gruppe festgestellt werden. Im Bereich der CCR1 ${ }^{+}$Media-Fläche ( $p=0,243 \mathrm{~s}$. Abbildung 19c) sowie in der CCR $1^{+}$-Gesamtfläche $(p=0,114 \mathrm{~s}$. Abbildung 19d) konnten keine Unterschiede in der $\mathrm{ApoE}^{-/-}$x $\mathrm{CCL5}^{-/-}$- verglichen mit der $\mathrm{ApoE}^{-/-}$ x CCL5 ${ }^{+/+}$-Gruppe beobachtet werden.

a)
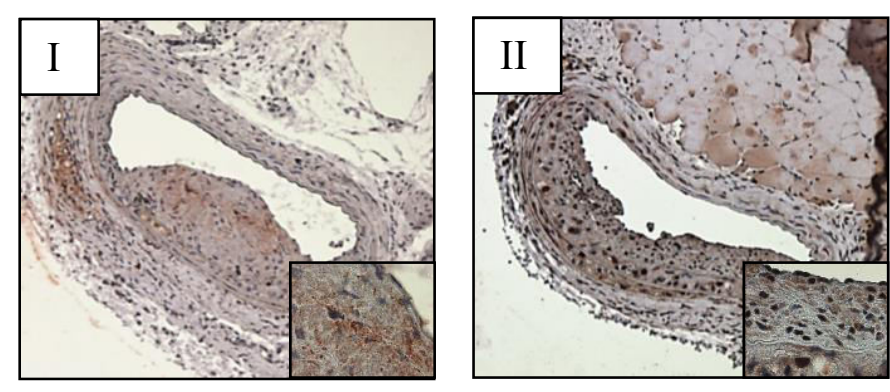

c)

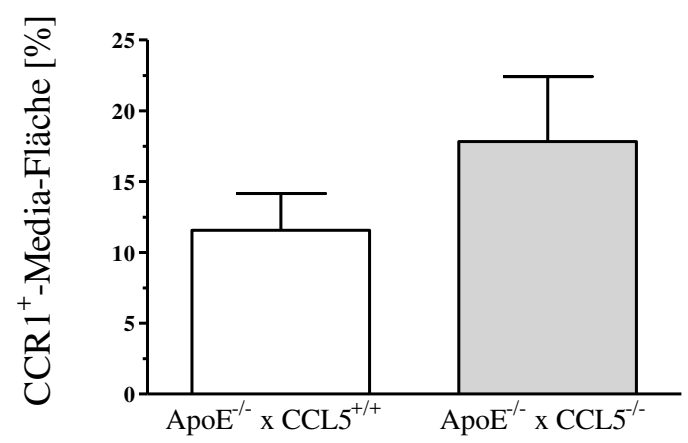

b)

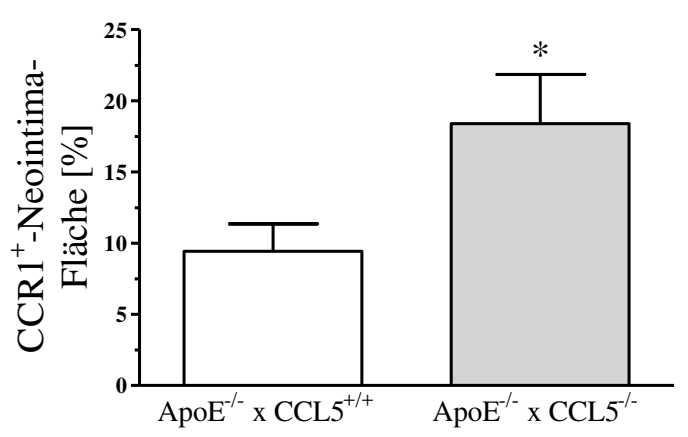

d)

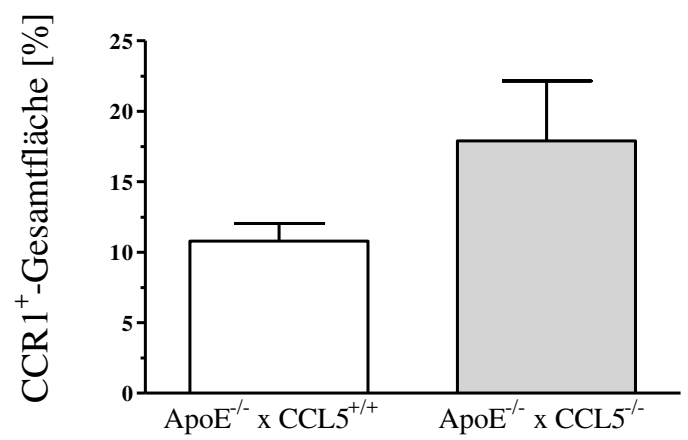

Abbildung 19 Repräsentative Bilder der $\mathrm{CCR1}^{+}$-Fläche nach $21 \mathrm{~d}$ (a) und morphometrische Analyse (b-d)

Dargestellt sind die verletzte A. carotis communis sin. der $\mathrm{ApoE}^{-/} \times \mathrm{CCL}^{+/+}-$(I) und der $\mathrm{ApoE}^{-/} \times \mathrm{CCL5}^{-/}$Gruppe ${ }^{-}$(II). Die Ergebnisse der morphometrischen Analyse der CCR $1^{+}$-Fläche werden sind in den Diagrammen (b-d) abgebildet. 100fache Vergrößerung, 1000fache Detailvergrößerung. Mittelwert \pm SEM, n $\geq 6$, *< $0,05=$ signifikant. 


\subsubsection{CC-Chemokin-Rezeptor 5}

In der immunhistochemischen anti-CCR5-Färbung konnten weder in der CCR5 $5^{+}$-ThrombusFläche ( $\mathrm{p}=0,330 \mathrm{~s}$. Abbildung 20a) noch in der $\mathrm{CCR} 5^{+}$-Media-Fläche ( $\mathrm{p}=0,149 \mathrm{~s}$. Abbildung 20b) signifikante Unterschiede zwischen der $\mathrm{ApoE}^{-/-}$x $\mathrm{CCLF}^{-/-}$-Gruppe und der $\mathrm{ApoE}^{-/-} \mathrm{x}$ $\mathrm{CCL}^{+/+}$-Gruppe beobachtet werden. In der Betrachtung der CCR5 ${ }^{+}$-Gesamtfläche zeichnete sich eine tendenziell geringere $\mathrm{CCR} 5^{+}$-Gesamtfläche $(\mathrm{p}=0,081$ s. Abbildung 20c) in der $\mathrm{ApoE}^{-/-}$x $\mathrm{CCL}^{-/-}$-Gruppe im Vergleich zur ApoE ${ }^{-/-}$x $\mathrm{CCL}^{+/+}-$Gruppe ab.

a)

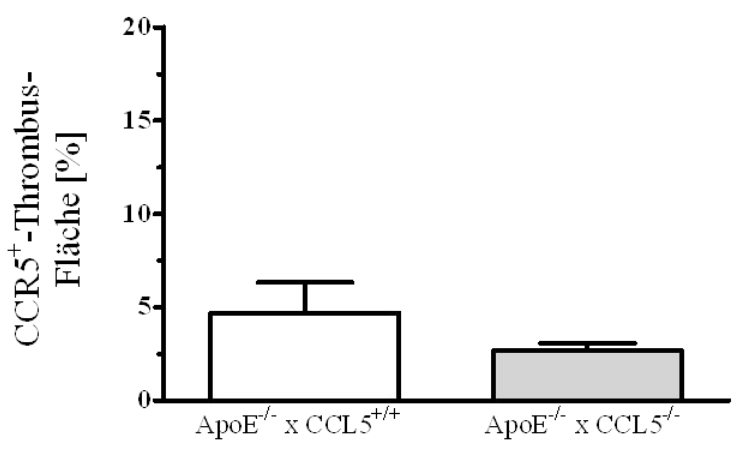

c)

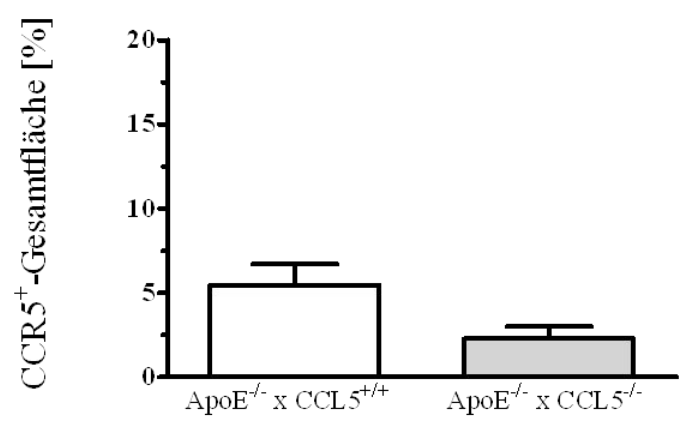

b)

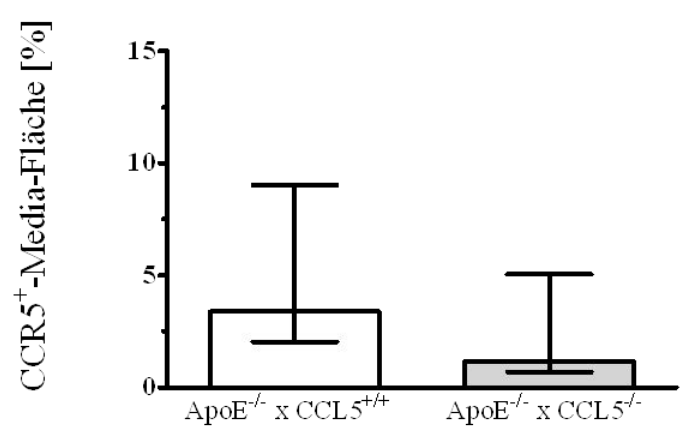

\section{Abbildung 20 Morphometrische Analyse der $\mathrm{CCR5}^{+}$-Fläche nach 7 d}

$\mathrm{CCR}^{+}{ }^{-}$-Thrombus-Fläche (a) und $\mathrm{CCR}^{+}{ }^{+}$-Gesamtfläche (c), Mittelwert + SEM. CCR5 ${ }^{+}$-Media-Fläche (b), Median \pm IQR, $\mathrm{n} \geq 5$. 
In der Betrachtung der $\mathrm{CCR}^{+}{ }^{+}$-Neointima-Fläche nach $21 \mathrm{~d}$ konnte kein Unterschied in der $\mathrm{ApoE}^{-/-}$x CCL5 ${ }^{-/-}$-Gruppe verglichen mit der $\mathrm{ApoE}^{-/-}$x $\mathrm{CCL}^{+/+}$-Gruppe ermittelt werden ( $\mathrm{p}=0,231 \mathrm{~s}$. Abbildung 21b). Eine reduzierte Infiltration von $\mathrm{CCR} 5^{+}$-Zellen konnte sowohl in der Analyse der CCR5 ${ }^{+}$-Media-Fläche ( $\mathrm{p}=0,006 \mathrm{~s}$. Abbildung 21c) als auch in der CCR5 $5^{+}$ Gesamtfläche ( $\mathrm{p}=0,005$ s. Abbildung 21d) in der $\mathrm{ApoE}^{-/-}$x CCL5 ${ }^{-/-}$-Gruppe im Vergleich zur $\mathrm{ApoE}^{-/-}$x CCL5 ${ }^{+/+}$-Gruppe demonstriert werden.

a)
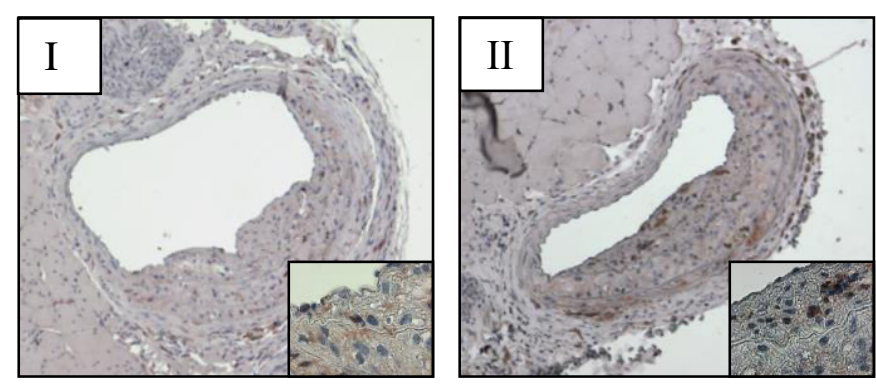

c)

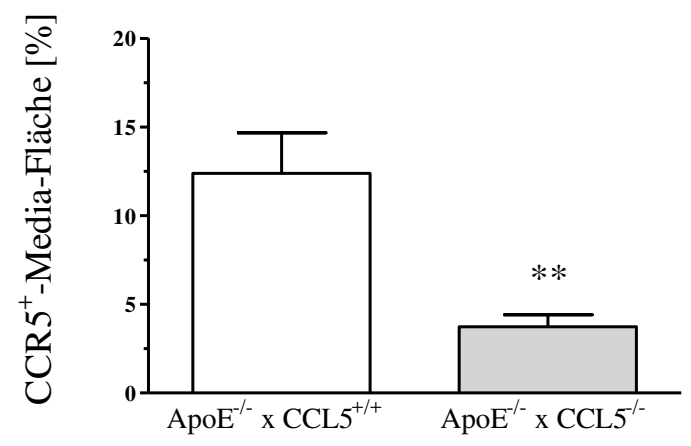

b)

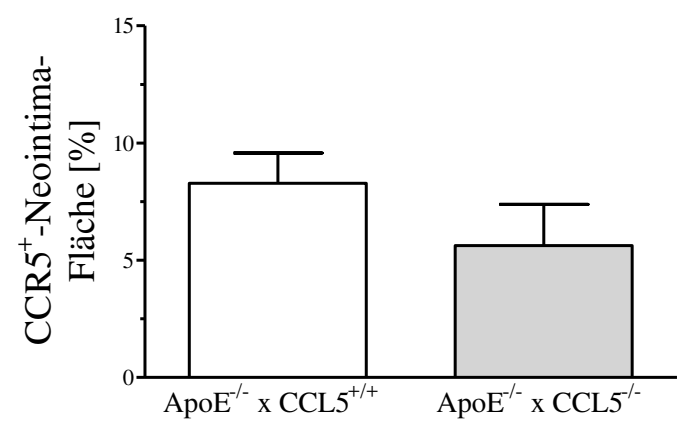

d)

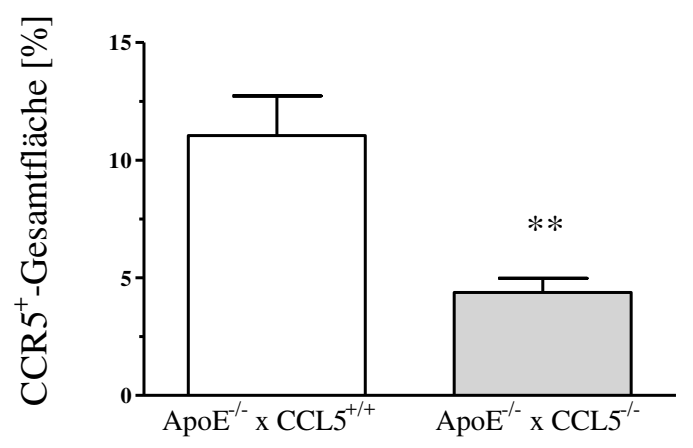

Abbildung 21 Repräsentative Bilder der $\mathrm{CCR5}^{+}$-Fläche nach $21 \mathrm{~d}$ (a) und morphometrische Analyse (b-d) Dargestellt sind die verletzte A. carotis communis sin. der $\mathrm{ApoE}^{-/} \times \mathrm{CCL}^{+/+}$- (I) und der $\mathrm{ApoE}^{-/-} \times \mathrm{CCL5}^{-/}$Gruppe (II). Die Ergebnisse der morphometrischen Analyse der CCR $5^{+}$-Fläche sind in den Diagrammen (b-d) abgebildet. 100fache Vergrößerung,1000fache Detailvergrößerung. Mittelwert \pm SEM, $\mathrm{n} \geq 7, * *<0,01=$ hoch signifikant. 


\subsubsection{Makrophagenantigen-2}

In weiterführenden immunhistochemischen Untersuchungen der Zellinfiltration nach $7 \mathrm{~d}$ wurde der Einfluss der CCL5-Defizienz auf die Infiltration von Makrophagen anhand des Makrophagenantigens Mac-2 untersucht. Es zeigte sich, dass sowohl in der Analyse Mac- $2^{+}-$ Thrombus-Fläche ( $p=0,390 \mathrm{~s}$. Abbildung 22a) als auch in der Mac-2 ${ }^{+}$-Media-Fläche ( $p=0,615$ s. Abbildung 22b) und der Mac- $2^{+}-$Gesamtfläche ( $\mathrm{p}=0,448$ s. Abbildung 22c) keine signifikanten Unterschiede in der $\mathrm{ApoE}^{-/-} \mathrm{xCCL}^{-/-}$- im Vergleich zur $\mathrm{ApoE}^{-/-}$x $\mathrm{CCL}^{+/+}$-Gruppe ermittelt werden konnten.

a)
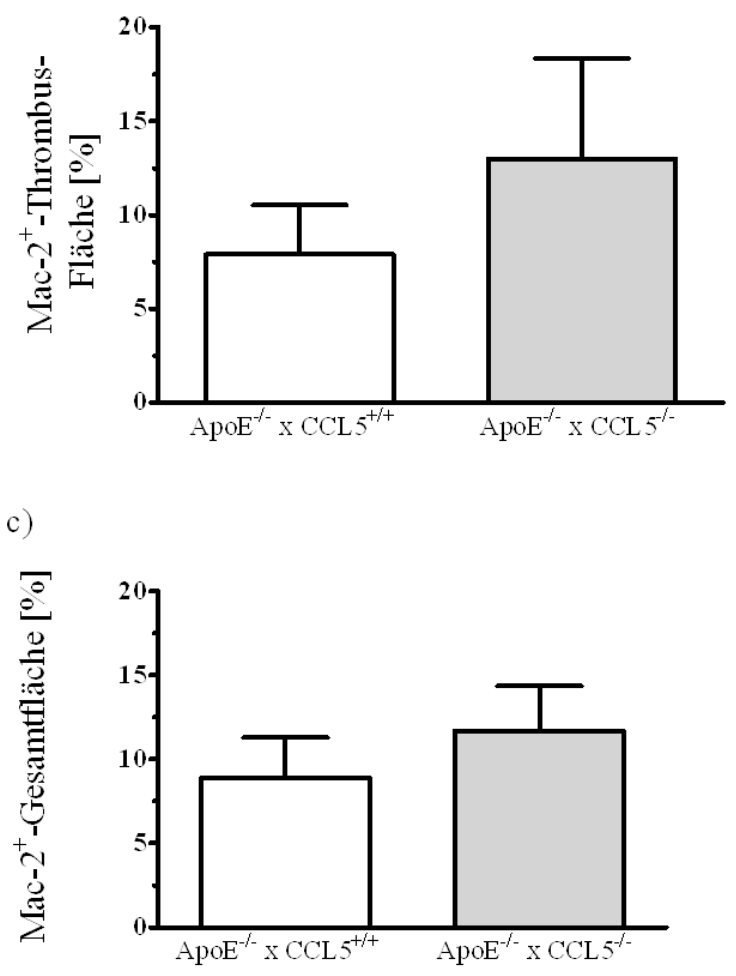

b)

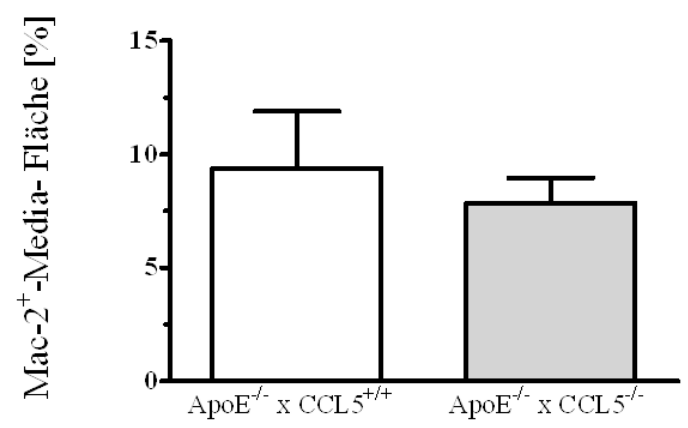

\section{Abbildung 22 Morphometrische Analyse der Mac2 ${ }^{+}$-Fläche nach 7 d}

Mac-2 $2^{+}$-Thrombus-Fläche (a), Mac-2 $2^{+}$-Media-Fläche (b) und Mac-2 $2^{+}$-Gesamtfläche (c), Mittelwert + SEM, $\mathrm{n} \geq 5$. 
In der immunhistochemischen Analyse der Makrophageninfiltration nach $21 \mathrm{~d}$ konnte kein signifikanter Unterschied in der Mac- $2^{+}$-Neointima-Fläche ( $p=0,286$ s. Abbildung 23a und b) beobachtet werden. Jedoch konnte eine signifikante Zunahme der Mac-2 ${ }^{+}$-Media-Fläche ( $\mathrm{p}=0,0321 \mathrm{~s}$. Abbildung 23c), als auch eine signifikante Zunahme der Mac-2 $2^{+}$-Gesamtfläche ( $\mathrm{p}=0,035$ s. Abbildung 23d) in der $\mathrm{ApoE}^{-/-} \mathrm{x} \mathrm{CCL}^{-/-}$-Gruppe im Vergleich zur ApoE ${ }^{-/-} \mathrm{x}$ $\mathrm{CCL}^{+/+}$-Gruppe gezeigt werden.

a)
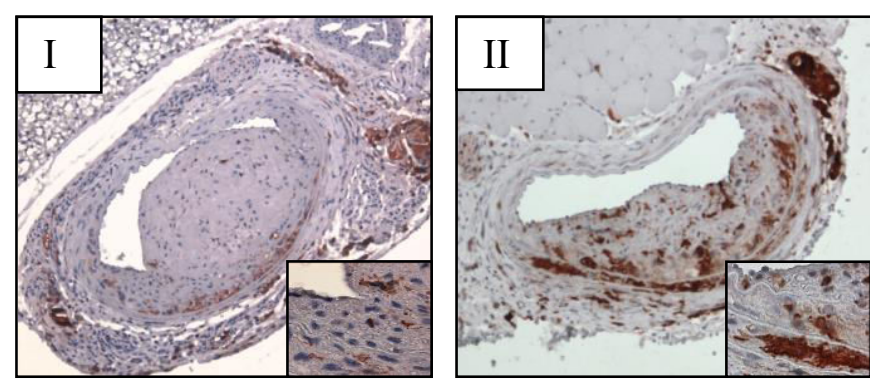

c)

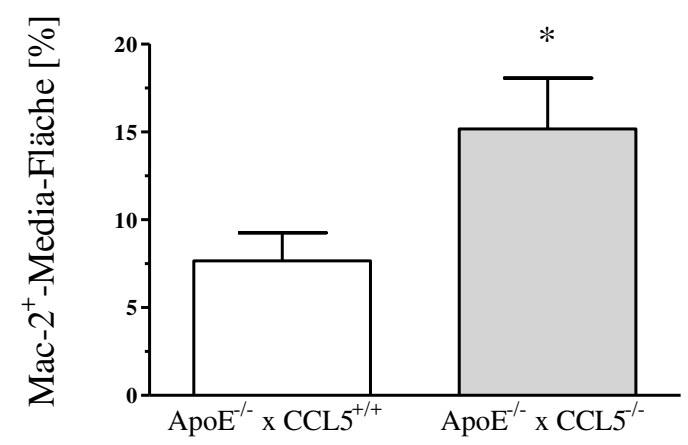

b)

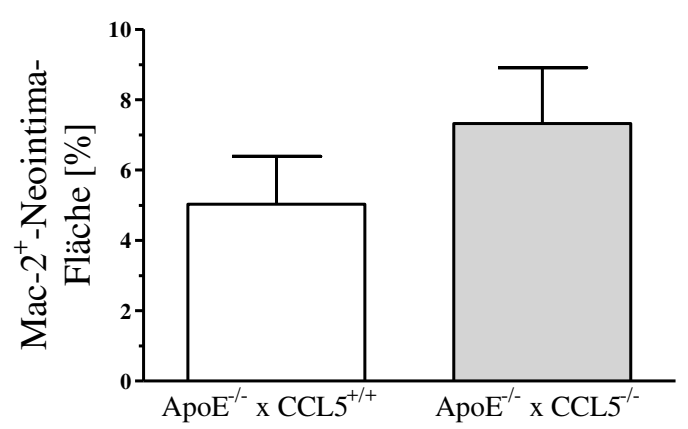

d)

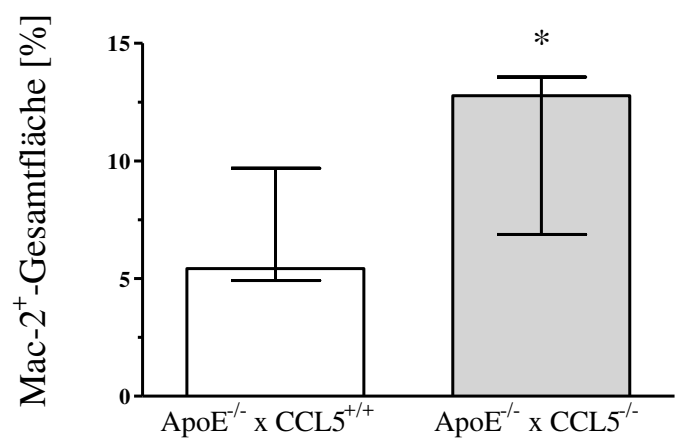

Abbildung 23 Repräsentative Bilder der Mac-2 ${ }^{+}$-Fläche nach 21 d (a) und morphometrische Analyse (b-d)

Dargestellt sind die verletzte A. carotis communis sin. der $\mathrm{ApoE}^{-/-} \times \mathrm{CCL5}^{+/+}$- (I) und der $\mathrm{ApoE}^{-/-} \times \mathrm{CCL5}^{-/-}$Gruppe (II). Die Ergebnisse der morphometrischen Analyse der Mac-2 ${ }^{+}$-Fläche sind in den Diagrammen (bd) abgebildet. 100fache Vergrößerung, 1000fache Detailvergrößerung.

Mittelwert \pm SEM, $\mathrm{n} \geq 9, *<0,05=$ signifikant.

Die immunhistochemischen Untersuchungen des Einflusses der CCL5-Defizienz auf die Makrophageninfiltration zeigt eine signifikante Zunahme der Mac-2 $2^{+}$-Media-Fläche und der Mac- $2^{+}-$Gesamtfläche und ist somit gleich gerichtet mit den Beobachtungen der immunhistochemischen Analyse der anti-CCR1-Färbung. Demgegenüber steht die gegensätzlich gerichtete signifikante Abnahme der CCR5 ${ }^{+}$-Media-Fläche und CCR5 ${ }^{+}$-Gesamtfläche. 


\subsubsection{Cluster of Differentiation 45}

In der Analyse der anti-CD45-Färbung zur Quantifizierung der Leukozyteninfiltration konnten keine signifikanten Unterschiede in der CD45 $5^{+}$Thrombus-Fläche nach $7 \mathrm{~d}(\mathrm{p}=0,1 \mathrm{~s}$. Abbildung 24a), der $C D 45^{+}$-Media-Fläche ( $\mathrm{p}=1,0$ s. Abbildung 24b) oder der $\mathrm{CD} 45^{+}$Gesamtfläche ( $\mathrm{p}=0,4 \mathrm{~s}$. Abbildung 24c) beobachtet werden.

a)

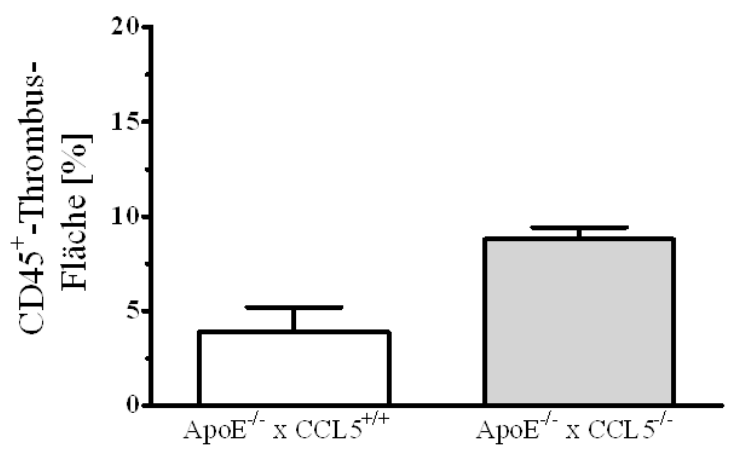

c)

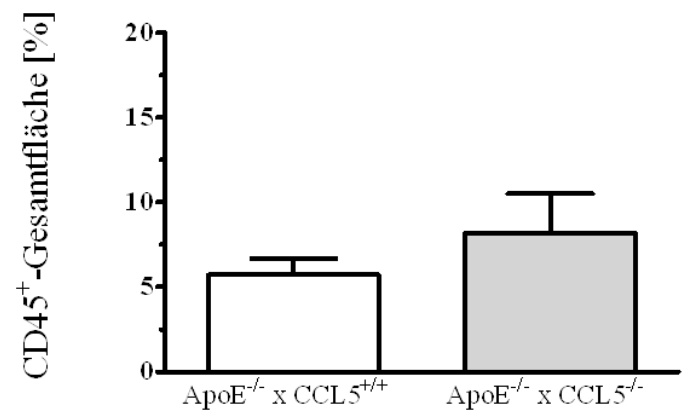

b)

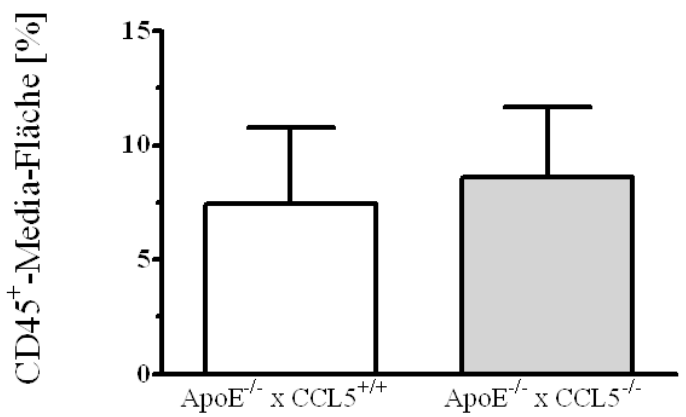

Abbildung 24 Morphometrische Analyse der CD45 ${ }^{+}$-Fläche nach 7 d

CD45 -Thrombus-Fläche (a), CD45 -Media-Fläche (b) und CD45+-Gesamtfläche (c), Median \pm IQR, n = 3 . 
Die Analyse der Leukozyteninfiltration nach 21 d zeigte eine signifikante Zunahme der $\mathrm{CD} 45^{+}$-Neointima-Fläche in der $\mathrm{ApoE}^{-/-} \mathrm{x} \mathrm{CCL5}^{-/-}$- verglichen mit der $\mathrm{ApoE}^{-/-} \mathrm{x} \mathrm{CCL5}^{+/+}$ Gruppe ( $\mathrm{p}=0,016 \mathrm{~s}$. Abbildung 25a und b), wohingegen kein signifikanter Unterschied in der CD45 ${ }^{+}$-Media-Fläche ( $\mathrm{p}=0,683 \mathrm{~s}$. Abbildung 25c) und der der CD45 ${ }^{+}$-Gesamtfläche ( $\mathrm{p}=0,214$ s. Abbildung 25d) dargestellt werden konnte.

a)
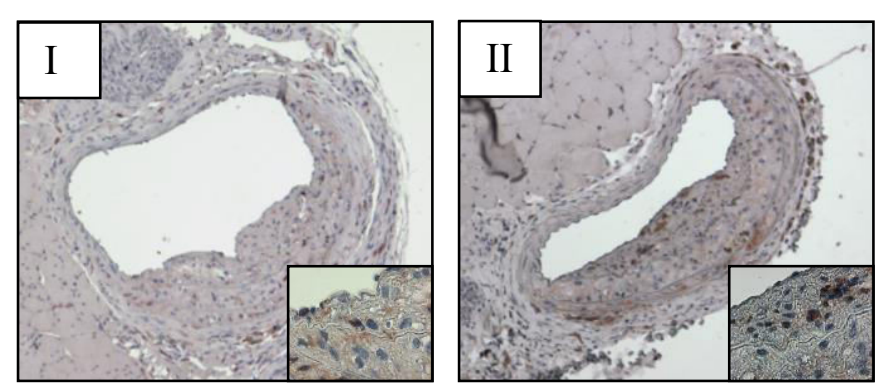

c)

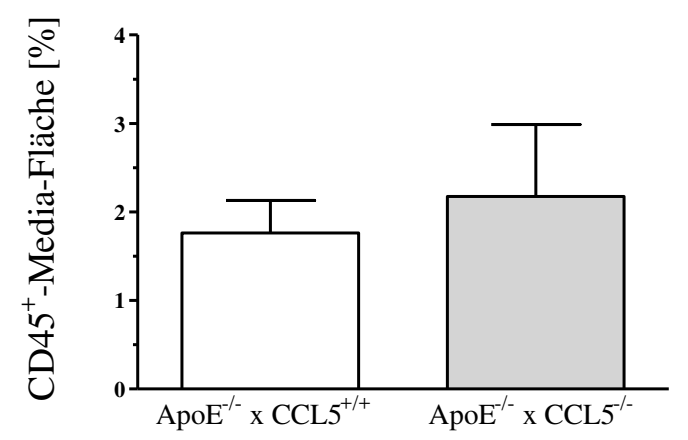

b)

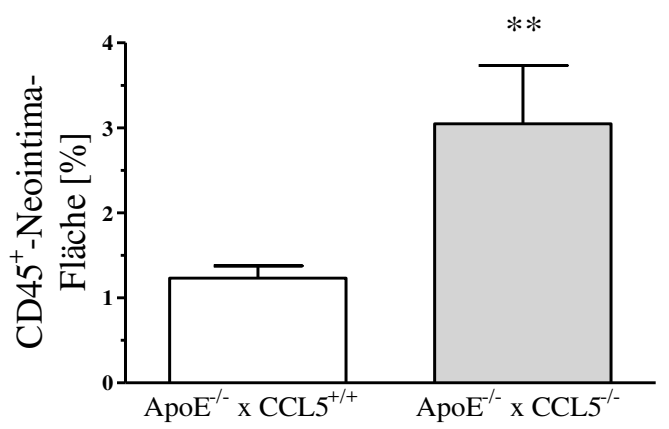

d)

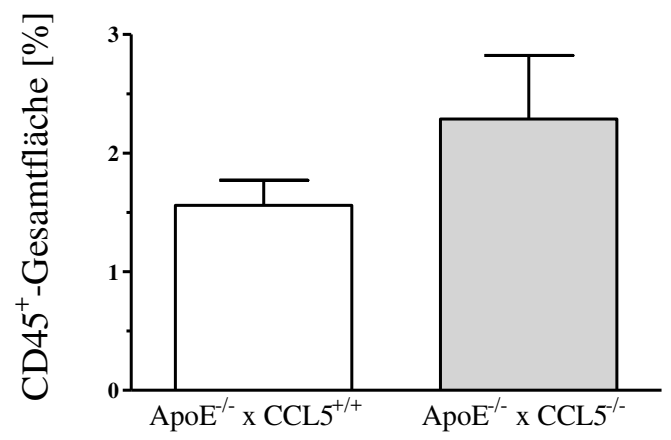

Abbildung 25 Repräsentative Bilder der $\mathrm{CD}^{+} 5^{+}$-Fläche nach $21 \mathrm{~d}$ (a) und morphometrische Analyse (b-d) Dargestellt sind die verletzte A. carotis communis sin. der $\mathrm{ApoE}^{-/-}$x $\mathrm{CCL}^{+/+}$-(I) und $\mathrm{der}^{\mathrm{ApoE}}{ }^{-/-} \mathrm{x} \mathrm{CCL}^{-/-}$Gruppe (II). Die Ergebnisse der morphometrischen Analyse der CD45 ${ }^{+}$-Fläche sind in den Diagrammen (c-d) abgebildet. 100fache Vergrößerung, 1000fache Detailvergrößerung. Mittelwert \pm SEM, $\mathrm{n} \geq 5, * *<0,01=$ hoch signifikant. 


\subsubsection{Krüppel-like Faktor 4}

Die immunhistochemische Analyse der anti-KLF4-Färbung diente der Untersuchung des möglichen Einflusses der CCL5-Defizienz auf den antiatherogenen Transskriptionsfaktor KLF4. In der Analyse nach $7 \mathrm{~d}$ konnte kein signifikanter Unterschied in der $\mathrm{KLF}^{+}{ }^{+}$ Thrombus-Fläche ( $\mathrm{p}=0,700$ s. Abbildung 26a) demonstriert werden. Darüber hinaus konnte kein signifikanter Unterschied in der $\mathrm{KLF}^{+}$-Media-Fläche ( $\mathrm{p}=0,538 \mathrm{~s}$. Abbildung 26b) und der $\mathrm{KLF}^{+}$-Gesamtfläche ( $\mathrm{p}=0,640$ s. Abbildung 26c) zwischen der $\mathrm{ApoE}^{-/-} \mathrm{x} \mathrm{CCL5}^{-/-}$ Gruppe und der $\mathrm{ApoE}^{-/-}$x $\mathrm{CCL}^{+/+}$-Gruppe nachgewiesen werden.

a)

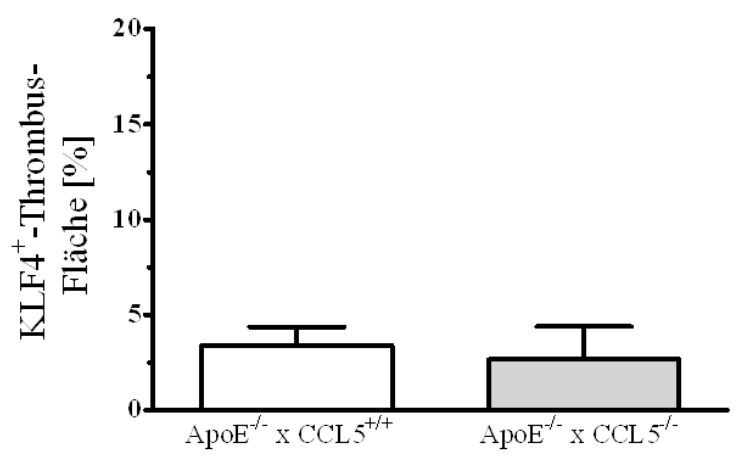

c)

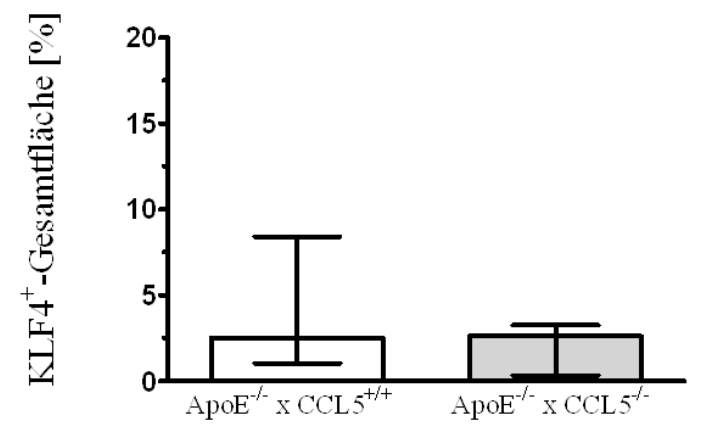

b)

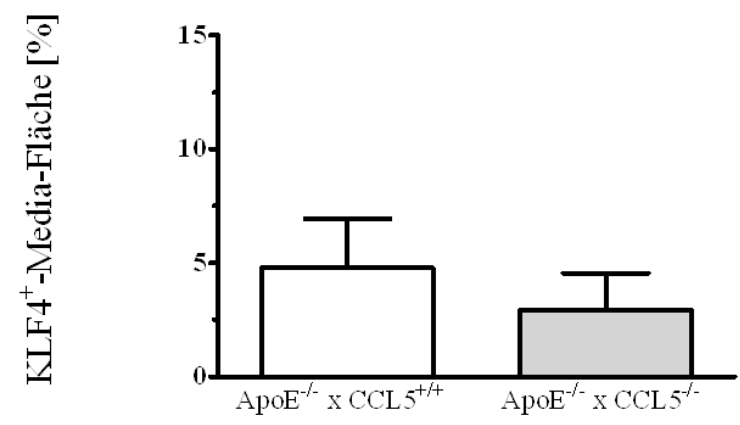

Abbildung 26 Morphometrische Analyse der anti-KLF4-Färbung nach 7 d

$\mathrm{KLF}^{+}{ }^{-}$-Thrombus-Fläche (a), KLF4 ${ }^{+}$-Media-Fläche (b) und KLF4 ${ }^{+}$-Gesamtfläche (c), Median $\pm \mathrm{IQR}, \mathrm{n} \geq 5$. 
In der immunhistochemischen Analyse nach $21 \mathrm{~d}$ zeigte sich eine signifikant erhöhte $\mathrm{KLF}^{+}{ }^{+}$ Neointima-Fläche in der $\mathrm{ApoE}^{-/-}$x $\mathrm{CCL5}^{-/-}$im Vergleich zur $\mathrm{ApoE}^{-{ }_{-}}$x $\mathrm{CCL5}^{+/+}$-Gruppe ( $\mathrm{p}=0,016 \mathrm{~s}$. Abbildung 27a und Abbildung 27b). Gleichgerichtet konnte die Tendenz in einer Zunahme der $\mathrm{KLF}^{+}{ }^{-}$-Media-Fläche in der $\mathrm{ApoE}^{-/-}$x $\mathrm{CCL}^{-/-}$-Gruppe (p=0,244 s. Abbildung 27c) und in der $\mathrm{KLF}^{+}{ }^{-}$-Gesamtfläche ein Trend in der $\mathrm{ApoE}^{-/-} \mathrm{xCL}^{-/-}$- im Vergleich zur $\mathrm{ApoE}^{-/-}$x CCL5 ${ }^{+/+}$-Gruppe (p=0,076 s. Abbildung 27d) dargestellt werden.

a)
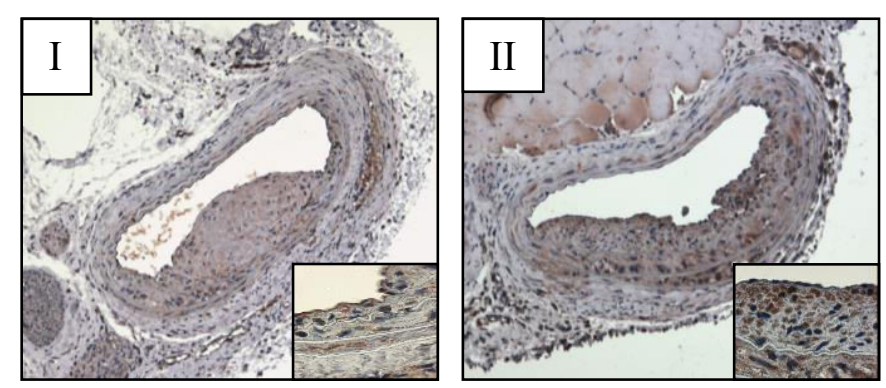

c)

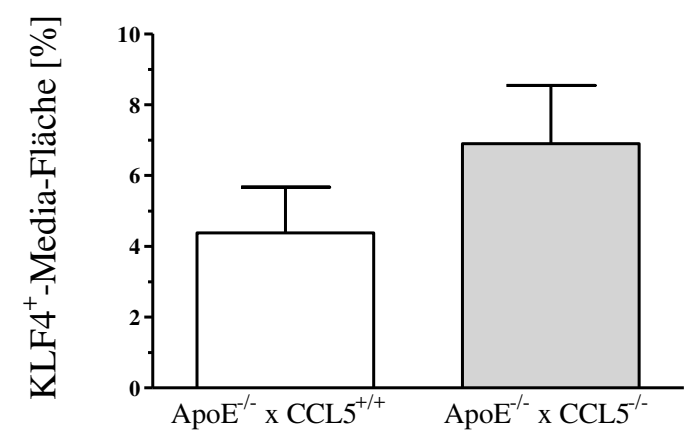

b)

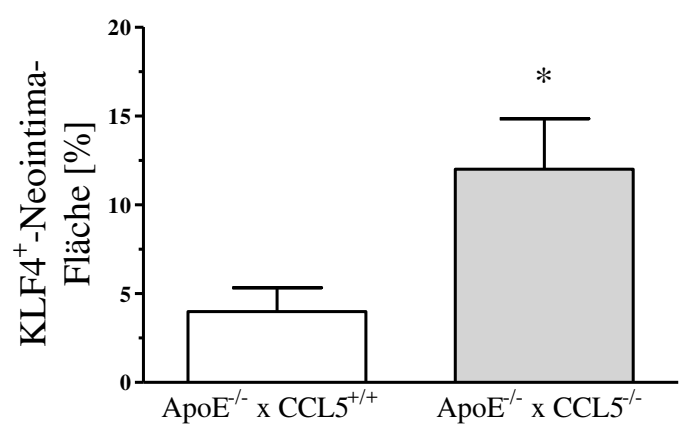

d)

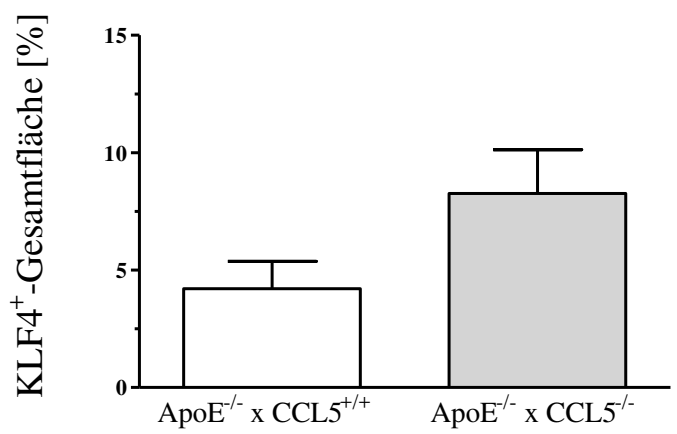

Abbildung 27 Repräsentative Bilder der KLF4 $4^{+}$-Fläche nach 21 d (a) und morphometrische Analyse (bd)

Dargestellt sind die verletzte A. carotis communis sin. der $\mathrm{ApoE}^{-/-} \times \mathrm{CCL5}^{+/+}$- (I) und der $\mathrm{ApoE}^{-/-} \times \mathrm{CCL5}^{-/-}$Gruppe (II). Die Ergebnisse der morphometrischen Analyse der KLF4 ${ }^{+}$-Fläche sind in den Diagrammen (b-d) abgebildet. 100fache Vergrößerung, 1000fache Detailvergrößerung. Mittelwert \pm SEM, $\mathrm{n} \geq 7$, $*<0,05=$ signifikant. 


\subsection{Auswirkungen der CCL5-Defizienz auf humorale Faktoren}

Um zu überprüfen, ob die CCL5-Defizienz Einfluss auf das entzündliche Milieu ausübt, wurde weiterhin eine TNF- $\alpha$-ELISA-Untersuchung (s. Abbildung 28) durchgeführt, die keinen signifikanten Unterschied im Serum der $\mathrm{ApoE}^{-/-}$x $\mathrm{CCL}^{+/+}$-Gruppe im Vergleich zur ApoE ${ }^{-/-}$ x $\mathrm{CCL5}^{-/-}$-Gruppe erbrachte.

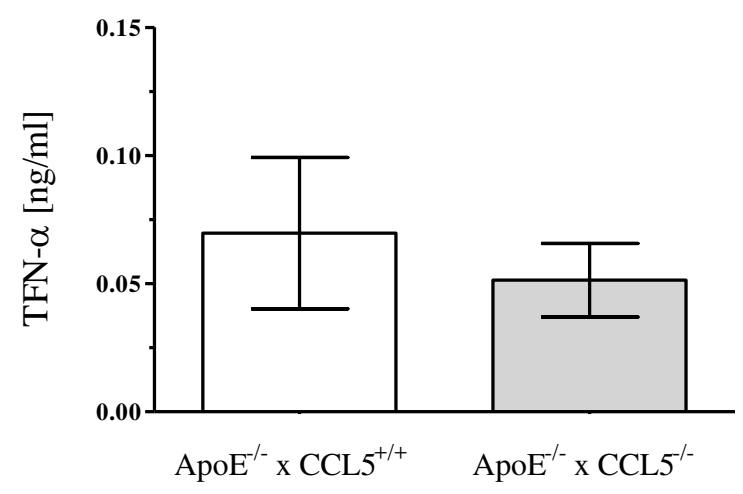

\section{Abbildung 28 TNF- $\alpha$-ELISA}

Graphische Darstellung der Ergebnisse der TNF- $\alpha$-Konzentration im Serum der ApoE ${ }^{-/-} \times$CCL5 $^{-/}$- und $\mathrm{ApoE}^{-/} \times \mathrm{CCL}^{+/+}$-Gruppe. Median $\pm \mathrm{IQR}, \mathrm{n} \geq 5$.

Bezüglich der Untersuchung von CCL5 konnte in der ApoE ${ }^{-/-}$x CCL5 ${ }^{-{ }^{-}}$-Gruppe eine hoch signifikant verringerte Konzentration demonstriert werden. Die CCL5-Konzentration in der $\mathrm{ApoE}^{-/-}$x CCL5 ${ }^{+/+}$-Gruppe betrug $0,018 \mathrm{ng} / \mathrm{ml}[0,016 ; 0,036]$, hingegen war die CCL5Konzentration in der $\mathrm{ApoE}^{-/-}$x $\mathrm{CCL5}^{-/-}$-Gruppe erwartungsgemäß kaum nachweisbar $(0,010$ $\mathrm{ng} / \mathrm{ml}[0,009 ; 0,011],(\mathrm{p}=0,002))$. 


\section{Diskussion}

Die Genese der Atherosklerose stellt ein multifaktorielles Ereignis dar und basiert unter anderem auf der „Lipoprotein-induced atherosclerosis“-Hypothese nach Goldstein (Goldstein und Brown 1977) sowie der „Response-to-injury“-Hypothese nach Ross (Ross et al. 1977). Dem von aktivierten Plättchen freigesetzten Chemokin CCL5 scheint eine maßgebliche Bedeutung in der Immunmodulation der Bildung einer atherosklerotischen Plaque zuzukommen (Veillard et al. 2004). Anhand der „Atherosclerosis Risk in Communities (ARIC) Carotid MRI“-Studie konnte gezeigt werden, dass Studienteilnehmer mit einem höherem Proteinlevel für CCL5 ein erhöhtes Volumen des Lipidkerns als Marker für eine Hochrisiko-Plaque aufwiesen sowie ein erhöhtes Wandvolumen der Koronargefäße aufgrund einer verstärkten fibroproliferativen Reaktion (Virani et al. 2011).

In der vorliegenden Studie wurde der Einfluss der CCL5-Defizienz auf die arterielle Thrombose und Neointimabildung nach experimenteller Induktion einer Gefäßwandläsion untersucht.

\subsection{CCL5 und arterielle Thrombose}

Mithilfe der Aufzeichnung des Blutflusses konnte indirekt die Bildung der arteriellen Thrombose nach Induktion der Gefäßwandläsion mittels Applikation des Eisenchlorids auf die Adventitia der A. carotis communis sin. detektiert werden. Gleichermaßen konnten Kwon et al. die Zuverlässigkeit der arteriellen Thrombose aufgrund der Induktion einer Gefäßläsion durch Eisenchlorid im elektronenmikroskopischen Bild belegen (Kwon et al. 2013). Nachdem eine verlässliche arterielle Thrombose durch eine vollständige Okklusion in der ultraschallgestützten Blutflussmessung festgestellt werden konnte, wurden in der Transmissions- und Rasterelektronenmikroskopie verschiedene Regionen des induzierten Thrombus untersucht (Kwon et al. 2013). Dabei wurden aktivierte und aggregierte Plättchen beobachtet, die im Übergangsbereich hin zum Thrombus an der verletzten luminalen Oberfläche anhafteten, sowie das Fehlen von intakten Endothelzellen. In schwer beschädigten Regionen wurden plättchenreiche Thrombi entdeckt, die Erythrozyten enthielten und das Gefäßlumen vollständig okkludierten (Kwon et al. 2013). Die Aktivierung von Thrombozyten resultiert einerseits in der Formation eines Thrombusaggregats sowie andererseits in einer Sekretion von Chemokinen wie bspw. CCL5. Darüber hinaus fanden Mause et al. heraus, dass zirkulierende Platelet MicroParticles (PMP) mit prokoagulatorischer Aktivität als transzelluläres Depotsystem für 
CCL5 fungieren, das den Monozytenarrest am entzündeten und atherosklerotisch veränderten Endothel $\operatorname{der}$ A. carotis in $\mathrm{ApoE}^{-/-}$-Mäusen triggert (Mause et al. 2005). In gleicher Studie konnte weiterhin gezeigt werden, dass der prozentuale Monozytenarrest signifikant reduziert war, sofern die murine A. carotis mit PMP und dem Met-RANTES-Antikörper für CCL5 zuvor ex vivo perfundiert wurden. Dagegen war der prozentuale Monozytenarrest signifikant erhöht, wenn die Arterien lediglich mit PMP zuvor perfundiert wurden (Mause et al. 2005). Analog konnten Van Wijk et al. zeigen, dass erhöhte Level von zirkulierenden PMPs in Patienten mit kardiovaskulären Erkrankungen identifiziert wurden (Van Wijk et al. 2003). Folglich lassen diese Ergebnisse darauf schließen, dass die ex vivo demonstrierten Resultate von Mause et al. in gleicher Weise im lebendigen Organismus ablaufen.

In der hier vorliegenden Analyse des Einflusses der CCL5-Defizienz auf den Blutfluss zeigte sich kein Unterschied in der Untersuchung des basalen Blutflusses, so dass genotypspezifische Veränderungen ausgeschlossen werden konnten. Nach einer Induktion der Gefäßwandläsion charakterisiert $t_{1}$ den Zeitpunkt, an dem erstmalig ein Blutflussabfall auf $\leq 0,2$ $\mathrm{ml} / \mathrm{min}$ detektiert werden konnte und somit die Okklusion der A. carotis communis sin. durch Entstehung einer arteriellen Thrombose manifestierte. Hierbei stellte sich ein früheres zeitliches Auftreten der arteriellen Thrombose unter dem Einfluss der CCL5-Defizienz im Trend dar sowie ein latent geringeres Blutvolumen, dass bis zu diesem Zeitpunkt durch die A. carotis communis sin. geflossen ist. Jedoch konnte weder ein Einfluss der CCL5-Defizienz auf das gesamte Blutvolumen aufgezeigt werden, noch konnte abschließend eine differente Blutflussgeschwindigkeit ermittelt werden.

Die Beobachtungen der laminaren Strömung von Mause et al. anhand von in-vitro-Analysen mit der Vermutung, dass diese Ergebnisse auch auf in vivo Analysen übertragbar sein könnten (Mause et al. 2005), konnten durch die Ergebnisse der vorliegenden Studie nicht bestätigt werden. Schlussfolgernd kann der entscheidende Effekt, der letztlich zu einer reduzierten Bildung der atherosklerotischen Plaque durch den Einfluss der CCL5-Defizienz führt, nicht durch einen Einfluss auf den Blutfluss unmittelbar nach Induktion der Gefäßwandläsion sowie der arteriellen Thrombose im Rahmen der durchgeführten Analysen begründet werden. Allerdings ist anzumerken, dass der beobachtete Zeitraum nicht ausreichend lang genug gewesen sein könnte, so dass ein möglicher Einfluss der CCL5-Defizienz im Hinblick auf einen gesteigerten Monozytenarrest noch nicht detektierbar gewesen sein könnte. 


\subsection{CCL5 und Neointimabildung}

In bisherigen Studien konnte bereits eine Reduktion der Bildung einer atherosklerotischen Plaque durch einen medikamentösen, kompetitiven Antagonismus an den CCL5-Rezeptoren nach experimenteller arterieller Gefäßwandläsion im Tiermodell gezeigt werden (Schober 2002; Veillard et al. 2004; Braunersreuther et al. 2008). Des Weiteren konnten Cipriani et al. in einer aktuellen Studie demonstrieren, dass sowohl die frühe, entzündlich bedingte Atherosklerose, als auch die späte, durch Störungen im Lipidstoffwechsel hervorgerufene, spontane Atherosklerose durch einen kompetitiven Antagonismus an CCR5 die Progression der atherosklerotischen Plaque reduziert werden kann (Cipriani et al. 2013).

In der vorliegenden Analyse wurde der Einfluss einer kongenitalen CCL5-Defizienz untersucht, der in einer signifikant reduzierten Neointima-Fläche $21 \mathrm{~d}$ nach Induktion einer experimentellen Gefäßwandläsion resultierte. Somit konnte gezeigt werden, dass nicht nur der medikamentöse Antagonismus, sondern auch der Gen-Knockout für CCL5 in einer reduzierten Neointimabildung resultiert.

Unter Anwendung eines anderen Tiermodells konnten Braunersreuther et al. weiterführend zeigen, dass die Inhibition des endogenen CCL5 in vivo die Progression der atherosklerotischen Plaque in Mäusen reduziert, die Stabilität der Plaque erhöht sowie die inflammatorische Antwort reduziert wird. Hierfür wurden männliche Tiere mit einem Gen-Knockout für den LDL-Rezeptor verwendet, die zusätzlich mit cholesterinreichem Futter für 22 Wochen versorgt und denen ab der Mitte dieser Zeit der potente Inhibitor $\left[{ }^{44}\right.$ AANA $\left.{ }^{47}\right]$-RANTES bzw. PBS als Kontrolle injiziert wurde (Braunersreuther et al. 2008). Folglich konnten Braunersreuther et al. signifikant reduzierte atherosklerotische Läsionen in der A.thoracica et abdominalis nachweisen, in denen zusätzlich eine signifikante Reduktion der Infiltration inflammatorischer Leukozyten und Makrophagen vorlag. Darüber hinaus zeigten diese Läsionen eine signifikant reduzierte Produktion an Matrix-Metalloproteinase-9 (MMP-9) und einen signifikant erhöhten Gehalt an Kollagen, sodass Braunersreuther et al. daraus schlossen, dass die Behandlung mittels $\left[{ }^{44} \mathrm{AANA}{ }^{47}\right]$-RANTES in einer reduzierten Läsion und einer stabileren Plaque resultiert (Braunersreuther et al. 2008).

Im Gegensatz zu den Experimenten von Veillard et al. und Braunersreuther et al. wurde in der vorliegenden Studie auf eine zusätzlich hochkalorische Diät der Mäuse verzichtet. Somit liefert die vorliegende Studie übereinstimmende Ergebnisse, die in einer reduzierten NeointimaFläche resultieren, auf der Basis einer Normalfutterdiät und dem Hintergrund eines GenKnockouts für ApoE. 


\subsection{CCL5 und Inflammation}

\subsubsection{CCL5 und Leukozyten}

Bei der Evaluation der Laborwerte fielen eine signifikant erniedrigte Anzahl an Monozyten (absolut) und neutrophilen Granulozyten (\%) bei erhöhter Anzahl an Lymphozyten (absolut und \%) in der $\mathrm{ApoE}^{-/-}$x CCL5 ${ }^{-/-}$-Gruppe gegenüber der $\mathrm{ApoE}^{-/-} \mathrm{x} \mathrm{CCL5}^{+/+}$-Gruppe in der Bestimmung des präoperativen Differentialblutbildes auf. Weitere Analysen wären notwendig, um die Lymphozyten hinsichtlich der beeinträchtigen T-Zellfunktion (Makino et al. 2002), im Sinne einer kompensatorischen Steigerung bei beeinträchtigter Funktionalität, zu analysieren. Die Untersuchungen von Makino et al. konnten zeigen, dass CCL5 für die normale TZellfunktion sowie für die Rekrutierung von Monozyten und T-Zellen in entzündete Gebiete erforderlich ist (Makino et al. 2002).

Darüber hinaus konnten signifikant verringerte Anzahlen von Leukozyten und Lymphozyten zum Zeitpunkt der Untersuchung der Neointima nach $21 \mathrm{~d}$ innerhalb der $\mathrm{ApoE}^{-/-} \mathrm{x} \mathrm{CCL5}^{-/-}$Gruppe im manuellen Differentialblutbild nachgewiesen werden. Dem gegenüber ist die Anzahl der Neutrophilen Granulozyten innerhalb der $\mathrm{ApoE}^{-/-}$x $\mathrm{CCL5}^{-/-}$-Gruppe 21d nach Induktion der experimentellen Gefäßwandläsion erhöht. Diese Beobachtungen könnten auf ein geringeres Niveau der Rekrutierung von Neutrophilen Granulozyten in das entzündliche Areal aufgrund der CCL5-Defizienz deuten. Eine ähnliche Vermutung stellten ebenso Braunersreuther et al. im Rahmen ihrer Analysen zur Reduktion des myokardialen Reperfusionsschaden durch CCL5-Inhibition in einem atherosklerotischen Tiermodell auf, nachdem sie in Abwesenheit zirkulierender Immunzellen einen ausbleibenden Effekt von CCL5 nachgewiesen haben (Braunersreuther et al. 2010). In Folge dieser Beobachtungen beschrieben Braunersreuther et al. die anti-inflammatorische Wirkung von CCL5 als maßgebliches Resultat der Infiltration der Leukozyten (Braunersreuther et al. 2010).

Zusätzlich wurde der Gehalt an Leukozyten immunhistochemisch analysiert. Cluster of differentiation 45 (CD45) stellt ein transmembranöses Glykoprotein dar, das auf allen kernhaltigen hämatopoetischen Zellen exprimiert wird und in acht Isoformen vorkommt. Diese unterscheiden sich anhand der extrazellulären Domäne, bei gleicher intrazellulärer Domäne und sind zellspezifisch im Immunsystem verteilt (Thomas und Lefrançois 1988; Thomas 1989). In der vorliegenden Studie konnte kein Unterschied in der CD45 ${ }^{+}$-Thrombus-Fläche gezeigt werden. In der Untersuchung der Neointima nach 21d konnte eine signifikant gesteigerte CD $45^{+}-$ Neointima-Fläche demonstriert werden, indessen zeigten sich keine Unterschiede in der CD45 ${ }^{+}$-Media- und Gesamtfläche. Folglich konnte eine signifikant erhöhte Leukozyten Infilt- 
ration in die Neointima-Fläche in der $\mathrm{ApoE}^{-/-}$x $\mathrm{CCL5}^{-/-}$-Gruppe verglichen mit der $\mathrm{ApoE}^{-/-} \mathrm{x}$ $\mathrm{CCL}^{+/+}$-Gruppe beobachtet werden. Diese Ergebnisse stehen im Kontrast zu den Beobachtungen von Veillard et al. und Braunersreuther et al., die eine signifikant verringerte Infiltration von Leukozyten anhand von $\mathrm{CD}^{+}$-T-Lymphozyten in die atherosklerotische Plaque, bedingt durch eine Inhibition von CCL5, demonstriert haben (Veillard et al. 2004; Braunersreuther et al. 2008). Diese unterschiedlichen Beobachtungen können auf kompensatorische Mechanismen hindeuten, die lediglich durch die CCL5-Defizienz, nicht jedoch durch eine CCL5-Inhibition hervorgerufen werden können.

\subsubsection{CCL5 und seine Rezeptorzellen}

\subsubsection{Mac-2}

Mac-2 ist ein Lektin, ein Kohlenhydrat bindendes Protein, das im Speziellen Galaktose bindet. Das Lektin wird von inflammatorischen Makrophagen exprimiert, die zuvor eine Induktion durch Thioglycolat erfahren haben (Sato und Hughes 1994). Die Ergebnisse der vorliegenden Studie konnte keinen Einfluss der CCL5-Defizienz hinsichtlich der Mac-2 ${ }^{+}$-Fläche im Thrombus zeigen, indessen konnte in der Untersuchung der Neointima eine signifikant gesteigerte Mac-2 ${ }^{+}$-Media- und Gesamtfläche in der $\mathrm{ApoE}^{-/-}$x $\mathrm{CCL5}^{-/}$-Gruppe verglichen mit der $\mathrm{ApoE}^{-/-}$x $\mathrm{CCL}^{+/+}$-Gruppe ermittelt werden. Dies deutet daraufhin, dass sich der Einfluss der CCL5-Defizienz nicht zum Zeitpunkt des Thrombus, sondern erst im zeitlichen Verlauf der Neointimabildung ausübt. Ebenso konnten Cipriani et al. durch die Anwendung des CCR5-Inhibitors eine signifikant reduzierte Infiltration von Makrophagen zeigen. Diese Ergebnisse konnten ebenfalls in der Analyse der spontanen Atherosklerose demonstriert werden (Cipriani et al. 2013). Im Gegensatz zu den Beobachtungen von Veillard et al. und Braunersreuther et al. (Veillard et al. 2004; Braunersreuther et al. 2008) konnte in der vorliegenden Studie eine signifikant erhöhte Makrophagen Infiltration in der Media-Fläche und der gesamten Fläche nachgewiesen werden. Die Ergebnisse der vorliegenden Studie könnten ein weiterer Hinweis dafür sein, dass Mechanismen der Kompensation bedingt durch die CCL5Defizienz zur einer gesteigerten Makrophagen Infiltration führen, welche bei alleinigem Antagonismus von CCL5 ausbleiben.

Darüber hinaus können diese Unterschiede in den Ergebnissen auf die differenten Tiermodelle zurückgeführt werden, indem der Gen-Knockout für CCL5 andere mechanistische Auswirkungen auf den Organismus ausübt als der Antagonismus durch $\left[{ }^{44}\right.$ AANA $\left.{ }^{47}\right]$-RANTES. Wei- 
terführende Untersuchungen müssten klären, welche Effekte durch das veränderte Rezeptorprofil aufgrund der CCL5-Defizienz resultieren.

\subsubsection{CCR1 und CCR5}

Bezüglich der Untersuchung des Einflusses der CCL5-Defizienz auf das Rezeptorprofil wurden die Rezeptoren CCR1 sowie CCR5 zu den Zeitpunkten 7 d bzw. 21 d nach Induktion der Gefäßwandläsion mittels immunhistochemischer Analysen betrachtet. In der vorliegenden Analyse des Thrombus konnte kein Einfluss der CCL5-Defizienz auf den Rezeptor CCR1 nachgewiesen werden, indessen konnte eine tendenziell reduzierte CCR5 ${ }^{+}$-Fläche in der gesamten Thrombusfläche gezeigt werden. Diese Ergebnisse können in den Kontext zu den Beobachtungen von Kuziel et al. gesetzt werden, in denen die CCR5-Defizienz im Tiermodell in sehr frühen Stadien atherosklerotischer Läsionen als nicht protektiv beschrieben wurde (Kuziel et al. 2003). Dies deutet daraufhin, dass sich der atherogene Effekt der CCL5-Defizienz über CCR5 nicht zum untersuchten Zeitpunkt des Thrombus niederschlägt, sondern sich erst im späteren zeitlichen Verlauf der Neointimabildung ausbildet. Weiterhin konnte in der vorliegenden Analyse der Neointima eine signifikant erhöhte $\mathrm{CCR} 1^{+}$-Neointima-Fläche, sowie eine signifikant reduzierte $\mathrm{CCR} 5^{+}$-Media-Fläche und der CCR5 ${ }^{+}$-Gesamtfläche nachgewiesen werden. Aufgrund dieser Resultate kann ein stärkerer Einfluss von CCL5 über CCR5 vermutet werden, wohingegen die antizipatorische Hochregulation von CCR1 auf kompensatorische Mechanismen aufgrund des pleiotropen Ansprechens der CC-Chemokinrezeptoren auf diverse Liganden zurück geführt werden könnte. Diese kontroversen Ergebnisse könnten ein weiterer Hinweis dafür sein, dass die kompensatorische Hochregulation von CCR1 in einer gesteigerten Immunantwort resultiert, die außerhalb der CCL5/CCR5-Achse zu einer verstärkten Transmigration von Leukozyten und Monozyten in atherosklerotische Läsionen führt.

Diese Ergebnisse werden durch die Beobachtungen von Braunersreuther et al. gestützt, die eine signifikant reduzierte Expression sowohl von CCR5 als auch CCR2 durch die Anwendung des Antagonisten $\left[{ }^{44} \mathrm{AANA}{ }^{47}\right]$-RANTES zeigen konnten, jedoch hat dieser weder einen Einfluss auf die Expression von CCR1 noch auf CCR3 (Braunersreuther et al. 2008). Allerdings muss berücksichtigt werden, dass in letzterer Studie lediglich ein Antagonismus von CCL5 untersucht worden ist, bei denen die Tiere erst im Alter von 21 Wochen mittels Injektion von $\left[{ }^{44} \mathrm{AANA}^{47}\right]$-RANTES eine Modulation erfahren haben. Hingegen wurde in der vorliegenden Studie ein kongenitaler Gen-Knockout für CCL5 untersucht, weshalb eine veränderte Expression von CC-Chemokinrezeptoren aufgrund pleiotroper Effekte von CCL5 auf weitere, bisher unbekannte Mechanismen, zurück geführt werden könnte. Darüber hinaus sind 
die beobachteten Auswirkungen der CCL5-Defizienz auf das Rezeptorprofil konsistent mit den Ergebnissen von Zernecke et al., die sowohl bei Tieren mit einem doppelten GenKnockout für ApoE ${ }^{-/-}$und $\mathrm{CCR} 5^{-/-}$, als auch bei Tieren mit dem doppelten Gen-Knockout für $\mathrm{ApoE}^{-/-}$und $\mathrm{CCR}^{-/-}$eine Gefäßwandläsion induziert haben. Dabei konnten Zernecke et al. zeigen, dass eine CCR5-Defizienz in einer reduzierten Bildung einer Neointima $28 \mathrm{~d}$ nach Induktion einer Gefäßwandläsion resultiert, nicht jedoch die CCR1-Defizienz. Des Weiteren demonstrierten Zernecke et al., dass die CCR5-Defizienz in einer Hochregulation des antiinflammatorischen Interleukin-10 (IL-10) in neointimalen glatten Muskelzellen führt und das die Blockade von IL-10 anderseits in einer signifikant erhöhten Neointima-Fläche resultiert (Zernecke et al. 2006). Weiterhin konnten Cipriani et al. zeigen, dass der selektive CCR5Inhibitor Maraviroc die Progression atherosklerotischer Plaque abschwächt, die zuvor durch den HIV-Proteaseinhibitor Ritonavir induziert worden war (Cipriani et al. 2013).

\subsubsection{TNF- $\alpha$}

Tumor necrosis factor $\alpha$ (TNF- $\alpha$ ) ist ein inflammatorisches Zytokin, das von Monozyten bzw. Makrophagen im Rahmen einer akuten Entzündung produziert wird und für eine Vielzahl von Signalereignissen innerhalb der Zellen verantwortlich ist, die zu Nekrose oder Apoptose führen (Idriss und Naismith 2000).

TNF- $\alpha$ ist entscheidend an der Pathogenese und Progression der Atherosklerose, Ischämie und Herzversagen beteiligt. Die Bildung und Freisetzung von TNF- $\alpha$ sowie die herunterregulierende Signaltransduktionskaskade folgen der Aktivierung durch die zwei Rezeptor-Subtypen. Im Gefäßsystem wechselt TNF- $\alpha$ zwischen Endothel- und glatter Gefäßmuskelzellfunktion, sowie zwischen der Interaktion zwischen Endothelzellen und zellulären Bestandteilen des Blutes (Kleinbongard et al. 2010).

Die Verringerung der Bioverfügbarkeit an Stickstoffmonoxid (NO) stellt einen entscheidenden Schritt in der Wirkung von TNF- $\alpha$ hin zur endothelialen Dysfunktion dar. Es konnte gezeigt werden, dass TNF- $\alpha$ die Inhibition eines Promotors induziert, so dass die endotheliale Stickstoffmonoxid-Synthase (eNOS) herunter reguliert wird, mit der Folge einer verringerten Expression von eNOS (Neumann et al. 2004; Kleinbongard et al. 2010).

Darüber hinaus konnten Braunersreuther et al. durch den Antagonismus von CCL5 mittels [44AANA47]-RANTES eine signifikant reduzierte Sekretion von TNF- $\alpha$ nachweisen, so dass die Einflussnahme von CCL5 über eine Interaktion mit TNF- $\alpha$ im Rahmen der Atherosklerose nahe liegt (Braunersreuther et al. 2008). Ebenso konnten Cipriani et al. durch einen Antagonismus an CCR5 eine hoch signifikante reduzierte TNF- $\alpha$-Sekretion beobachten (Cipriani et 
al. 2013). In der vorliegenden Arbeit konnten keine Unterschiede in der Konzentration von TNF- $\alpha$ mittels ELISA-Untersuchung nachgewiesen werden, so dass präoperativ von keinen Unterschieden des proinflammatorischen Zytokins zwischen den Gruppen, bedingt durch die CCL5-Defizienz, ausgegangen werden kann. Diese differierenden Resultate können auf den unterschiedlichen Untersuchungszeitpunkt zurückgeführt werden, da die Bestimmung von TNF- $\alpha$ in der vorliegenden Arbeit präoperativ erfolgte, wohingegen die Bestimmung von TNF- $\alpha$ bei Braunersreuther et al. sowie Cipriani et al. postinterventionell durchgeführt wurden. Die in der vorliegenden Studie erhobenen Daten reichen nicht aus, um eine exakte Vergleichbarkeit der unterschiedlichen Ergebnisse zu ermöglichen.

\subsubsection{CCL5 und KLF4}

KLF4, das von Endothelzellen exprimiert wird, ist ein negativer Regulator im Rahmen der Bildung einer Neointima als biologische Antwort auf eine Gefäßwandläsion (Yoshida et al. 2008), indem es als Gegenspieler des Transkriptionsfaktors nuclear factor kappa B (NF-kB) agiert, einem zentralen Regulator des Entzündungsprozesses (Tugal et al. 2013). Zou et al. konnten zeigen, dass KLF4 einen essenzieller Faktor in der Atherogenese und Thrombose darstellt (Zhou et al. 2012). Unter Anwendung eines Modells der Überexpression von KLF4 in Endothelzellen einerseits und des konditionellen, endothelzellspezifischen Gen-Knockouts für KLF4 im Mausmodell anderseits demonstrierten sie, dass KLF4 einen anti-adhäsiven und antithrombotischen Einfluss ausübt. Im Detail konnten sie zeigen, dass der konditionelle, endothelzellspezifische Gen-Knockout für KLF4 mit dem Hintergrund eines zusätzlichen ApoEGen-Knockout und einer hochkalorischen Diät sowohl in einer moderaten Zunahme des Gesamtcholesterols sowie der atherosklerotischen Plaque, als auch in einer signifikanten $\mathrm{Zu}$ nahme der inflammatorischen Zellen resultierte. Indessen führte das Modell der Überexpression von KLF4 in transgenen Mäusen zu einer signifikanten Reduktion der atherosklerotischen Plaque und einer signifikanten Reduktion der inflammatorischen Zellen (Zhou et al. 2012).

In der vorliegenden Analyse konnte kein Einfluss der CCL5-Defizienz auf die $\mathrm{KLF}^{+}{ }_{-}^{-}$ Expression nach $7 \mathrm{~d}$ nachgewiesen werden. Indessen konnten Zhou et al. in Untersuchungen der arteriellen Thrombose zeigen, dass die konditionelle, endothelzellspezifische KLF4Defizienz in einer signifikant verkürzten Gerinnungszeit resultiert und diese weiterhin durch eine Zytokinstimulation mittels TNF- $\alpha$ reduziert werden konnte (Zhou et al. 2012). Dem gegenüber steht die signifikant verlängerte Gerinnungszeit, hervorgerufen durch eine KLF4Überexpression, welche nach Zytokinstimulation mittels TNF- $\alpha$ abgeschwächt wird (Zhou et 
al. 2012). Diese Beobachtungen konnten Zhou et al. durch zusätzliche in vitro Analysen bekräftigen, die eine signifikant erhöhte KLF4-Expression in einem atheroprotektivem hämodynamischen Schubspannungsprofil zeigten. Schlussfolgernd übt KLF4 eine antiatherogene und antithrombotische Wirkung aus (Zhou et al. 2012). Diese Diskrepanz in den Untersuchungsergebnissen kann auf die Anwendung unterschiedlicher Tiermodelle zurückgeführt werden. Während Zhou et al. ein Tiermodell des konditionellen, endothelzellspezifischen GenKnockouts für KLF4 bzw. einer Überexpression ohne Intervention verwendet haben, wurde in der vorliegenden Analyse mittels immunhistochemischer Methoden eine KLF4 ${ }^{+}$-Fläche postinterventionell in einem Wildtypmodell hinsichtlich KLF4 detektiert.

In der vorliegenden Untersuchung der Neointima nach 21 d konnte eine signifikant erhöhte $\mathrm{KLF}^{+}{ }^{+}$-Neonintima-Fläche in der $\mathrm{ApoE}^{-/-} \mathrm{x} \mathrm{CCL5}^{-/-}$-Gruppe im Vergleich zur ApoE ${ }^{-/-} \mathrm{x}$ $\mathrm{CCL}^{+/+}$-Gruppe ermittelt werden. Diese Beobachtungen sind deckungsgleich mit der Hypothese von Yoshida et al., dass KLF4 endothelialen Ursprungs die Bildung einer Neointima nach Induktion einer arteriellen Gefäßwandläsion reguliert, indem es die arterielle Entzündung unterdrückt (Yoshida et al. 2014). Darüber hinaus konnten Zhou et al. in einem Tiermodell der konditionellen KLF4-Defzienz in Endothelzellen eine signifikant erhöhte Ablagerung atherosklerotischer Plaque sowie eine signifikant erhöhte Leukozyteninfiltration zeigen (Zhou et al. 2012). Diese Ergebnisse konnten durch die Anwendung eines Tiermodells der endothelialen KLF4-Überexpression bestätigt werden, indem diese in einer signifikant reduzierten atherosklerotischen Plaque sowie einer signifikant reduzierten inflammatorischen Zellinfiltration resultieren (Zhou et al. 2012).

Das Ergebnis einer signifikant erhöhten $\mathrm{KLF}^{+}{ }^{+}$-Neonintima-Fläche in der vorliegenden Untersuchung könnte ein Hinweis dafür sein, dass die gesteigerte Leukozyteninfiltration als Immunantwort eine verstärkte Transkription von KLF4 zur Folge hat und diese in einer reduzierten Neointima resultiert. Die in der vorliegenden Studie erhobenen Daten reichen jedoch nicht aus, um einen Zusammenhang zwischen der verstärkten KLF4-Transskription und der CCL5Defizienz sowie deren Auswirkungen näher zu beschreiben.

\subsection{Limitationen der Arbeit}

In der vorliegenden Studie wurden die Auswirkungen der CCL5-Defizienz auf die Neointimabildung nach Induktion einer experimentellen Gefäßwandläsion hinsichtlich einer möglichen Einflussnahme auf die arterielle Thrombose sowie einer veränderten zellulären Zusammensetzung der atherosklerotischen Plaque untersucht. Im Gegensatz zu den oben genannten 
Studien wurde auf eine zusätzliche hochkalorische Diät der Tiere verzichtet, so dass der Einfluss der CCL5-Defizienz allein auf dem Boden der genetischen Hypercholesterinämie, bedingt durch die ApoE-Defizienz, untersucht werden konnte. Die Vergleichbarkeit der Studien untereinander ist dadurch zusätzlich eingeschränkt. Darüber hinaus wurden in der vorliegenden Untersuchung jeweils die positiven Flächen anhand immunhistochemischer Färbungen analysiert, nicht jedoch direkt die positiven Zellen.

Nicht zuletzt ist die Anzahl der Tiere in den jeweiligen Gruppen durch die vielen verschiedenen immunhistochemischen Analysen mit den daraus resultierenden Gruppenaufteilungen auf teilweise drei Tiere gesunken. Für die Erhebung von statistisch signifikanten Daten mag diese Zahl zu gering gewesen sein.

\subsection{Ausblick}

Ausgehend von diesen Erkenntnissen sind weitere Studien nötig, um mögliche Kompensationsmechanismen aufgrund des CCL5-Gen-Knockouts zu untersuchen, die über pleiotrope Effekte Einfluss auf die zelluläre Immunmodulation nach Induktion einer arteriellen Gefäßwandläsion nehmen könnten.

Durch die bereits beschriebene Assoziation von CCL5 mit dem Auftreten einer KHK durch humane in-vitro-Analysen, wird angedeutet, dass CCL5 möglicherweise als Biomarker für die Ausprägung einer KHK herangezogen werden könnte. Auf diese Weise wäre eine Anwendung in der Diagnostik denkbar, die eine Wahrscheinlichkeit für das Auftreten der Atherosklerose beschreiben oder möglicherweise den Grad der Ausprägung quantifizieren könnte. Auf diese Weise könnte sich die Einleitung einer Sekundärprävention im Sinne einer personalisierten Medizin anschließen, um Komplikationen wie bspw. einem MI vorzubeugen. Diese orientiert sich an individuellen Merkmalen eines kranken Menschen, um Diagnosen, Therapie und Prognose eines Patienten ideal abstimmen zu können (Deutscher Ethikrat 2013). Anderseits konnte der protektive Einfluss der CCL5-Defizienz durch einen Antagonismus im Tiermodell beschrieben werden, so dass ein zukünftiger Einsatz als Therapeutikum bspw. im Rahmen einer Sekundärprävention denkbar ist. So konnten Braunersreuther et al. bereits eine Reduktion des Reperfusionsschaden durch die Inhibition von CCL5 nach stattgefundenem MI im Tiermodell zeigen (Braunersreuther et al. 2010). 


\section{ZUSAMMENFASSUNG}

Die Atherosklerose ist eine progressiv fortschreitende entzündliche Erkrankung der Gefäße. Dem Chemokin CCL5 kommt in der Modulation sowie der Progression eine entscheidende Rolle zu. In der vorliegenden Studie wurde der Einfluss der genetischen CCL5-Defizienz auf dem Boden einer Hypercholesterinämie nach Induktion einer experimentellen Gefäßwandläsion hinsichtlich der arteriellen Thrombose und Bildung einer Neointima untersucht. Zur Verfügung standen Tiere mit dem doppelten Gen-Knockout für $\mathrm{ApoE}^{-/-}$und $\mathrm{CCL}^{-/-}$sowie Tiere mit dem einzelnen Gen-Knockout für $\mathrm{ApoE}^{-/-}$und $\mathrm{CCL}^{+/+}$. Hinsichtlich der Untersuchung des Einflusses auf die arterielle Thrombose konnten keine signifikanten Unterschiede hinsichtlich der Entstehung und der morphometrischen und immunhistochemischen Analysen gezeigt werden. Hingegen konnte eine signifikante Reduktion der Neointima-Fläche sowie eine signifikant verringerte Lumenstenose in der $\mathrm{ApoE}^{-/-}$x $\mathrm{CCL5}^{-/-}$-Gruppe (jeweils $\mathrm{p}<0,05$ vs. ApoE ${ }^{-/-}$x $\mathrm{CCL5}^{+/+}$-Gruppe) bei ähnlicher Media-Fläche mit einer signifikant reduzierten I/M-Ratio ( $<<0,05$ vs. ApoE ${ }^{-/-}$x $\mathrm{CCL}^{+/+}$-Gruppe) ermittelt werden. Die Analysen der immunhistochemischen Untersuchung demonstrierten eine signifikante Reduktion der $\mathrm{CCR}^{+}$-

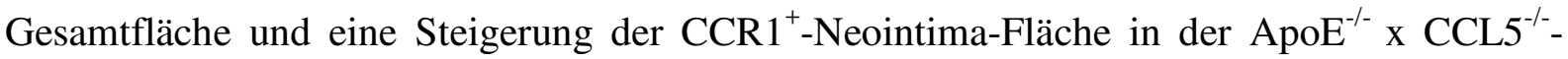
Gruppe (jeweils p<0,05 vs. ApoE ${ }^{-/-} \mathrm{xCCL}^{+/+}$-Gruppe). Weiterführend wurde ein signifikanter Anstieg der CD45 $5^{+}$-Neointima-Fläche, der Mac-2 $2^{+}$-Neointima-Fläche ( $<<0,05$ vs. ApoE ${ }^{-/-}$ x $\mathrm{CCL}^{+/+}$-Gruppe) sowie der Mac-2+-Media-Fläche und der Mac-2+-Gesamtfläche in der $\mathrm{ApoE}^{-/-} \mathrm{x} \mathrm{CCL5}^{-/-}$-Gruppe (jeweils p<0,05 vs. ApoE ${ }^{-/-} \mathrm{x} \mathrm{CCL5}^{+/+}$-Gruppe) als Ausdruck einer gesteigerten Immunantwort beobachtet. Es konnte kein Einfluss der CCL5-Defizienz auf das proinflammatorische Milieu gezeigt werden. Hingegen konnte eine signifikante Steigerung des antiatherogen wirkenden Transskriptionsfaktors KLF4 in der $\mathrm{KLF}^{+}{ }^{+}$-Neointima-Fläche in der $\mathrm{ApoE}^{-/-}$x CCL5 ${ }^{-/-}$-Gruppe ( $<00,05$ vs. ApoE ${ }^{-/-}$x CCL5 ${ }^{+/+}$-Gruppe) gezeigt werden, sodass die Hypothese einer gegenseitigen Beeinflussung nahe liegt. Die vorliegenden Beobachtungen stehen im Einklang mit bisherigen Analysen, die eine atherogene Wirkung von CCL5 demonstriert haben. Auf der anderen Seite konnte entgegen bisherigen Ergebnisse eine gesteigerte Immunantwort in der reduzierten Neointima-Fläche gezeigt werden, die aufgrund der gesteigerten Expression von CCR1 über kompensatorische Effekte durch andere Chemokine oder proinflammatorische Moleküle erklärt werden könnte. In weiteren Analysen müssten bisher nicht untersuchte Faktoren hinsichtlich ihres Beitrags bzw. ihrer gegenseitigen Beeinflussung im Wirkungsgefüge des entzündlichen Prozesses der Atherosklerose geprüft werden, um die Ursachen des Einflusses der CCL5-Defizienz näher beschreiben zu können. 


\section{LITERATURVERZEICHNIS}

Alder JK, Georgantas RW, Hildreth RL, Kaplan IM, Morisot S, Yu X, McDevitt M, Civin CI (2008): Kruppel-Like Factor 4 Is Essential for Inflammatory Monocyte Differentiation In Vivo1. J Immunol 180, 5645-5652

Appay V, Rowland-Jones SL (2001): RANTES: a versatile and controversial chemokine. Trends Immunol 22, 83-87

Assmann G, Cullen P, Jossa F, Lewis B, Mancini M (1999): Coronary Heart Disease: Reducing the Risk: The Scientific Background to Primary and Secondary Prevention of Coronary Heart DiseaseA Worldwide View. Arterioscler Thromb Vasc Biol 19, 1819 1824

Atkins GB, Jain MK (2007): Role of Krüppel-like transcription factors in endothelial biology. Circ Res $\underline{100}, 1686-1695$

Atkins GB, Wang Y, Mahabeleshwar GH, Shi H, Gao H, Kawanami D, Natesan V, Lin Z, Simon DI, Jain MK (2008): Hemizygous deficiency of Krüppel-like factor 2 augments experimental atherosclerosis. Circ Res $\underline{103}$, 690-693

Badimon L, Vilahur G (2014): Thrombosis formation on atherosclerotic lesions and plaque rupture. J Intern Med 276, 618-632

Baggiolini M, Dewald B, Moser B (1994): Interleukin-8 and related chemotactic cytokines-CXC and CC chemokines. Adv Immunol 55, 97-179

Baltus T, Weber, Kim S C, Johnson Z, Proudfoot, Amanda E I, Weber C (2003): Oligomerization of RANTES is required for CCR1-mediated arrest but not CCR5-mediated transmigration of leukocytes on inflamed endothelium. Blood 102, 1985-1988

Bentzon JF, Otsuka F, Virmani R, Falk E (2014): Mechanisms of Plaque Formation and Rupture. Circ Res $\underline{114}, 1852-1866$

Berger K, Kolominsky-Rabas P, Heuschmann P, Keil U (2000): Die Häufigkeit des Schlaganfalls in Deutschland: Prävalenzen, Inzidenzen und ihre Datenquellen. Dtsch Med Wochenschr $\underline{125}, 21-25$

Blanpain C, Migeotte I, Lee B, Vakili J, Doranz BJ, Govaerts C, Vassart G, Doms RW, Parmentier M (1999): CCR5 binds multiple CC-chemokines: MCP-3 acts as a natural antagonist. Blood 94, 1899-1905

Botella LM, Sánchez-Elsner T, Sanz-Rodriguez F, Kojima S, Shimada J, Guerrero-Esteo M, Cooreman MP, Ratziu V, Langa C, Vary, Calvin P H et al. (2002): Transcriptional activation of endoglin and transforming growth factor-beta signaling components by cooperative interaction between Sp1 and KLF6: their potential role in the response to vascular injury. Blood $\underline{100}, 4001-4010$ 
Bousser MG, Ferro JM (2007): Cerebral venous thrombosis: an update. Lancet Neurol $\underline{6}$, $162-170$

Braunersreuther V, Steffens S, Arnaud C, Pelli G, Burger F, Proudfoot A, Mach F (2008): A novel RANTES antagonist prevents progression of established atherosclerotic lesions in mice. Arterioscl Thromb Vasc Biol 28, 1090-1096

Braunersreuther V, Pellieux C, Pelli G, Burger F, Steffens S, Montessuit C, Weber C, Proudfoot A, Mach F, Arnaud C (2010): Chemokine CCL5/RANTES inhibition reduces myocardial reperfusion injury in atherosclerotic mice. J Mol Cell Cardiol $\underline{48}, 789$ 798

Charo IF, Taubman MB (2004): Chemokines in the pathogenesis of vascular disease. Circ Res $\underline{95}, 858-866$

Cipriani S, Francisci D, Mencarelli A, Renga B, Schiaroli E, D'Amore C, Baldelli F, Fiorucci S (2013): Efficacy of the CCR5 Antagonist Maraviroc in Reducing Early, RitonavirInduced Atherogenesis and Advanced Plaque Progression in Mice. Circulation 127, $2114-2124$

Clark-Lewis I, Kim KS, Rajarathnam K, Gong JH, Dewald B, Moser B, Baggiolini M, Sykes BD (1995): Structure-activity relationships of chemokines. J Leukoc Biol 57, 703711

Clinton SK, Underwood R, Hayes L, Sherman ML, Kufe DW, Libby P (1992): Macrophage Colony-stimulating Factor Gene Expression in Vascular Cells and in Experimental and Human Atherosclerosis. Am J Pathol 140, 301-316

Davies MJ (2000): CORONARY DISEASE: The pathophysiology of acute coronary syndromes. Heart $\underline{83}, 361-366$

Deutscher Ethikrat (2013): Personalisierte Medizin - der Patient als Nutznießer oder Opfer?: Vorträge der Jahrestagung des Deutschen Ethikrates 2012 http://www.ethikrat.org/dateien/pdf/tagungsdokumentation-personalisiertemedizin.pdf (Zugriff am 03.03.2015)

Dietel M, Suttorp N, Zeitz M: Harrisons Innere Medizin. 18. Aufl., dt. Ausg. in Zusammenarb. mit der Charité; ABW Wissenschaftsverlag, Berlin 2012

Falk E, Shah PK, Fuster V (1995): Coronary Plaque Disruption. Circulation 92, 657-671

Ferrandi C, Ardissone V, Ferro P, Rückle T, Zaratin P, Ammannati E, Hauben E, Rommel C, Cirillo R (2007): Phosphoinositide 3-kinase gamma inhibition plays a crucial role in early steps of inflammation by blocking neutrophil recruitment. J Pharmacol Exp Ther $\underline{322}$, 923-930

Fowkes, F G R, Murray GD, Butcher I, Heald CL, Lee RJ, Chambless LE, Folsom AR, Hirsch AT, Dramaix M, deBacker G et al. (2008): Ankle brachial index combined with Framingham Risk Score to predict cardiovascular events and mortality: a metaanalysis. JAMA $\underline{300}, 197-208$

Goldstein JL, Brown MS (1977): Atherosclerosis: the low-density lipoprotein receptor hypo- 
thesis. Metabolism 26, 1257-1275

Heald CL, Fowkes, F G R, Murray GD, Price JF (2006): Risk of mortality and cardiovascular disease associated with the ankle-brachial index: Systematic review. Atherosclerosis $\underline{189}, 61-69$

Houard X, Touat Z, Ollivier V, Louedec L, Philippe M, Sebbag U, Meilhac O, Rossignol P, Michel J (2009): Mediators of neutrophil recruitment in human abdominal aortic aneurysms. Cardiovasc Res $\underline{82}, 532-541$

Huo Y, Schober A, Forlow SB, Smith DF, Hyman MC, Jung S, Littman DR, Weber C, Ley K (2003): Circulating activated platelets exacerbate atherosclerosis in mice deficient in apolipoprotein E. Nat Med 9, 61-67

Iannuzzi A, Wilcosky T, Mercuri M, Rubba P, Bryan FA, Bond MG (1995): Ultrasonographic Correlates of Carotid Atherosclerosis in Transient Ischemic Attack and Stroke. Stroke 26, 614-619

Idriss HT, Naismith JH (2000): TNF alpha and the TNF receptor superfamily: structurefunction relationship(s). Microsc Res Tech $\underline{3}, 184-195$

Junqueira LCU, Carneiro J, Gratzl M: Histologie. 6. Auflage; Springer Medizin Verlag, Heidelberg 2004

Kleinbongard P, Heusch G, Schulz R (2010): TNFalpha in atherosclerosis, myocardial ische mia/reperfusion and heart failure. Pharmacol Ther $\underline{3}, 295-314$

Kodali R, Hajjou M, Berman AB, Bansal MB, Zhang S, Pan JJ, Schecter AD (2006): Chemokines induce matrix metalloproteinase-2 through activation of epidermal growth factor receptor in arterial smooth muscle cells. Cardiovasc Res $\underline{69}$, 706-715

Kojima S, Hayashi S, Simokado K, Suzuki Y, Shimada J, Crippa MP, Friedman SL. (2000): Transcriptional activation of urokinase by the Krüppel-like factor Zf9/COPEB activa-tes latent TGF-beta1 in vascular endothelial cells. Blood 95, 1309-1316

Kolominsky-Rabas PL, Sarti C, Heuschmann PU, Graf C, Siemonsen S, Neundoerfer B, Katalinic A, Lang E, Gassmann KG, Ritter von Stockert T (1998): A Prospective Community-Based Study of Stroke in Germany-The Erlangen Stroke Project (ESPro): Incidence and Case Fatality at 1, 3, and 12 Months. Stroke 29, 2501-2506

Konstantinides S, Schäfer K, Thinnes T, Loskutoff DJ (2001): Plasminogen Activator Inhibitor-1 and Its Cofactor Vitronectin Stabilize Arterial Thrombi After Vascular Injury in Mice. Circulation 103, 576-583

Kuo CT, Veselits ML, Barton KP, Lu MM, Clendenin C, Leiden JM (1997): The LKLF transcription factor is required for normal tunica media formation and blood vessel stabilization during murine embryogenesis. Genes Dev 11, 2996-3006

Kuziel WA, Dawson TC, Quinones M, Garavito E, Chenaux G, Ahuja SS, Reddick RL, Maeda N (2003): CCR5 deficiency is not protective in the early stages of atherogenesis in apoE knockout mice. Atherosclerosis $\underline{167}, 25-32$ 
Kwon I, Hong S, Kim YD, Nam HS, Kang S, Yang S, Heo JH (2013): Thrombolytic effects of the snake venom disintegrin saxatilin determined by novel assessment methods: a $\mathrm{FeCl} 3$-induced thrombosis model in mice. PLoS ONE $\underline{8}$, e81165

Levy JA (2009): The unexpected pleiotropic activities of RANTES. J Immunol 182, 39453946

Liu H, Ning H, Men H, Hou R, Fu M, Zhang H, Liu J, Proost P (2012): Regulation of CCL5 Expression in Smooth Muscle Cells Following Arterial Injury. PLoS ONE 7, e30873

Lusis AJ (2000): Atherosclerosis. Nature 407, 233-241

Makino Y, Cook DN, Smithies O, Hwang OY, Neilson EG, Turka LA, Sato H, Wells AD, Danoff TM (2002): Impaired T cell function in RANTES-deficient mice. Clin Immunol $\underline{102}, 302-309$

Mause SF, Hundelshausen P von, Zernecke A, Koenen RR, Weber C (2005): Platelet microparticles: a transcellular delivery system for RANTES promoting monocyte recruit ment on endothelium. Arterioscler Thromb Vasc Biol 25, 15121518

Mendis S, Thygesen K, Kuulasmaa K, Giampaoli S, Mähönen M, Ngu Blackett K, Lisheng L (2011): World Health Organization definition of myocardial infarction: 2008-09 revision. Int J Epidemiol 40, 139-146

Mestas J, Ley K (2008): Monocyte-endothelial cell interactions in the development of atherosclerosis. Trends Cardiovasc Med $\underline{18}, 228-232$

Neumann P, Gertzberg N, Johnson A (2004): TNF-alpha induces a decrease in eNOS promoter activity. Am J Physiol Lung Cell Mol Physiol_2, L452- 459

Osterud B., Bjorklid E. (2003): Role of Monocytes in Atherogenesis. Physiol Rev $\underline{83}$, 10691112

Roger VL, Go AS, Lloyd-Jones DM, Benjamin EJ, Berry JD, Borden WB, Bravata DM, Dai S, Ford ES, Fox CS et al. (2012): Executive summary: heart disease and stroke statistics--2012 update: a report from the American Heart Association. Circulation 125, $188-197$

Ross R, Glomset J, Harker L (1977): Response to Injury and Atherogenesis. Am J Pathol $\underline{86}$, 675-684

Ross R (1999): Atherosclerosis--an inflammatory disease. N Engl J Med 눙, 115-126

Rothwell PM, Coull AJ, Giles MF, Howard SC, Le Silver, Bull LM, Gutnikov SA, Edwards P, Mant D, Sackley CM et al. (2004): Change in stroke incidence, mortality, casefatality, severity, and risk factors in Oxfordshire, UK from 1981 to 2004 (Oxford Vascular Study). Lancet $\underline{363}$, 1925-1933

Sakakura K, Nakano M, Otsuka F, Ladich E, Kolodgie FD, Virmani R (2013): Pathophysio- 
logy of atherosclerosis plaque progression. Heart Lung Circ 22, 399-411

Sato S, Hughes RC (1994): Regulation of secretion and surface expression of Mac-2, a galactoside-binding protein of macrophages. J Biol Chem $\underline{269}$, 4424-4430

Schober A (2002): Deposition of Platelet RANTES Triggering Monocyte Recruitment Requires P-Selectin and Is Involved in Neointima Formation After Arterial Injury. Circulation $\underline{106}, 1523-1529$

Stary HC (1987): Macrophages, macrophage foam cells, and eccentric intimal thickening in the coronary arteries of young children. Atherosclerosis $\underline{64}, 91-108$

Stary HC (1989): Evolution and progression of atherosclerotic lesions in coronary arteries of children and young adults. Atherosclerosis $\underline{9}, 1-19,1-32$

Stary HC, Chandler AB, Dinsmore RE, Fuster V, Glagov S, Insull W, Rosenfeld ME, Schwartz CJ, Wagner WD, Wissler RW (1995): A Definition of Advanced Types of Atherosclerotic Lesions and a Histological Classification of Atherosclerosis: A Report From the Committee on Vascular Lesions of the Council on Arteriosclerosis, American Heart Association. Circulation 92, 1355-1374

Stary HC, Blankenhorn DH, Chandler AB, Glagov S, Insull W, Richardson M, Rosenfeld ME, Schaffer SA, Schwartz CJ, Wagner WD (1992): A definition of the intima of human arteries and of its atherosclerosis- prone regions. A report from the Committee on Vascular Lesions of the Council on Arteriosclerosis, American Heart Association. Arterioscler Thromb Vasc Biol 12, 120-134

Stary HC, Chandler AB, Glagov S, Guyton JR, Insull W, Rosenfeld ME, Schaffer SA, Schwartz CJ, Wagner WD, Wissler RW (1994): A definition of initial, fatty streak, and intermediate lesions of atherosclerosis. A report from the Committee on Vascular Lesions of the Council on Arteriosclerosis, American Heart Association. Arterioscler Thromb Vasc Biol 14, 840-856

Statistisches Bundesamt (2013): Todesursachen in Deutschland - Fachserie 12 Reihe 4 - 2012

Strieter RM, Koch AE, Antony VB, Fick RB Jr, Standiford TJ, Kunkel SL (1994): The immunopathology of chemotactic cytokines: the role of interleukin-8 and monocyte chemoattractant protein-1. J Lab Clin Med 123, 183-197

Suarez JI, Tarr RW, Selman WR (2006): Aneurysmal Subarachnoid Hemorrhage. N Engl J Med 354, 387-396

Sudlow CML, Warlow CP (1996): Comparing Stroke Incidence Worldwide: What Makes Studies Comparable? Stroke 27, 550-558

Thomas ML (1989): Differential expression of the leucocyte-common antigen family. Annu Rev Immonul 7, 339-369

Thomas ML, Lefrançois L (1988): Differential expression of the leucocyte-common antigen family. Immunol Today $\underline{10}, 320-326$

Tugal D, Jain MK, Simon DI (2013): Endothelial KLF4: Crippling Vascular Injury? J Am 
Heart Assoc $\underline{3}$, e000769

van der Worp HB, van Gijn J (2007): Acute Ischemic Stroke. N Engl J Med 푸, 572-579

Van Wijk MJ, Van Bavel E, Sturk A, Nieuwland R (2003): Microparticles in cardiovascular diseases. Cardiovasc Res $\underline{59}$, 277-287

Veillard NR, Kwak B, Pelli G, Mulhaupt F, James RW, Proudfoot AE, Mach F (2004): Antagonism of RANTES Receptors Reduces Atherosclerotic Plaque Formation in Mice. Circ Res 94, 253-261

Virani SS, Nambi V, Hoogeveen R, Wasserman BA, Coresh J, Gonzalez F, Chambless LE, Mosley TH, Boerwinkle E, Ballantyne CM (2011): Relationship between circulating levels of RANTES (regulated on activation, normal T-cell expressed, and secreted) and carotid plaque characteristics: the Atherosclerosis Risk in Communities (ARIC) Carotid MRI Study. Eur Heart J 32, 459-468

von Hundelshausen P, Weber KS, Huo Y, Proudfoot AE, Nelson PJ, Ley K, Weber C. (2001): RANTES Deposition by Platelets Triggers Monocyte Arrest on Inflamed and Atherosclerotic Endothelium. Circulation 103, 1772-1777

Weber C, Noels H (2011): Atherosclerosis: current pathogenesis and therapeutic options. Nat Med 17, 1410-1422

Yet S, McA'Nulty MM, Folta SC, Yen H, Yoshizumi M, Hsieh C, Layne MD, Chin MT, Wang H, Perrella MA et al. (1998): Human EZF, a Kruppel-like Zinc Finger Protein, Is Expressed in Vascular Endothelial Cells and Contains Transcriptional Activation and Repression Domains. J Biol Chem 273, 1026-1031

Yoshida T, Kaestner KH, Owens GK (2008): Conditional Deletion of Kruppel-Like Factor 4 Delays Downregulation of Smooth Muscle Cell Differentiation Markers but Accelerates Neointimal Formation Following Vascular Injury. Circ Res 102, 15481557

Yoshida T, Yamashita M, Horimai C, Hayashi M (2014): Deletion of Krüppel-like factor 4 in endothelial and hematopoietic cells enhances neointimal formation following vascular injury. J Am Heart Assoc $\underline{3}$, e000622

Zernecke A, Liehn EA, Gao J, Kuziel WA, Murphy PM, Weber C (2006): Deficiency in CCR5 but not CCR1 protects against neointima formation in atherosclerosis-prone mice: involvement of IL-10. Blood 107, 4240-4243

Zhou G, Hamik A, Nayak L, Tian H, Shi H, Lu Y, Sharma N, Liao X, Hale A, Boerboom L et al. (2012): Endothelial Kruppel-like factor 4 protects against atherothrombosis in mice. J Clin Invest 122, 4727-4731 


\section{ABbILDUNGSVERZEICHNIS}

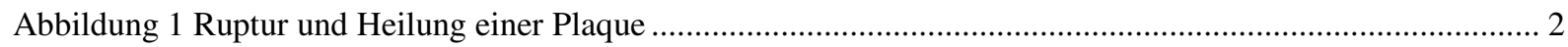

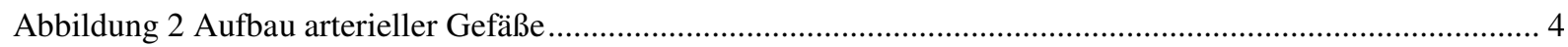

Abbildung 3 Synopsis der Liganden-Rezeptoren-Interaktionen ..................................................................... 9

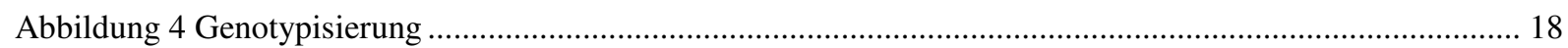

Abbildung 5 Eisen(III)-chlorid-Maus-Modell der Gefäßwandläsion.................................................................. 19

Abbildung 6 Repräsentative Flusskurven der Blutflussgeschwindigkeit ............................................................. 20

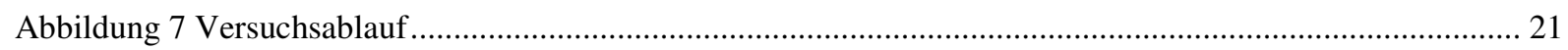

Abbildung 8 Beispielhafte Fotografien eines Blutausstriches (Papenheim-Färbung) .......................................... 23

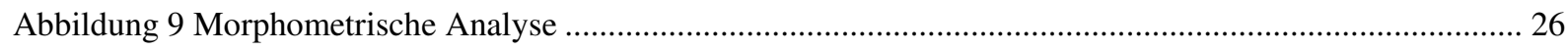

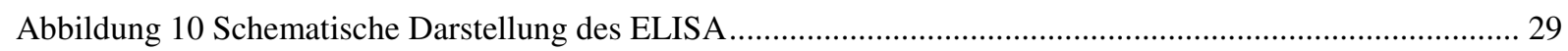

Abbildung 11 Okklusionsverhalten nach Induktion der Gefäßwandläsion ....................................................... 35

Abbildung 12 Organisation der arteriellen Thrombose anhand histologischer Schnittbilder................................ 36

Abbildung 13 Quantifizierung der Organisation der arteriellen Thrombose....................................................... 37

Abbildung 14 Repräsentative histologische Gewebeschnitte des arteriellen Thrombus ....................................... 38

Abbildung 15 Morphometrische Analyse der Thrombus-Fläche ....................................................................... 38

Abbildung 16 Repräsentative histologische Gewebeschnitte der Neointima-Fläche .......................................... 39

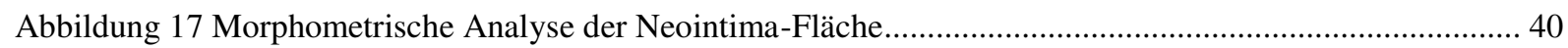

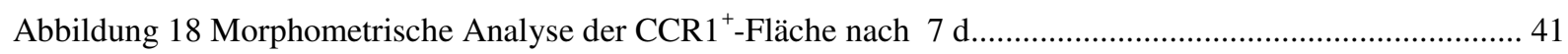

Abbildung 19 Repräsentative Bilder der CCR $1^{+}$-Fläche nach $21 \mathrm{~d}$ (a) und morphometrische Analyse (b-d) ...... 42

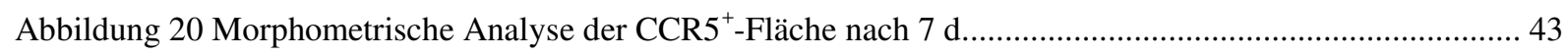

Abbildung 21 Repräsentative Bilder der CCR5 ${ }^{+}$-Fläche nach 21 d (a) und morphometrische Analyse (b-d) ...... 44

Abbildung 22 Morphometrische Analyse der Mac2 ${ }^{+}$-Fläche nach 7 d ............................................................... 45

Abbildung 23 Repräsentative Bilder der Mac-2+-Fläche nach $21 \mathrm{~d}$ (a) und morphometrische Analyse (b-d)..... 46

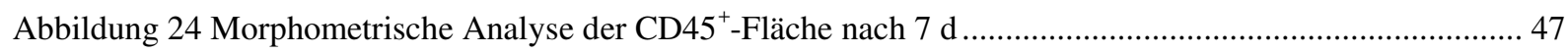

Abbildung 25 Repräsentative Bilder der CD45 $5^{+}$-Fläche nach $21 \mathrm{~d}$ (a) und morphometrische Analyse (b-d)....... 48

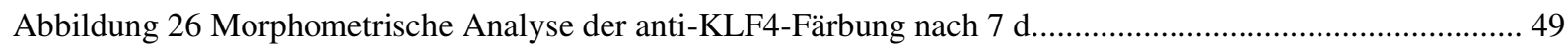

Abbildung 27 Repräsentative Bilder der KLF4 ${ }^{+}$-Fläche nach $21 \mathrm{~d}$ (a) und morphometrische Analyse (b-d)....... 50

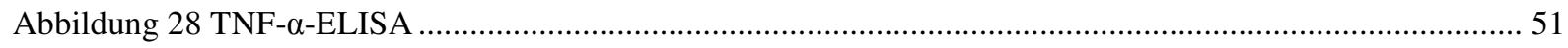




\section{TABELLENVERZEICHNIS}

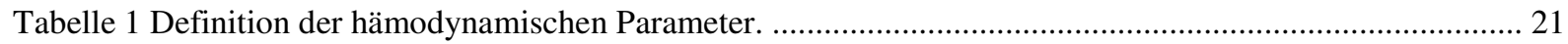

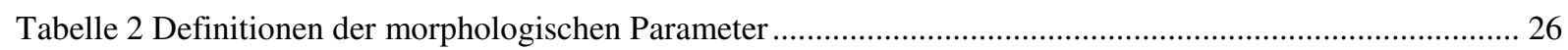

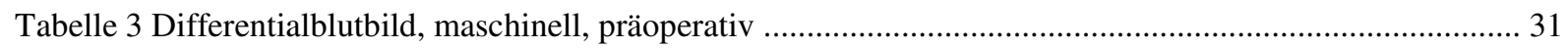

Tabelle 4 Differentialblutbild, maschinell, $21 \mathrm{~d}$ nach Induktion einer Gefäßwandverletzung............................ 32

Tabelle 5 Manuelles Differentialblutbild, manuell, präoperativ .............................................................. 33

Tabelle 6 Differentialblutbild, manuell, 21d nach Induktion einer Gefäßwandverletzung ................................ 33

Tabelle 7 Gesamtcholesterin-und Triglyzeridbestimmungen, präoperativ................................................... 34

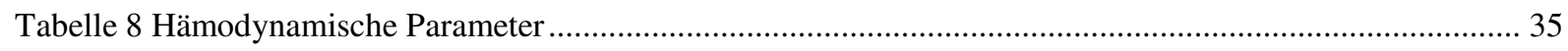




\section{DANKSAGUNG}

Danken möchte ich all denen, die mich während der Erstellung dieser Arbeit unterstützt und dadurch zum Gelingen beigetragen haben.

Ganz herzlich möchte ich mich bei Frau Prof. Dr. med. Katrin Schäfer für die kontinuierlich engagierte und motivierende Förderung und Unterstützung unseres Projektes danken. Sie hat mir die Grundzüge wissenschaftlichen Arbeitens vermittelt und mein Interesse für die Vaskuläre Biologie geweckt.

Mein besonderer Dank gilt Frau PD Dr. med. Frauke S. Czepluch für die Bereitstellung des Themas sowie für die umfassende, kompetente und engagierte Betreuung. Sie stand mir jederzeit mit Fachwissen und vielen wertvollen Hinweisen zur Seite und hat mich über den gesamten Zeitraum sehr gut betreut und unterstützt. Durch Frau PD Dr. med. Frauke S. Czepluch erhielt ich die Möglichkeit, auf einem nationalen Kongress Erfahrungen sammeln zu dürfen.

Herrn Prof. Dr. med. Gerd Hasenfuß danke ich für die Möglichkeit zur Durchführung meiner Forschungsarbeit in seiner Abteilung.

Ausdrücklich und von Herzen möchte ich mich bei meiner Arbeitsgruppe bedanken, in der mir jeder Einzelne stets hilfsbereiter Ansprechpartner war. Ganz besonders möchte ich dabei Frau Celina Fraatz und Herrn Gerrit Gründer für die ausgezeichnete Einarbeitung und für die großartige Hilfe bei den Genotypisierungen sowie für die unermüdliche Hilfestellung bei jeglichen Problemen danken. 


\section{LEBENSLAUF}

Am 11. Juli 1988 wurde ich, Julia Meier, als erstes Kind meiner Eltern Holger Meier und Daniela Kastenbauer, geb. Bruske, in Altenburg geboren. Von 1995 bis 1999 besuchte ich die Grund- und Hauptschule in Bücken. Anschließend besuchte ich die Orientierungsstufe von 1999 bis 2001 in Hoya, gefolgt vom Besuch des Johann-Beckmann-Gymnasiums in Hoya und erlangte 2008 mit dem Abitur die Allgemeine Hochschulreife.

Nach meinem Schulabschluss absolvierte ich zunächst ein Freiwilliges Soziales Jahr in der Asklepios Fachklinik München-Gauting. Im Sommersemester 2009 nahm ich das Studium der Humanmedizin in Göttingen auf und absolvierte nach vier Semestern den 1. Abschnitt der Ärztlichen Approbationsprüfung (Physikum) im Frühjahr 2011. Den daran anschließenden klinischen Studienabschnitt beendete ich im Frühjahr 2014 mit Bestehen der schriftlichen Prüfungen des 2. Abschnitts der Ärztlichen Approbationsordnung. Anschließend absolvierte ich mein Praktisches Jahr (PJ) in der Klinik für Urologie sowie in den Kliniken für Allgemein-, Viszeral- und Kinderchirurgie und Thorax-, Herz- und Gefäßchirurgie an der UMG. Das Tertial der Inneren Medizin absolvierte ich zur Hälfte in der Klinik für Kardiologie des Royal London Hospital in London sowie im Evangelischen Krankenhaus Göttingen-Weende. Das Studium der Humanmedizin konnte ich am 10.06.2015 mit dem Bestehen der mündlichpraktischen Prüfung des 2. Abschnittes der Ärztlichen Approbationsordnung mit der Gesamtnote 2,16 abschließen.

Während meiner Studienzeit war ich als studentische Hilfskraft im Pflegedienst des Asklepios Fachklinikums in Göttingen beschäftigt und arbeitete im Wintersemester 2010/2011 als studentische Hilfskraft im Zentrum Anatomie der Universität Göttingen. Von Frühjahr 2013 bis Herbst 2013 arbeitete ich darüber hinaus als studentische Hilfskraft im Rufdienst der Orthopädie und Unfallchirurgie der UMG.

Im Oktober 2011 nahm ich meine Forschungstätigkeit im Rahmen meiner Dissertation in der Arbeitsgruppe von Frau Prof. Katrin Schäfer, Klinik für Kardiologie und Pneumologie der UMG, auf. Erste Ergebnisse dieser Arbeit konnte ich in Form eines Posters während der 79. Jahrestagung der Deutschen Gesellschaft für Kardiologie- Herz- und Kreislaufforschung im April 2013 in Mannheim präsentieren.

Seit dem 01.08.2015 bin ich als Assistenzärztin in der Klinik für Herz-, Thorax-, Transplantations- und Gefäßchirurgie unter dem ärztlichen Direktor Herrn Prof. Dr. A. Haverich an der Medizinischen Hochschule in Hannover beschäftigt. 


\section{ABSTRACTS}

Czepluch FS, Vogler M, Kuschicke H, Meier J, Gogiraju R, Katschinski DM, Riggert J, Hasenfuss G, Schäfer K (2015): Circulating endothelial cells expressing the angiogenic transcription factor Krüppel-like factor 4 are decreased in patients with coronary artery disease. Microcirculation 10.1111/micc.12226

Czepluch FS, Vogler M, Kuschicke H, Meier J, Gogiraju R, Katschinski D, Riggert J, Hasenfuss G, Schaefer K (2103): The transcription factor Krueppel-like factor 4 is a positive regulator of angiogenic properties in endothelial cells. Eur Heart J 34: Suppl, (1052), ESC Congress 2013

Czepluch FS, Vogler M, Kuschicke H, Meier J, Gogiraju R, Katschinski DM, Riggert J, Hasenfuß G, Schäfer K (2013): Bedeutung des Transkriptionsfaktors Krüppel-Like Factor 4 für die Endothelzellfunktion und Gefäßneubildung. Clin Res Cardiol 102: Suppl 1, 79. Jahrestagung der Deutschen Gesellschaft für Kardiologie 2013

Czepluch FS, Meier J, Hasenfuß G, Schäfer K (2013): Bedeutung des Plättchen-Chemokins CCL5 für die arterielle Thrombose und Neointimabildung. Clin Res Cardiol 102: Suppl1, 79. Jahrestagung der Deutschen Gesellschaft für Kardiologie 2013. 